Tesis

\title{
Implementación de un procedimiento de pronóstico hidrológico para el alerta de inundaciones utilizando datos de sensores remotos
}

Autor: Lic. Juan Federico Bianchi

Director: Ing. Mag. Marcelo Uriburu Quirno

Codirectora: Dra. Fernanda Gaspari 


\section{Tabla de contenidos}

Resumen 2

1. Introducción 3

2. Caracterización de la cuenca $\quad 6$

3. Objetivos $\quad 8$

3.1. General . . . . . . . . . . . . . . . . . . . . . . 8

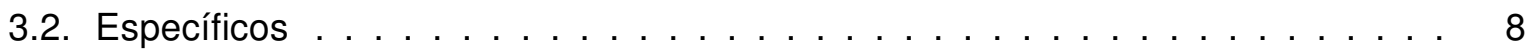

4. Marco conceptual 9

5. Materiales y Metodología

5.1. Esquema funcional del sistema de pronóstico hidrológico . . . . . . . . . . . 13

5.2. Obtención de los datos . . . . . . . . . . . . . . . . . . . . . . . . . . 14

5.2.1. Precipitaciones . . . . . . . . . . . . . . . . . . . . 15

5.2.2. Evapotranspiración potencial . . . . . . . . . . . . . . . . 22

5.2.3. Caudales . . . . . . . . . . . . . . . . . . . . . . . . 24

5.2.4. Humedad del suelo . . . . . . . . . . . . . . . . . . . 25

5.2.5. Pronóstico cuantitativo de precipitación . . . . . . . . . . . . . . 27

5.3. Base de datos hidrometeorológicos . . . . . . . . . . . . . . . . . . 28

5.4. Modelación hidrológica continua . . . . . . . . . . . . . . . 30

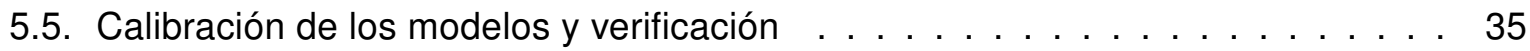

5.6. Actualización de las variables de estado mediante asimilación de datos . . . . . 38

5.6.1. Filtro de Kalman en ensamble . . . . . . . . . . . . . . . . . . . . 39

5.7. Uso operativo para pronóstico hidrológico . . . . . . . . . . . . . . . . 43

6. Experimentos y Resultados $\quad 45$

6.1. Modelación matemática sin asimilación de datos (modo autónomo) . . . . . . . 45

6.2. Modelación matemática con asimilación de datos (modo actualizado) . . . . . . 46

6.3. Modelación matemática con pronóstico cuantitativo de precipitación . . . . . . . 49

$\begin{array}{ll}\text { 7. Conclusiones } & 51\end{array}$

8. Agradecimientos 53

9. Bibliografía $\quad 54$

$\begin{array}{ll}\text { 10. ANEXO I } & 58\end{array}$

$\begin{array}{ll}\text { 11. ANEXO II } & 79\end{array}$ 


\section{Resumen}

En un contexto de hidrología operativa se desarrolló y se implementó un sistema de pronóstico para una cuenca de llanura en territorio Argentino (río Gualeguay) basado en la captura de datos de entrada a tiempo real y la modelación hidrológica continua a paso diario. Como forzante de precipitación se utilizaron datos de estaciones meteorológicas convencionales y automáticas, estimaciones satelitales y pronósticos cuantitativos en base a modelos meteorológicos. Para la componente de modelación se implementaron los modelos Sacramento modificado y GR4P con filtrado de Kalman en ensamble para la asimilación de datos de caudal y humedad del suelo. Para la componente de captura y almacenamiento de datos se desarrolló una base de datos relacional POSTGRESQL así como también rutinas de actualización automática e interfaces entre la misma y la componente de modelación. Se evaluaron las distintas alternativas y se compararon los resultados en términos de eficiencia en el pronóstico de caudales a distintos horizontes de pronóstico en la sección de cierre de la cuenca. Los resultados mostraron la utilidad de este sistema para la anticipación de situaciones hídricas extremas en zonas ribereñas de la cuenca estudiada con tiempos de antelación adecuados para la preparación ante la amenaza, especialmente cuando se asimilan mediciones de caudal obtenidas a tiempo real. 


\section{Implementación de un procedimiento de pronóstico hidrológico para el alerta de inundaciones utilizando datos de sensores remo- tos}

\section{Introducción}

En el presente, a nivel global y particulamente en Argentina, los desastres asociados a desbordes de cursos de agua están entre los que producen los impactos más graves para la sociedad (O‘Connor, 2007). Además, el acelerado proceso de urbanización no planificada amplifica la amenaza y aumenta la exposición de personas y bienes vulnerables a estos desastres (O'Connor, 2007). Por lo tanto, cobran gran relevancia los sistemas de alerta temprana como una medida no estructural eficiente y efectiva para la protección de la población en el marco de la gestión integral del riesgo.

Un tipo de evento hidrológico extremo, las crecidas ribereñas, se asocia con desbordes de cursos de agua que ocurren cuando el caudal en una sección excede la capacidad del cauce ordinario. Superado el nivel de banca (natural o artificial) de la sección, las aguas se expanden transversalmente ocupando un área deprimida delimitada por barrancas más o menos definidas que constituye el valle de inundación del curso de agua. El valle cumple un rol hidrodinámico y ecológico ya que sobre el mismo el flujo pierde energía (debido a la menor profundidad y mayor rugosidad por la presencia de vegetación) depositando material en suspensión y recargando lentes de agua que en situaciones normales se encuentran desconectados con el sistema de drenaje. Esta dinámica responde al régimen hídrico natural de la región y debe entenderse al valle de inundación como una componente escencial del sistema de drenaje natural de una cuenca.

En planicies húmedas extensas como la llanura Chacopampeana, donde las pendientes son tan suaves, pequeños incrementos en el nivel del agua por encima de la banca se traducen en una gran expansión transversal del área inundada. Por lo tanto, los valles de inundación son muy anchos en comparación con el curso ordinario y contienen grandes áreas de vegetación natural hidrófila (esteros, pastizales y bosques) y espejos de agua permanentes y transitorios de importancia ecológica y productiva (Fuentes Godo, 1984). Además, debe considerarse que debido a la sucesión de periodos secos y húmedos que es característica del clima de la región (Ameghino, 1984), un determinado curso de agua puede permanecer encauzado durante varios años, o desbordarse varias veces en un mismo año.

El riesgo asociado a estos eventos surge a medida que las actividades antrópicas se desarrollan sobre los valles de inundación, exponiendo a personas y bienes vulnerables a la amenaza de inundaciones. En particular, el riesgo de pérdida de vidas humanas, del deterioro de la salud y el ambiente, y de daños materiales crece desmedidamente cuando el uso urbano del suelo ocupa estas áreas, aun cuando existan medidas estructurales como terraplenes de defensa o sistemas de drenaje urbano. El grado de conocimiento de la amenaza por parte de la población y las instituciones locales, incluyendo las limitaciones de las medidas estructurales, y el grado de preparación ante una emergencia, también constituyen factores clave en la configuración del riesgo.

El conocimiento de la amenaza mediante la recolección de información relevante y la conceptualización de su funcionamiento es una actividad que permite anticiparse a situaciones 
de riesgo. Una vez conceptualizado el sistema que genera la amenaza (por ejemplo mediante uno o varios modelos matemáticos), si se cuenta con información a tiempo útil del estado del sistema y de sus forzantes, pueden conocerse los posibles escenarios de riesgo, lo cual reduce notablemente la incertidumbre a la hora de la toma de decisiones. En el caso particular de la amenaza de inundación por desbordes, ante un escenario meteorológico y un estado de humedad de la cuenca de aporte hacia el curso de agua en cuestión dados, mediante modelos conceptuales correctamente calibrados puede producirse un pronóstico hidrológico que permita vislumbrar la gravedad del escenario de riesgo hídrico para un horizonte de tiempo dado, y así poder anticipar la acciones de protección civil.

Desarrollos precedentes (Giordano, 2011) demuestran la viabilidad de realizar un monitoreo y pronósticos hidrológicos utilizando información hidrometeorológica en tiempo útil y modelos matemáticos. La extensión, fisiografía y tipo de suelos de la cuenca de aporte determinan que los tiempos de respuesta hidrológicos ante las precipitaciones otorguen un margen temporal de acción adecuado para activación de acciones preventivas ante un pronóstico hidrológico desfavorable.

En las últimas décadas, en forma acelerada se han hecho disponibles para la ciencia hidrológica nuevas tecnologías de gran utilidad. En especial, las nuevas tecnologías de comunicación y la teledetección ambiental abren nuevos caminos para la hidrología operativa, posibilitando el desarrollo de sistemas de monitoreo y alerta en regiones donde el acceso a la información resultaría de otra manera muy complicado. Adicionalmente, el crecimiento exponencial de la capacidad de almacenamiento y procesamiento computacional permiten que el manejo de la información y la operación de modelos matemáticos sea realizada en tiempos cada vez más expeditivos, lo cual agiliza notablemente las tareas operativas de la hidrología. Como herramientas de particular utilidad para la hidrología operativa, pueden mencionarse las redes meteorológicas telemétricas, los sensores remotos de estimación de precipitaciones, agua superficial y humedad del suelo, y los modelos numéricos de pronóstico meteorológico.

A pesar de estas nuevas posibilidades, aun no existe un consenso acerca de las técnicas óptimas mediante las cuales estas fuentes de información pueden incorporarse a la modelación hidrológica. Los resultados son muy dispares, dependiendo entre otras cosas de las características físicas de los sistemas y de la existencia o no de otras fuentes de información (Massari et al., 2015). Es en ese campo de investigación que pretendió aportar este trabajo de tesis, a la par que se elaboró una herramienta operativa para abordar un problema hídrico en un marco territorial en particular. Debe señalarse que además que la herramienta de modelación se elaboró de manera tal que pueda aplicarse fácilmente a otros punto de interés de la misma u otras cuencas, siempre y cuando se disponga de datos para su correcta calibración. Finalmente, este trabajo de tesis aportó al conocimiento hidrológico de los sistemas de llanura de la región Chacopampeana y sur del litoral Argentino, la cual contiene innumerables cuencas hídricas de características climatológicas y morfológicas similares que presentan problemas de inundaciones por desbordes y sobre las cuales existe poca información hidrométrica y pocos estudios con un enfoque operativo.

La Dirección de Sistemas de Información y Alerta Hidrológico del Instituto Nacional del Agua, donde se enmarca este trabajo de tesis, se lleva adelante el monitoreo hidrológico de la Cuenca del Plata en territorio Argentino, la cual contiene a la provincia de Entre Ríos. Sin embargo, en Argentina los cursos de agua no navegables (como el Gualeguay) son jurisdicción 
de los Estados provinciales. Por lo tanto, se ha elaborado un convenio mediante el cual se establece el trabajo en conjunto del Instituto con la provincia para el monitoreo y pronóstico hidrológico del río Gualeguay. 


\section{Caracterización de la cuenca}

El río Gualeguay, localizado enteramente en la provincia de Entre Ríos, Argentina, que forma parte de la Llanura Chacopampeana Sudoriental (Sala, 1984), es un curso de agua de llanura típico según la clasificación de Fertonani y Prendes (1984). Reducida en la sección próxima a la localidad de Rosario del Tala, considerado el límite entre los tramos medio e inferior del río (véase la figura 1), su cuenca de aporte cubre aproximadamente $16000 \mathrm{~km}^{2}$ (representando un $18 \%$ del total del área de la provincia) de una llanura ligeramente ondulada que presenta un sistema de cuchillas intercaladas con áreas deprimidas y una pendiente media del $1 \%$.

La precipitación anual media es de $1311 \mathrm{~mm}$, siendo octubre-abril el periodo más lluvioso, mientras que la evapotranspiración potencial anual es de aproximadamente $900 \mathrm{~mm}$.

El coeficiente de escorrentía global para el periodo 1993-2010 es 0,27 (Giordano, 2011). El caudal medio anual es $165 \mathrm{~m}^{3} / \mathrm{s}$, mientras que la descarga media mensual máxima es de $320 \mathrm{~m}^{3} / \mathrm{s}$ (mayo) (Goniadzki et al., 2011). De acuerdo con el método de Kirpich, con una longitud de escurrimiento máxima de $280 \mathrm{~km}$ y un desnivel de $50 \mathrm{~m}$, se obtuvo un tiempo de concentración de 5,87 días. El curso principal escurre en sentido Noreste-Sudoeste en la cuenca alta para luego tomar un rumbo Norte-Sur hasta desaguar en el delta del Paraná.

Los suelos predominantes en los interfluvios son los vertisoles, seguidos por los molisoles y los alfisoles, mientras que en los valles de inundación predominan los inceptisoles y los entisoles (Panigatti et al., 2002). En cuanto a la textura, predominan los arcillo-limosos seguidos por los franco arcillo-limosos (Cerana et al., 2006). En la sección de cierre el perfil transversal presenta una amplia planicie de inundación de aproximadamente $7 \mathrm{~km}$ de ancho, ocupada predominantemente por bosques y pasturas naturales, limitada por barrancas bien definidas. La misma recibe las aguas de desborde cuando es excedido el nivel de banca $(7 \mathrm{~m}$, $500 \mathrm{~m}^{3} / \mathrm{s}$ ), pudiendo ocuparse todo su ancho en caso de eventos extraordinarios (superiores a $8,3 \mathrm{~m}, 1500 \mathrm{~m}^{3} / \mathrm{s}$ ). A excepción de las instalaciones del balneario de Rosario del Tala, este área no presenta asentamientos humanos de importancia en las cercanías de la sección de interés, sin embargo aguas abajo pueden encontrarse áreas urbanas tales como la localidad de Gualeguay. La actividad económica predominante es la ganadería extensiva, siendo los productores los principales afectados por los recurrentes desbordes. 


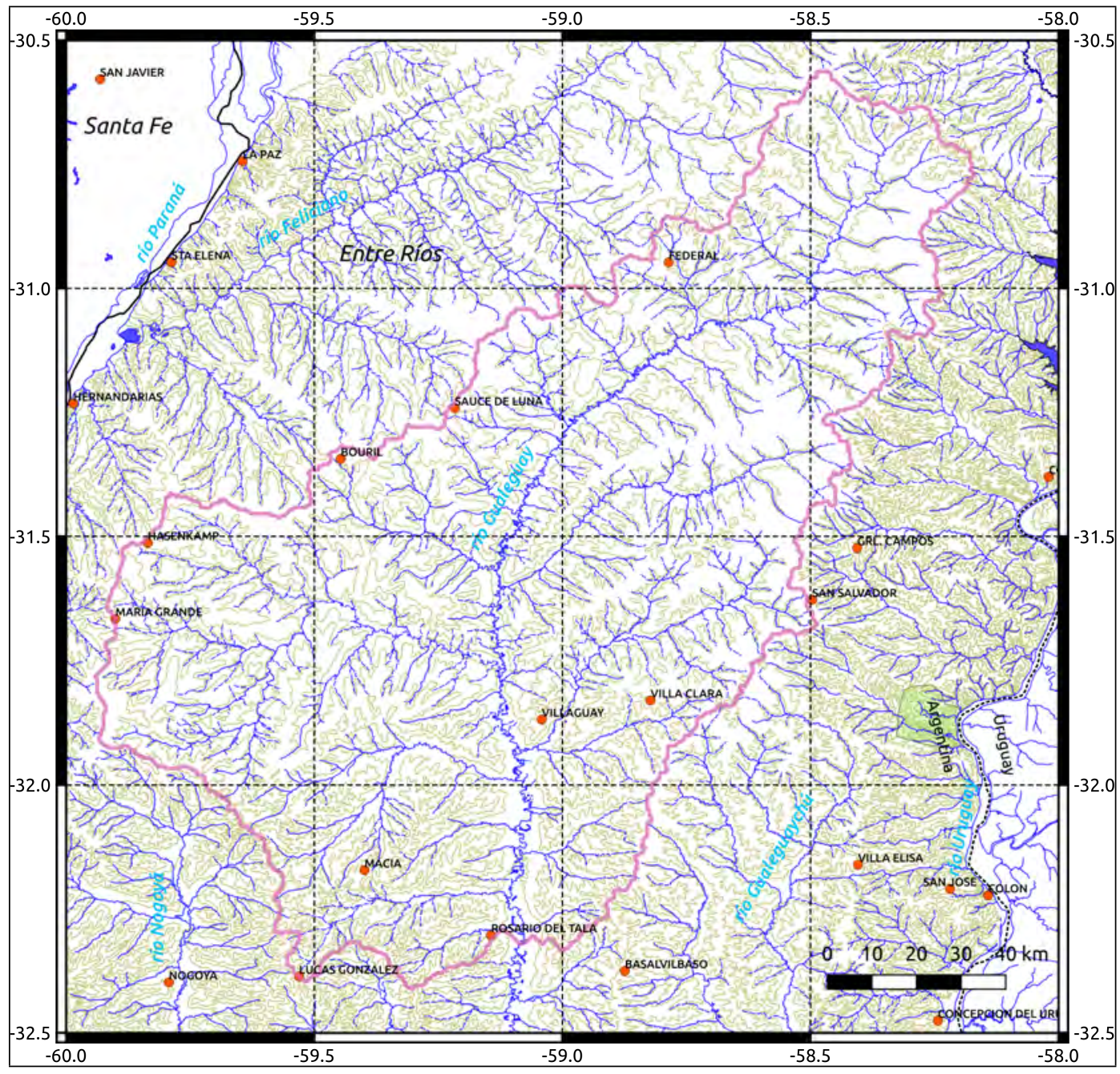

Figura 1: Cuenca del río Gualeguay con cierre en Rosario del Tala, Provincia de Entre Ríos. Capas de base: (IGN, 2019) 


\section{Objetivos}

\subsection{General}

Implementar un procedimiento de pronóstico hidrológico para un sistema de información y alerta hidrológico de la cuenca del río Gualeguay utilizando modelos hidrológicos conceptuales y datos de sensores in-situ y remotos disponibles a tiempo útil.

\subsection{Específicos}

- Generar medidas agregadas de precipitación, evapotranspiración potencial, caudal y humedad del suelo a paso diario para la cuenca de estudio a partir de datos in situ y satelitales.

- Calibrar y verificar modelos hidrológicos conceptuales continuos de paso diario para la cuenca de estudio.

- Implementar dichos modelos en modo actualizado, asimilando datos de caudal observado y estimaciones remotas de humedad del suelo y utilizando pronósticos cuantitativos de precipitación para el horizonte de pronóstico.

- Desarrollar un servidor de base de datos para el almacenamiento y fácil acceso a la información de entrada de los modelos.

- Elaborar rutinas de actualización automática de dicha base de datos.

- Confeccionar una aplicación para correr dichos modelos y obtener los respectivos hidrogramas simulados. 


\section{Marco conceptual}

La metodología escogida fue la simulación de los procesos generadores de escorrentía en la cuenca mediante modelos conceptuales continuos agregados, los cuales se incluyeron en procedimientos para su funcionamiento operativo.

Las expectativas asociadas a la predictabilidad de las crecidas en tiempo y magnitud han crecido a la par del reconocimiento de la importancia de los alertas de crecida como contribución al manejo integral de crecidas (O’Connor, 2007). Mientras que en el núcleo de un sistema de pronóstico hidrológico se encuentran uno o más modelos, la modelación hidrológica constituye solo uno de los elementos cruciales de los cuales depende la eficiencia y eficacia del sistema (O`Connor, 2007).

Un pronóstico hidrológico es una estimación del estado futuro de algún elemento hidrológico, tal como el caudal, volumen, nivel hidrométrico, área inundada o velocidad del flujo, en una locación geográfica particular (O‘Connor, 2007). El horizonte de pronóstico es el tiempo entre el momento en que se realiza el pronóstico y el punto en el futuro al cual corresponde el pronóstico(O‘Connor, 2007). La elección del tipo de modelo así como también las fuentes de información pluviométrica son cruciales para el éxito del sistema de pronóstico, teniendo en cuenta que las forzantes meteorológicas son una fuente significativa de incertidumbre (O‘Connor, 2007). Por otro lado, estudios recientes (Oudin et al., 2005) muestran que en el caso de los modelos conceptuales agregados la estimación de la evapotranspiración puede basarse en métodos simples de temperatura (O‘Connor, 2007).

Los modelos conceptuales de precipitación-escorrentía se utilizan para producir un pronóstico de caudales en la sección de la salida de una cuenca a partir de observaciones y pronósticos de precipitación sobre la misma. Los procesos físicos de transferencia de materia involucrados en el sistema de transformación precipitación-escorrentía, desde el intercambio suelo-atmósfera hasta el flujo saliente por el sistema de drenaje, se representan mediante ecuaciones matemáticas simples que conservan la masa. La estructura de los modelos conceptuales generalmente incluye una red de reservorios o capas interconectados los cuales son sucesivamente recargados y descargados mediante los procesos de transformación apropiados, para luego propagar y combinar la escorrentía generada para producir los caudales de salida (Goniadzki et al., 2011). Lo modelos pueden ser de eventos o continuos según realicen la simulación de la respuesta hidrológica ante eventos de precipitación aislados o lo hagan continuamente en el tiempo considerando toda la precipitación caída sobre la cuenca. En el segundo caso los modelos son más complejos porque deben tener en cuenta además de las crecidas las recesiones en periodos secos.

La ventaja principal de los modelos continuos por sobre los modelos de eventos, en el contexto de la hidrología operativa, es que aquellos realizan explícitamente el balance hídrico a cada paso, el cual determina en gran medida la capacidad de amortiguar el flujo entrante (las precipitaciones) o, dicho de otro modo, la capacidad de generar escorrentía (Aubert et al., 2003). Se escogieron modelos conceptuales agregados debido a la relativa simplicidad de su estructura, la menor densidad espacial de datos de entrada demandados y su parsimonia en cuanto a la cantidad de parámetros (Guetter, 2000; Georgakakos et al., 1988). A pesar de que existe actualmente una tendencia hacia la implementación de modelos distribuidos de base física, si el objetivo es sólo reproducir la señal de caudal a la salida de la cuenca un modelo 
simple conceptual agregado puede obtener resultados igualmente satisfactorios que uno complejo de base física distribuido (Beven, 2001), lo cual explicaría por qué la implementación de estos últimos no se ha difundido aún mayormente (O'Connor, 2007). En este caso se implementaron los modelos Sacramento Simplificado (SAC-MOD) (Georgakakos y Baumer, 1996) y GR4P (Berthet, 2010). La elección de modelos agregados se basa en la necesidad de desarrollar herramientas de pronóstico aplicables a cuencas que dispongan solamente de datos hidrométricos en la sección de salida de la cuenca y datos pluviométricos de baja densidad espacial, con un grado aceptable de calibración. Al elegir modelos parsimoniosos (entre 4 y 10 parámetros), se hace posible extender la metodología utilizada a un gran número de cuencas en territorio Nacional y de la Región.

El paso de cálculo del modelo debe ser acorde con los objetivos de la modelación teniendo en cuenca las características de la respuesta hidrológica de la cuenca. Es decir que debe ser lo suficientemente corto como para describir adecuadamente los hidrogramas de crecida, pero también debe adecuarse a la resolución temporal de los datos de entrada. En esta cuenca, cuyo tiempo de concentración ronda los 6 días, consideramos adecuado el paso de cálculo diario, teniendo en cuenta también que los datos pluviométricos e hidrométricos disponibles son diarios.

Estos modelos representan al sistema hídrico en dos subsistemas: suelo y red de drenaje. El subsistema suelo se representa mediante una serie de reservorios o capas interconectados los cuales son sucesivamente recargados y descargados mediante los procesos de transformación apropiados para producir un flujo de salida (excedente hídrico superficial y subsuperficial). Dicho flujo es luego conducido a través del segundo subsistema, el cual lo atenúa y retrasa dándole la forma final al hidrograma.

Para la calibración de los parámetros de los modelos es necesario algún procedimiento de optimización, ya que por lo general su estimación a partir de mediciones o de conocimiento a priori no resulta posible (Beven, 2001). Los procedimientos de optimización consisten en realizar sucesivas corridas de simulación y comparar los resultados con las observaciones disponibles. Los parámetros se ajustan entre corridas del modelo, tanto manualmente como mediante algún algoritmo de optimización hasta encontrar un ajuste óptimo. Existen numerosos estudios acerca de distintos algoritmos de optimización y medidas de bondad del ajuste o funciones objetivo. El problema consiste en encontrar el pico en la superficie de respuesta en el espacio de parámetros definido por una o más funciones objetivo(Beven, 2001). La forma de la superficie de respuesta puede ser muy variada y su representación puede ser muy dificultosa cuando se trata de modelos de más de 3 parámetros, además de ser muy costoso computacionalmente cubrir el espacio de parámetros con una densidad adecuada. Por lo tanto existen algoritmos que, partiendo de un conjunto de parámetros dado, exploran la vecindad para encontrar la dirección ascendente en forma iterativa hasta encontrar un pico(Beven, 2001). Uno de estos algoritmos, denominados Hill-climbing direct-search, es el Downhill Simplex(Mathews y Fink, 2004) utilizado en este trabajo. Un problema de estos métodos es que en una superficie de respuesta compleja el pico encontrado depende fuertemente de la posición inicial, y pueden existir otros picos con igual o mayor valor de la función objetivo(Beven, 2001). Por lo tanto en este trabajo se optó por hacer variar el punto inicial aleatoriamente dentro de un rango de valores considerados a priori como posibles para la cuenca estudiada, para realizar sucesivas corridas del algoritmo de optimización y seleccionar 
los mejores de entre los óptimos resultantes.

La operación a tiempo real de dichos modelos requiere la mejor estimación posible tanto de los parámetros del modelo como de las forzantes y los estados del sistema al inicio del horizonte de pronóstico, para minimizar los errores de pronóstico (Goniadzki et al., 2011; Uriburu Quirno, 2011). Por lo tanto resulta de interés la disponibilidad de información a tiempo real o cuasi-real que ayude a describir el estado hídrico de la cuenca, de modo tal de contar con tiempos de respuesta adecuados ante la amenaza de inundaciones.

En la actualidad es cada vez mayor la disponibilidad de información útil para la hidrología a tiempo real a través de Internet, haya sido obtenida ésta in-situ (estaciones meteorológicas automáticas telemétricas) o remotamente (sensores en plataformas satelitales y radares meteorológicos). En el contexto de la hidrología operativa, la pronta disponibilidad de los datos, así como su accesibilidad y facilidad de interpretación son factores tan importantes como la calidad misma del dato a la hora de escoger las fuentes para alimentar un modelo. Por lo tanto se vuelve relevante la puesta a prueba de sistemas de alerta basados en datos de sensores remotos de plataformas satelitales, entre cuyas ventajas cuentan su bajo costo, su amplia cobertura espacial y su disponibilidad a tiempo cuasi-real. Sus desventajas son (dependiendo del producto) su baja resolución espacial y/o temporal (por lo general los productos de alta resolución temporal poseen baja resolución espacial, y viceversa), y su elevado grado de incertidumbre en comparación con las mediciones puntuales (Crow et al., 2005c; Brocca et al., 2005; Crow et al., 2005b). Sin embargo, a fines de la modelación hidrológica agregada lo que se necesitan no son mediciones puntuales sino areales, lo cual implica una ventaja intrínseca de los sensores remotos por sobre las mediciones directas y que además el dato es menos incierto cuanto mayor es el área de la cuenca.

Un desafío de la hidrología operativa constituye contar con las mejores estimaciones posibles del estado del sistema al inicio de un horizonte de pronóstico. Es bien conocida la fuerte influencia del estado de humedad antecedente de un sistema hídrico sobre la generación de escorrentía ante un evento de precipitación determinado (Crow et al., 2005a). Esto es especialmente cierto en cuencas de llanura, donde el almacenamiento de agua en suelos, cauce y planicie de inundación son a menudo muy importantes. Por lo tanto, se han desarrollado técnicas de actualización de las variables de estado utilizando información adicional derivada de observaciones independientes. La lógica de combinar información de observaciones con información derivada de modelos es que a pesar de que ambos métodos pueden tener fuertes limitaciones, la estructura del error en ambos es probablemente de distinta naturaleza, por lo cual su combinación puede ayudar a reducir la incertidumbre en las predicciones (Parajka et al., 2009). En este caso se ensayó la actualización de las variables de estado mediante asimilación de datos de caudal observado in-situ y estimaciones satelitales de humedad del suelo, mediante la técnica de filtrado de Kalman en ensamble. La asimilación de datos de caudal observado es ya un procedimiento conocido y ampliamente utilizado en la práctica hidrológica operativa(Georgakakos, 1987). En cambio, la asimilación de observaciones de humedad del suelo (obtenidas directa o remotamente) es de aplicación reciente (Aubert et al., 2003).

En la actualidad, la humedad del suelo, entendida como la relación entre el volumen de la fase líquida y el volumen total de un determinado volumen de suelo, está cobrando relevancia como una de las variables esenciales para la comprensión de los procesos climatológicos, 
biológicos e hidrológicos (GCOS-138, 2010). De acuerdo con lo anterior, un número creciente de misiones satelitales portan sensores activos y pasivos destinados a monitorear la humedad de la capa superficial del suelo a escala global con resolución espacial y temporal adecuada (Wagner et al., 2007). Sin embargo, aún son pocos los estudios que han demostrado la utilidad de incorporar estas mediciones para aplicaciones hidrológicas (Brocca et al., 2012). 


\section{Materiales y Metodología}

La cuenca estudiada constituye un banco de prueba adecuado para estas metodologías de pronóstico basadas en sensores remotos ya que se encuentra cubierta por una red de estaciones meteorológicas automáticas suficientemente densa, lo cual permite comparar los resultados de la modelación utilizando alternativamente mediciones directas y remotas de precipitación. Se utilizaron las estimaciones de tasa de precipitación del producto 3B42RT de la misión satelital TRMM y datos de la red telemétrica de estaciones meteorológicas automáticas de la provincia de Entre Ríos.

En este estudio se utilizaron tres productos de humedad del suelo de sensores de microondas pasivos: MIRAS de la misión SMOS, puesto en órbita por NASA en 2009, Aquarius a bordo de la plataforma SAC-D de CONAE y NASA, puesta en órbita en junio de 2011 y AMSR-2 a bordo de la plataforma GCOM-2, operada por NASA y JAXA desde octubre de 2012. Se evaluó el impacto en la eficiencia de los pronósticos al asimilar independientemente cada fuente de datos de humedad del suelo.

Los modelos hidrológicos se alimentan hasta la fecha de emisión del pronóstico con observaciones de precipitación y pueden, dependiendo de la disponibilidad de los datos, hacerlo en modo actualizado (es decir, corrigiendo los estados del modelo a partir de observaciones de caudal y/o humedad del suelo). Sin embargo, para los pasos subsiguientes, deben hacerlo en modo autónomo y en base a un pronóstico cuantitativo de precipitación. Contar con un pronóstico de precipitaciones permite ampliar el horizonte de pronóstico y así anticipar mejor situaciones hídricas extremas (O‘Connor, 2007). Para generarlo actualmente se utilizan modelos meteorológicos distribuidos de escala global o regional. En el contexto Nacional, el Servicio Meteorológico desarrolla e implementa operativamente una serie de estos modelos a escala regional. En este caso se utilizó el modelo ETA-SMN, el cual incluye, entre otros productos, un pronóstico cuantitativo de precipitación para un horizonte de $5 \frac{1}{2}$ días para todo Sudamérica con una resolución de $\frac{1}{3}$ grado lat/lon (Suaya, 2004). Se evaluó el cambio en la eficiencia al utilizar este pronóstico en lugar de un pronóstico nulo.

Por útimo, para la segura y ágil interacción entre los distintos componentes de la herramienta desarrollada se utilizó un servidor de base de datos relacional POSTGRESQL. En la misma se crearon tablas para almacenar la información estática (o de base) y dinámica (o forzantes) de la cuenca y las salidas parciales y finales de los modelos, lo cual facilitó la evaluación de los resultados y la presentación de los mismos en forma gráfica y tabular. A su vez se generaron rutinas para la automatización de la obtención, el procesamiento y el almacenamiento de dicha información, de manera de mantenerla actualizada.

\subsection{Esquema funcional del sistema de pronóstico hidrológico}

En el presente trabajo se conceptualizó un sistema de información y pronóstico hidrológico como una suma de componentes (o subsistemas) conectados entre sí por flujos de información, que abarcan desde la producción de los datos de entrada hasta la diseminación del pronóstico a las partes interesadas. En el diagrama que se presenta en esta sección (Figura 2, adaptado de (Nemec, 1986)) se muestran las distintas componentes (o subsistemas) y los flujos de información entre ellos. La cadena comienza con la captura de datos a tiempo real, realizada mediante sensores terrenos o remotos. Los datos capturados se transmiten a tiempo 
real mediante redes telemétricas para concentrarse en un subsistema de procesamiento y archivo. Esta componente a su vez alimenta la base de datos histórica de la cuenca, el procedimiento de pronóstico operativo y la componente de evaluación y actualización del pronóstico. Esta última, además de actualizar el pronóstico operativo, brinda información para mejorar la estructura del procedimiento de pronóstico, incluyendo la estructura y los parámetros de los modelos hidrológicos. Por último, la información generada mediante el procedimiento operativo es seleccionada y preparada adecuadamente para la diseminación del pronóstico.

De acuerdo con la conceptualización precedente, los desarrollos presentados en este trabajo constituyen el núcleo central del sistema, es decir, desde el procesamiento y archivo de datos hasta la generación de pronósticos, quedando excluidas las componentes de captura y transmisión de datos de entrada y diseminación del pronóstico. Por lo tanto, estos desarrollos se idearon en función de las posibilidades y limitaciones que ofrecen los sistemas de captura y transmisión de datos existentes para el área de estudio, abarcando desde los convencionales (p. ej. red de estaciones meteorológicas convencionales) hasta los resultantes de nuevas tecnologías (redes telemétricas, sensores remotos de microondas).

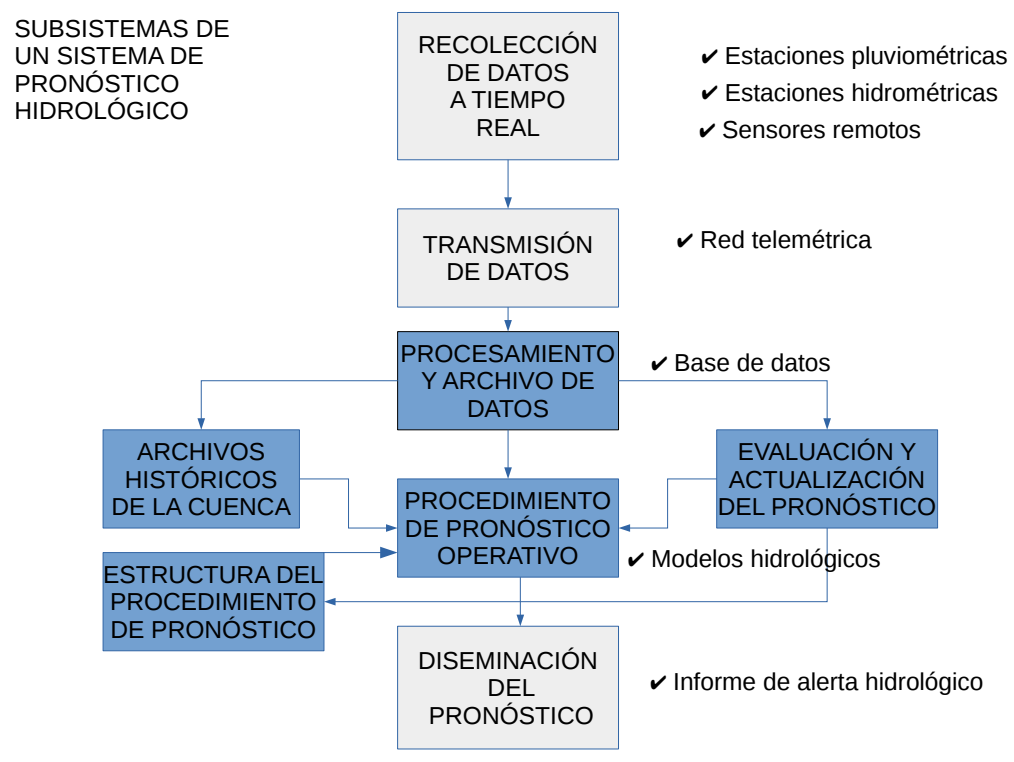

Figura 2: Diagrama funcional de un sistema de pronóstico hidrológico. Los recuadros con sombreado azul son los que se abordaron en este trabajo. Adaptado de Nemec(1986)

\subsection{Obtención de los datos}

Para la calibración y operación de modelos continuos agregados se necesitan valores de las forzantes promediadas espacial y temporalmente en coincidencia con la resolución y alcance propuestos, o sea en nuestro caso, pulsos diarios para la cuenca para el periodo 01-03-2000 a 31-01-2015. Sin embargo, los datos crudos de tasa de precipitación y evapotranspiración potencial (tanto los obtenidos in-situ como los satelitales) tienen disposiciones espaciales y temporales diversas. Por lo tanto, para cada forzante, se procedió a calcular:

- la tasa media diaria (promediación temporal): se calculó la tasa media diaria para cada día meteorológico (hora de corte 09:00 HOA, 12:00 UTC) a partir de los valores 
subdiarios. $^{1}$

- la tasa media areal (promediación espacial) para el área de la cuenca: se calculó el promedio ponderado de los valores puntuales utilizando el criterio de vecino más próximo (polígonos de Thiessen). En el caso de datos rasterizados se utilizó directamente la media aritmética de los valores de los píxeles superpuestos al área de la cuenca, ya que los píxeles son equidistantes. En el caso de datos puntuales se utilizó la función v.surf.idw de GRASS 6.4.0.

Por otro lado, las observaciones del estado del sistema (caudal y humedad del suelo) no constituyen pulsos sino valores instantáneos, siendo variables los horarios de captura. Por lo tanto, para utilizarlos, se interpolaron linealmente generando valores coincidentes con los instantes de comienzo del paso de cálculo del modelo (09:00).

Para delimitar el área de la cuenca se utilizó el modelo digital de elevación del terreno de la misión SRTM de NASA y JAXA (USGS, 2006). Dicha operación se realizó mediante las funciones r.watershed y r.water.outlet de GRASS 6.4.0 (GRASS Development Team, 2012).

\subsubsection{Precipitaciones}

La precipitación total que alcanza la superficie durante un periodo dado se expresa como la profundidad con la cual cubriría una proyección horizontal de la superficie terrestre (WMO, 2008). El objetivo primario de cualquier método de medición de la precipitación consiste en obtener muestras representativas de la caída de agua sobre el área a la cual se refiere (WMO, 2008). En el caso del presente estudio, el área a la cual se refiere la medición es el área de la cuenca.

Para cualquier tarea hidrológica existe una necesidad crítica de mediciones precisas de precipitación, para lo cual existen diversos métodos, cada uno con sus limitaciones y ventajas. Entre los métodos existentes, en el presente estudio se utilizaron dos: la medición mediante pluviómetros y la estimación satelital. Luego se compararon los resultados de la modelación hidrológica utilizando alternativamente ambas fuentes.

En hidrología operativa, es fundamental también la comunicación rápida y eficaz de las mediciones. En la Figura 3 se esquematiza el flujo de información desde la medición hasta la obtención de la precipitación media areal diaria (PMAD) de la cuenca de estudio.

\footnotetext{
${ }^{1}$ En los casos donde el dato crudo ya era diario se obvió este paso.
} 


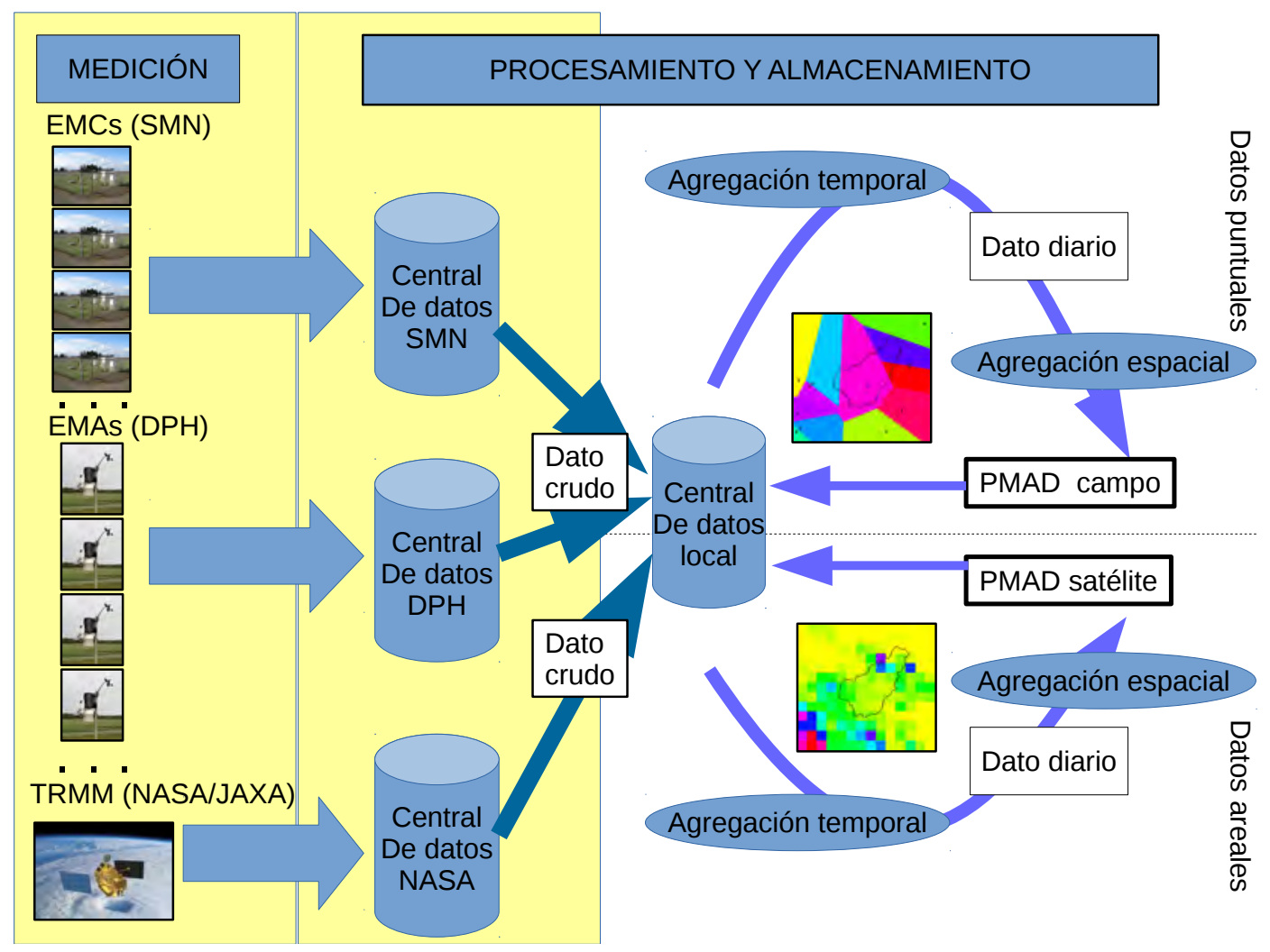

Figura 3: Diagrama de flujo de los datos de precipitación

Precipitación observada in-situ: pluviómetros de la red de estaciones meteorológicas convencionales y automáticas Un pluviómetro convencional de registro manual consiste en un recipiente que acumula agua de precipitación a través de un embudo durante un intervalo temporal determinado. Al finalizar dicho intervalo temporal se vierte el líquido acumulado en un cilindro graduado para obtener la medición. El área de la boca del embudo debe conocerse con precisión y la graduación del cilindro debe ser consistente con la misma (WMO, 2008). La ubicación del pluviómetro debe estar alejada de obstáculos de manera tal que la medición sea representativa del área circundante. Existen estándares internacionales para la fabricación, localización e instalación de estos equipos, como los establecidos por la Organización Meteorológica Mundial.

Se utilizaron los registros diarios (9 AM a 9AM del día siguiente) de las estaciones meteorológicas convencionales del Servicio Meteorológico Nacional. Los mismos son diseminados por el Servicio en formato digital a través de su servidor FTP diariamente luego del acopio y revisión de los datos, con un retraso máximo de 2 horas. Las ubicación de las estaciones activas durante el periodo de estudio en el área de interés se muestra en la Tabla 1 y en la Figura 4.

Adicionalmente, el gobierno de la provincia de Entre Ríos, a través de su Dirección de Hidráulica, opera una red de 23 estaciones meteorológicas automáticas telemétricas (véase Figura 4 y Tabla 1). Existen distintos métodos de registro automático in-situ de la precipitación. Estas estaciones cuentan con pluviómetros de cubeta basculante. Cada basculación de la cubeta representa una cantidad prefijada de precipitación y produce un registro. Un registrador de datos almacena la cantidad de basculaciones a intervalos de 10 minutos y transmite el valor a la central de datos. Esta información se publica a tiempo real en el servidor HTTP de la 
Dirección. En la Figura 8 puede observarse la disponibilidad de registros de esta red en función del tiempo.

Los datos pluviométricos del SMN son generados a través de métodos homologados y son revisados antes de ser difundidos. Por lo tanto los hemos considerado como el patrón de referencia para revisar los datos generados por DPH. A cada estación de la red de la DPH se le asignó la estación del SMN más cercana y se compararon los datos mediante gráficos de doble masa. De esta manera se descartaron los datos erróneos. En la Figura 5 se muestran los gráficos de doble masa resultantes de eliminar los datos erróneos.

Utilizando herramientas de software libre de código abierto, se elaboraron rutinas automáticas de captura, procesamiento y almacenamiento en base de datos de los datos pluviométricos publicados por el SMN y la DPH de Entre Ríos. En las Figuras 7 y 8 se muestra la disponibilidad de estos datos en función del tiempo. Como se puede ver, muchas de las estaciones no poseen un registro continuo desde el momento de su puesta en funcionamiento. Por lo tanto, a cada paso de cálculo de la precipitación media areal diaria (PMAD) de la cuenca se utilizaron las estaciones activas durante dicho paso. Es decir que la cantidad y configuración espacial de los puntos de medición de la precipitación varían día a día, entre un mínimo de 3 estaciones, un máximo de 14 y un promedio de 7. Para lograr una mejor representación de la variable de interés se combinaron ambas fuentes de datos para generar una única PMAD.
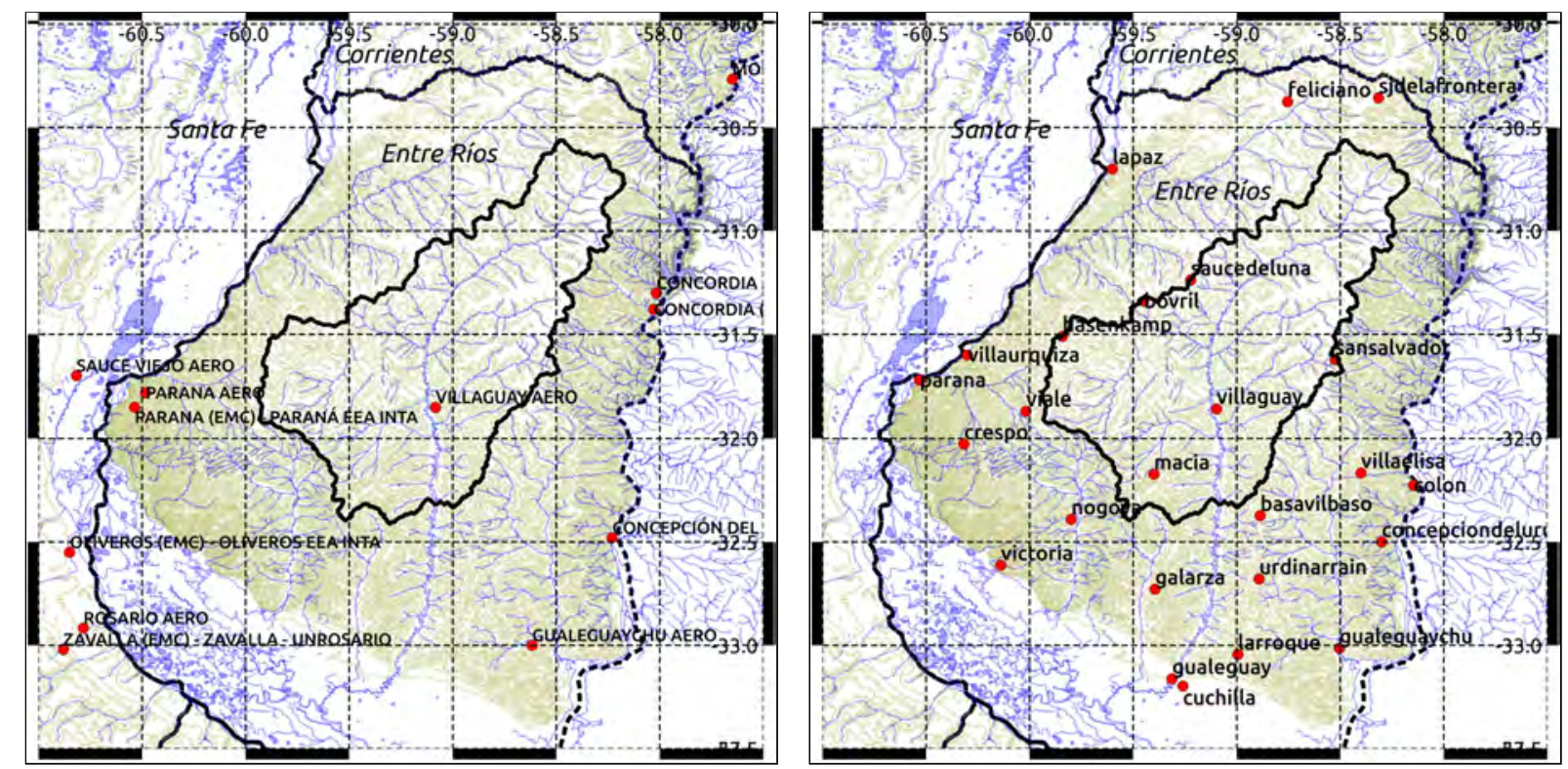

Figura 4: Red de estaciones meteorológicas convencionales (izquierda) y automáticas (derecha). Capas base: (IGN, 2019) 

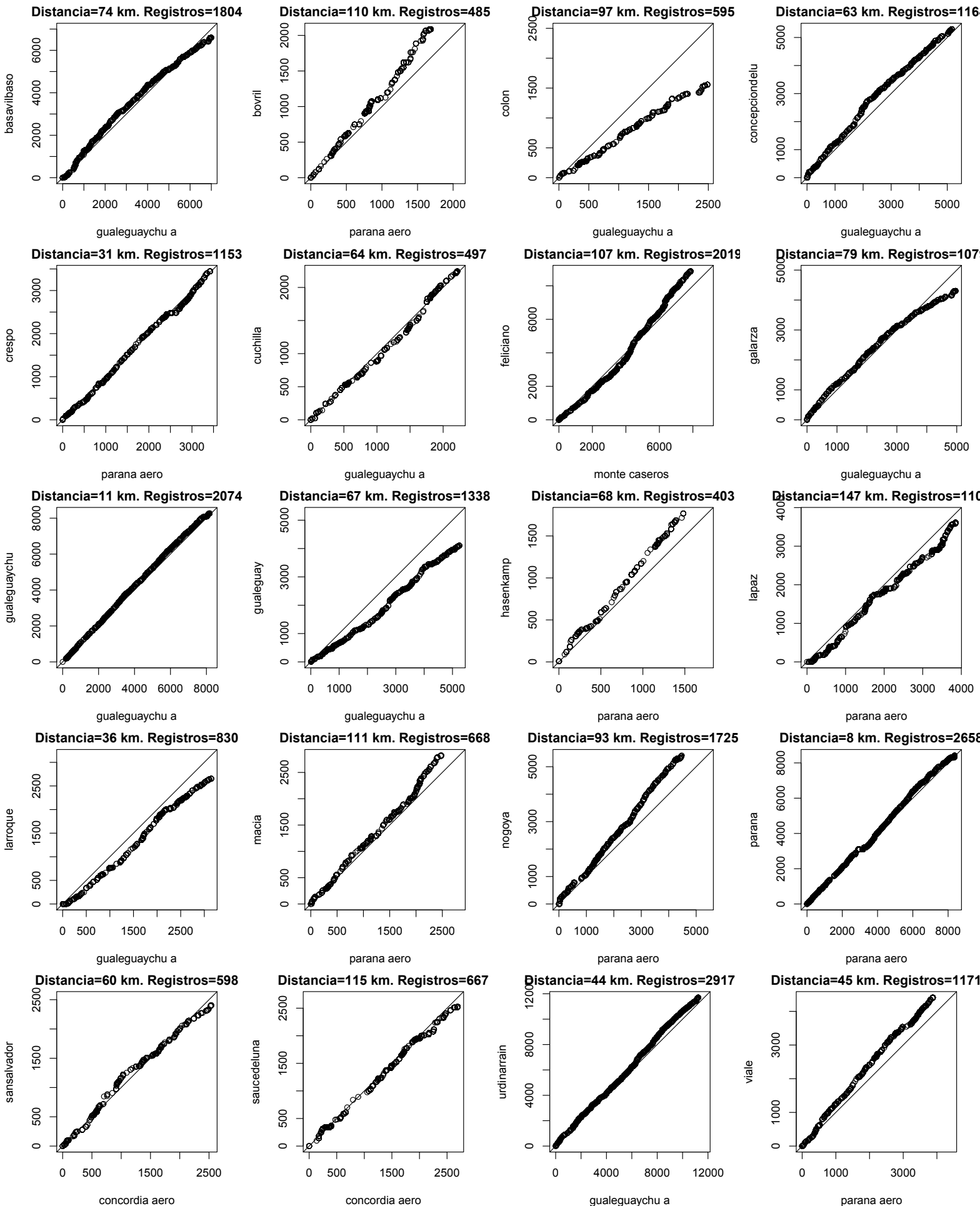

Figura 5: Gráficos de doble masa entre datos de precipitación de la red de estaciones de la red automática de DPH y la red convencional de SMN 

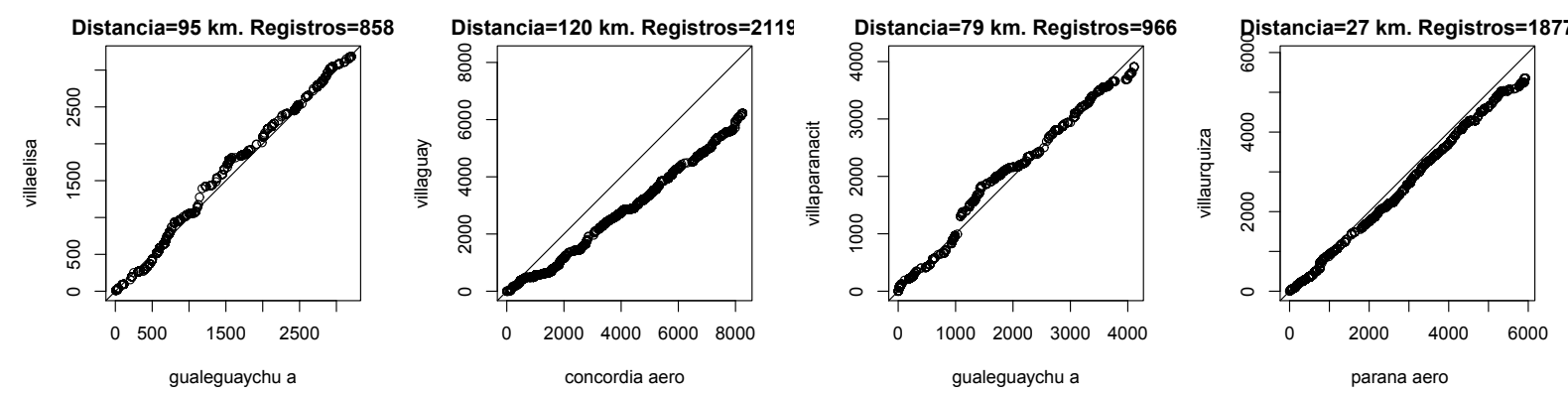

Figura 6: Gráficos de doble masa entre datos de precipitación de la red de estaciones de la red automática de DPH y la red convencional de SMN

Tabla 1: Red de estaciones meteorológicas convencionales (SMN) y automáticas (DPH Entre Ríos)

\begin{tabular}{|c|c|c|c|}
\hline Tipo & nombre & Lon & Lat \\
\hline convencional (SMN) & Monte Caseros Aero & $57: 39: 00 \mathrm{~W}$ & $30: 16: 01.2 \mathrm{~S}$ \\
convencional (SMN) & Paraná Aero & $60: 28: 58.8 \mathrm{~W}$ & $31: 46: 58.8 \mathrm{~S}$ \\
convencional (SMN) & Paraná INTA & $60: 31: 01.2 \mathrm{~W}$ & $31: 49: 58.8 \mathrm{~S}$ \\
convencional (SMN) & Villaguay Aero & $59: 04: 58.8 \mathrm{~W}$ & $31: 51: 00 \mathrm{~S}$ \\
convencional (SMN) & Concordia Aero & $58: 01: 01.2 \mathrm{~W}$ & $31: 18: 00 \mathrm{~S}$ \\
convencional (SMN) & La Paz & $59: 39: 00 \mathrm{~W}$ & $30: 45: 00 \mathrm{~S}$ \\
convencional (SMN) & Concepción del Uruguay INTA & $58: 19: 58.8 \mathrm{~W}$ & $32: 28: 58.8 \mathrm{~S}$ \\
convencional (SMN) & Gualeguaychú & $58: 37: 00 \mathrm{~W}$ & $33: 00: 00 \mathrm{~S}$ \\
automática (DPH) & Basavilbaso & $58: 53: 12 \mathrm{~W}$ & $32: 22: 24 \mathrm{~S}$ \\
automática (DPH) & Bovril & $59: 26: 55 \mathrm{~W}$ & $31: 20: 23 \mathrm{~S}$ \\
automática (DPH) & Colón & $58: 08: 45 \mathrm{~W}$ & $32: 13: 34 \mathrm{~S}$ \\
automática (DPH) & Concepción del Uruguay & $58: 18: 00 \mathrm{~W}$ & $32: 30: 00 \mathrm{~S}$ \\
automática (DPH) & Crespo & $60: 19: 02 \mathrm{~W}$ & $32: 01: 39 \mathrm{~S}$ \\
automática (DPH) & Feliciano & $58: 45: 16 \mathrm{~W}$ & $30: 22: 33 \mathrm{~S}$ \\
automática (DPH) & Galarza & $59: 23: 39 \mathrm{~W}$ & $32: 43: 44 \mathrm{~S}$ \\
automática (DPH) & Gualeguay & $59: 18: 45 \mathrm{~W}$ & $33: 09: 45 \mathrm{~S}$ \\
automática (DPH) & Gualeguaychú & $58: 30: 15 \mathrm{~W}$ & $33: 00: 52 \mathrm{~S}$ \\
automática (DPH) & Hasenkamp & $59: 50: 31 \mathrm{~W}$ & $31: 30: 39 \mathrm{~S}$ \\
automática (DPH) & La Paz & $59: 36: 00 \mathrm{~W}$ & $30: 42: 00 \mathrm{~S}$ \\
automática (DPH) & Larroque & $58: 59: 41 \mathrm{~W}$ & $33: 02: 40 \mathrm{~S}$ \\
automática (DPH) & Macia & $59: 24: 00 \mathrm{~W}$ & $32: 10: 22 \mathrm{~S}$ \\
automática (DPH) & Nogoyá & $59: 47: 57 \mathrm{~W}$ & $32: 23: 27 \mathrm{~S}$ \\
automática (DPH) & Paraná & $60: 31: 51 \mathrm{~W}$ & $31: 43: 19 \mathrm{~S}$ \\
automática (DPH) & San Salvador & $58: 31: 28 \mathrm{~W}$ & $31: 37: 19 \mathrm{~S}$ \\
automática (DPH) & Sauce de Luna & $59: 13: 19 \mathrm{~W}$ & $31: 14: 18 \mathrm{~S}$ \\
automática (DPH) & Urdinarrain & $58: 53: 31 \mathrm{~W}$ & $32: 40: 45 S$ \\
automática (DPH) & Viale & $60: 01: 04 \mathrm{~W}$ & $31: 52: 08 \mathrm{~S}$ \\
automática (DPH) & Victoria & $60: 08: 21 \mathrm{~W}$ & $32: 36: 46 \mathrm{~S}$ \\
automática (DPH) & Villaguay & $59: 05: 50 \mathrm{~W}$ & $31: 51: 27 \mathrm{~S}$ \\
automática (DPH) & Villa Paranacito & $58: 39: 37 \mathrm{~W}$ & $33: 42: 42 S$ \\
automática (DPH) & Villa Urquiza & $60: 18: 00 \mathrm{~W}$ & $31: 36: 00 \mathrm{~S}$ \\
\hline
\end{tabular}




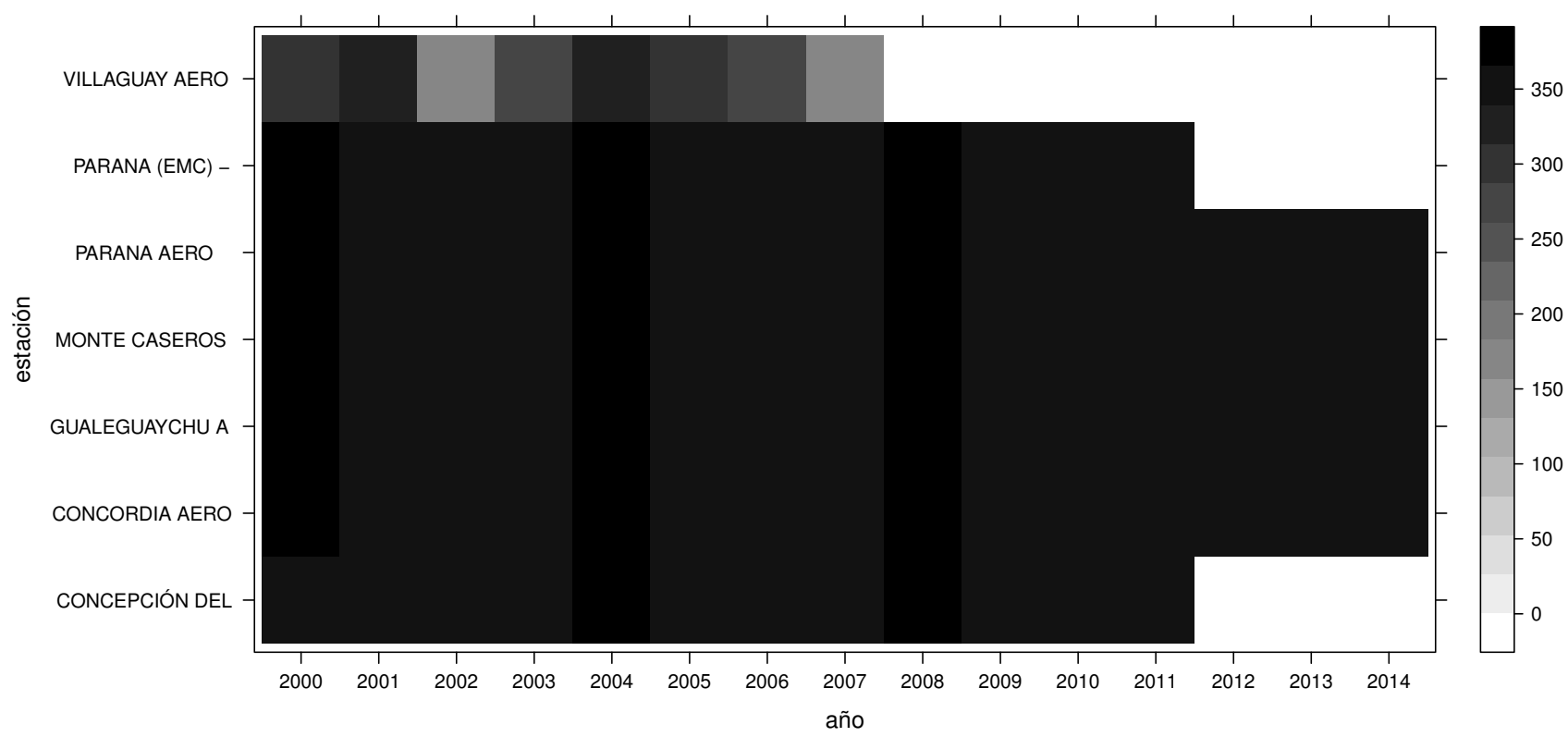

Figura 7: Cantidad de registros diarios de precipitación de estaciones meteorológicas convencionales 


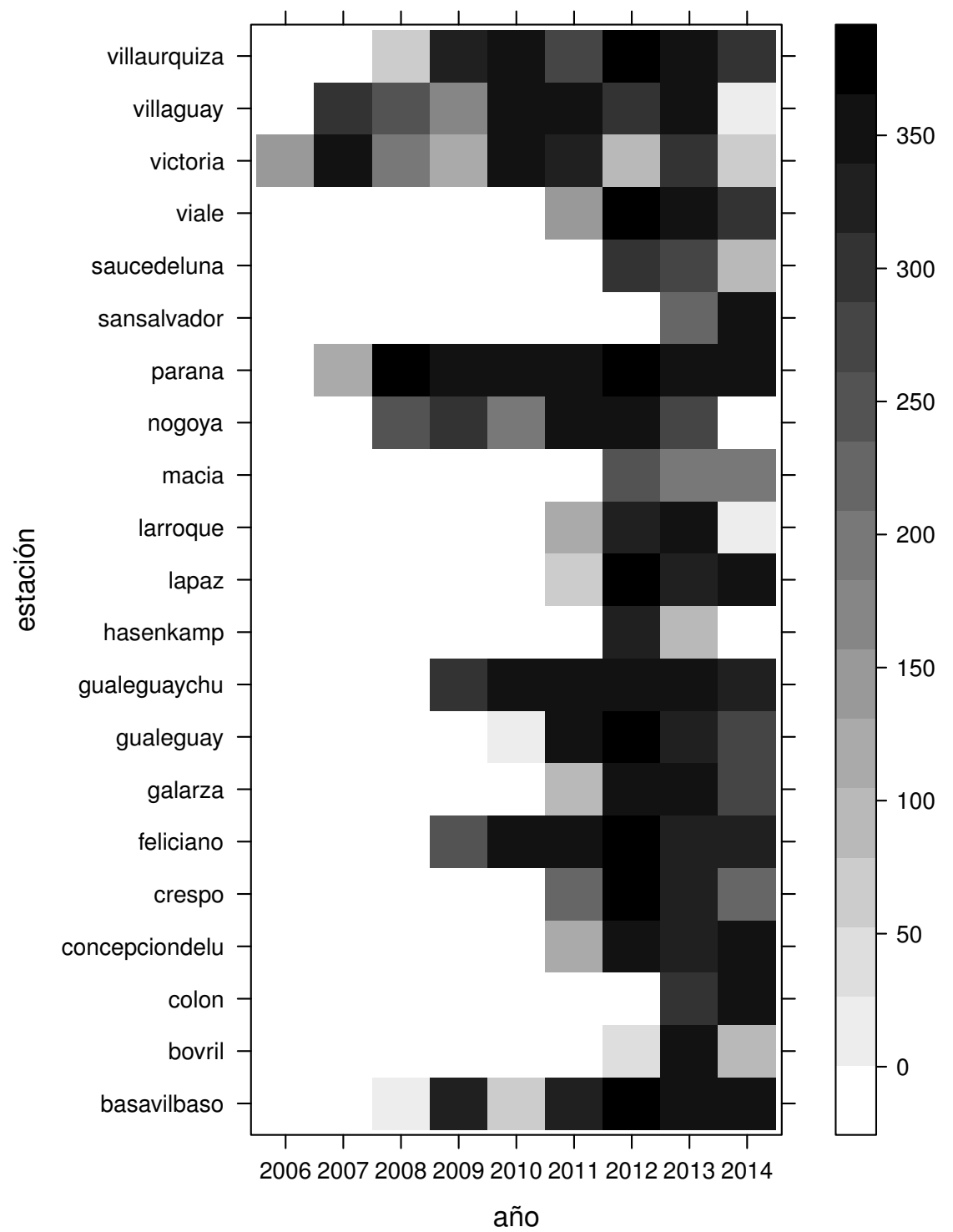

Figura 8: Cantidad de registros diarios de precipitación de estaciones meteorológicas automáticas

Estimación satelital de precipitación: TRMM 3B42RT La estimación de precipitaciones desde el espacio se basa en la medición de la cantidad de radiación reflejada y emitida a través de los topes nubosos. Debido a que la radiación no penetra más allá de la región de la nube donde el tamaño de partícula es mayor o igual a su longitud de onda, la mayor parte de la radiación proviene de la capa superior de las nubes. Por lo tanto, existe una gran diversidad de técnicas de estimación dependiendo del tipo de sensor y la longitud de onda utilizada (WMO, 2008).

En este trabajo se utilizó el producto de precipitación 3B42RT versión 7 (Huffman et al., 2009) de la misión conjunta TRMM de NASA y JAXA. El satélite TRMM (Tropical Rainfall Measuring Mission) posee un radar que transmite a una longitud de onda de $2,2 \mathrm{~cm}$ (microondas activo) que mide la distribución tridimensional de la precipitación, un radiómetro visible-infrarrojo de 5 canales, el cual provee información de alta resolución de la cobertura nubosa y la temperatura de los topes nubosos y un radiómetro de microondas en 5 frecuencias, 
el cual provee información del contenido integrado de precipitación de la columna de aire, el contenido de agua líquida, la intensidad de precipitación y el tipo de precipitación (Huffman et al., 2009). Utilizando los datos generados por estos sensores se calcula la intensidad media de precipitación [mm/h] para intervalos de 3 horas, a una resolución de $0,25^{\circ}$ para latitudes inferiores a los $50^{\circ}$. Los datos se publican en formato ráster binario de un repositorio FTP de libre acceso con un retraso aproximado de $18 \mathrm{hs}$ de capturado el dato. Se elaboraron rutinas automáticas de captura, procesamiento y almacenamiento en base de datos utilizando la librería de funciones GRASS 6.4.0 en una plataforma GNU (véase Figura 9).

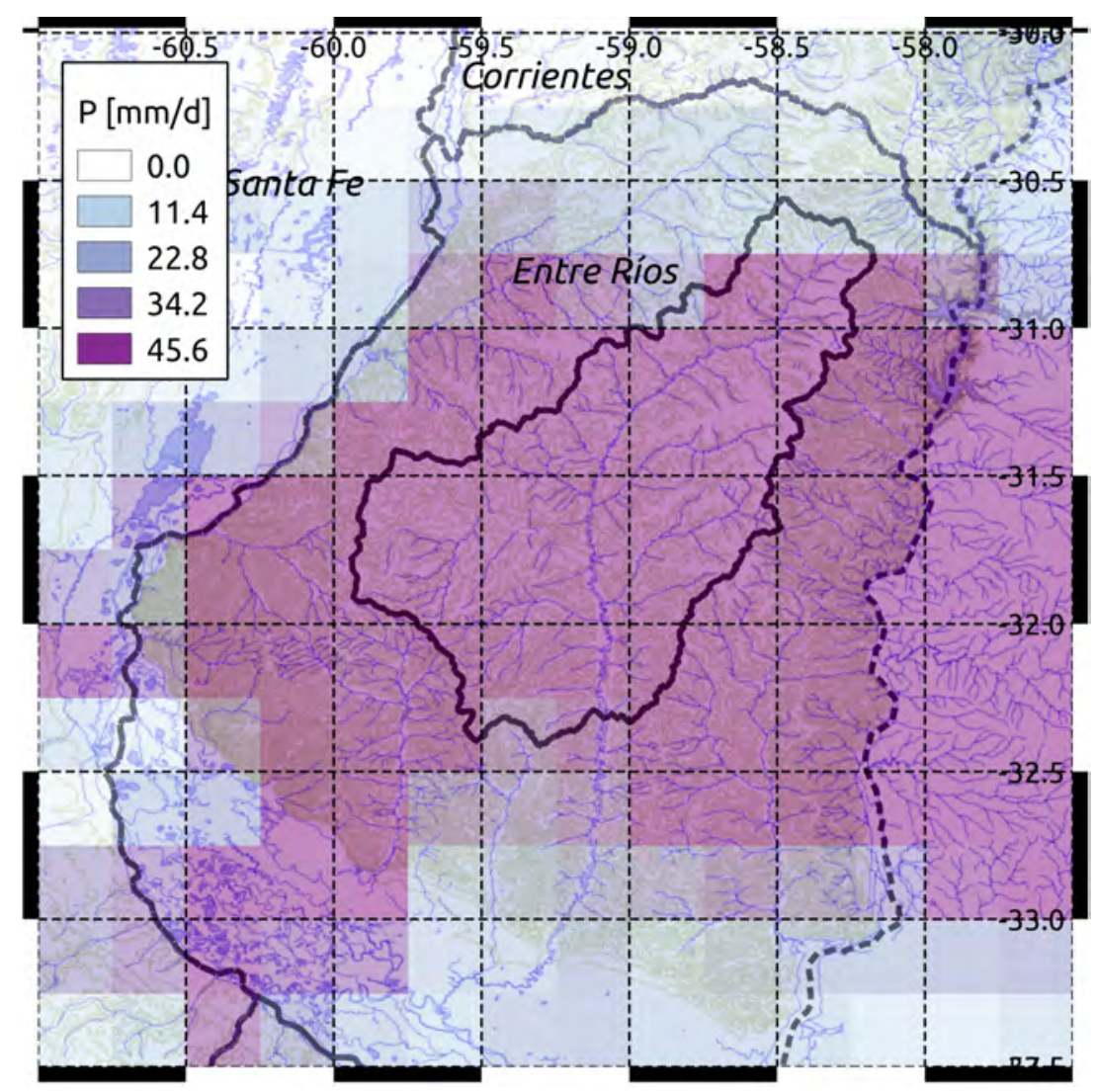

Figura 9: Producto de tasa media diaria de precipitación TRMM 3B42RT. Capas base: (IGN, 2019)

La figura 10 muestra distintos gráficos donde se compara la precipitación media areal extraída de datos TRMM 3B42RT con la extraída de datos de campo.

\subsubsection{Evapotranspiración potencial}

En base a la literatura (Aubert et al., 2003) se optó por utilizar una marcha anual de la evapotranspiración potencial en base a la climatología de la cuenca, debido a que se demostró que la utilización de datos observados no mejora significativamente la eficiencia de modelos de este tipo. Por lo tanto, se calculó la evapotranspiración potencial media anual con el método de Thornthwaite (1948) y se la distribuyó diariamente según el modelo basado en Jensen-Haise y McGuinness el cual necesita solamente temperaturas medias diarias climáticas y radiación 

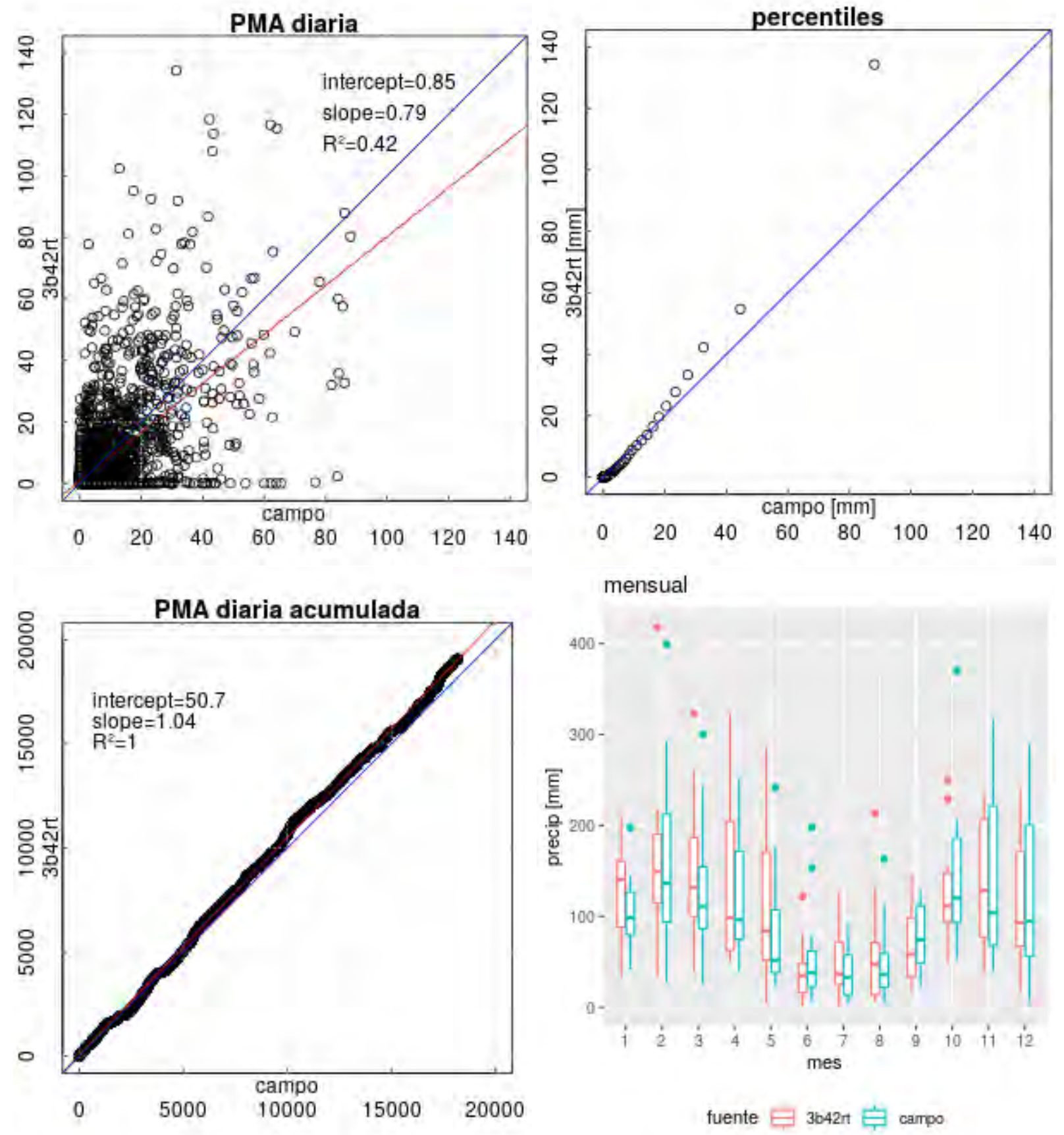

Figura 10: Comparación PMA campo vs. 3B42RT (serie 2000-2014) 
extraterrestre (Oudin et al., 2005). La fórmula utilizada fue:

$$
\mathrm{ETP}=\frac{R_{e}}{\lambda \rho} \frac{T_{a}+K_{2}}{K_{1}} 1000 \text { si } T_{a}+K_{2}>0 \quad \text { caso contrario } \quad E T P=0
$$

Donde:

ETP: Tasa de evapotanspiración potencial $\left(\mathrm{mm} \mathrm{día}^{-1}\right)$,

$R_{e}$ : Radiación extraterrestre ( $\mathrm{MJ} \mathrm{m}^{-2}$ día $^{-1}$ ), que depende de la latitud y el día Juliano,

$\lambda$ : Flujo de calor latente (se tomó el valor 2,45 $\mathrm{MJ} \mathrm{kg}^{-1}$ ),

$\rho$ : Densidad del agua $\left(\mathrm{kg} \mathrm{m}^{-3}\right)$,

$T_{a}$ : Temperatura media diaria del aire $\left({ }^{\circ} \mathrm{C}\right)$,

$K_{1}\left({ }^{\circ} \mathrm{C}\right)$ y $K_{2}\left({ }^{\circ} \mathrm{C}\right)$ : Parámetros para ajustar el modelo de modo tal que el total anual coincida con el valor anual calculado según la metodología de Thornthwaite (se obtuvo $K_{1}=108^{\circ} \mathrm{C} \mathrm{y}$ $\left.K_{2}=5^{\circ} \mathrm{C}\right)$.

Los datos de temperaturas medias diarias climáticas se tomaron de la estación meteorológica de Villaguay del Servicio Meteorológico Nacional.

\subsubsection{Caudales}

En la sección Rosario del Tala del río Gualeguay existe una regla limnimétrica, la cual se observa a paso diario y se registra la altura. Dicha tarea se encuentra en manos de la Subsecretaría de Recursos Hídricos de la Nación, operadora de la red hidrométrica nacional. Existen registros limnimétricos diarios con pocas discontinuidades desde 1992, acompañados por un conjunto considerable de aforos (un promedio de 4 por año), lo cual ha permitido construir una curva de gasto para esta sección (Giordano, 2011) (véase Figura 11). La misma presenta dos tramos: uno correspondiente al flujo encauzado (control de cauce) y el otro a los desbordes por encima del nivel de banca (control de planicie de inundación). Las ecuaciones correspondientes a dichos tramos se presentan en la Tabla 2. Las lecturas de escala se tranformaron en caudales utilizando dicha curva de descarga. Las alturas limnimétricas y los aforos se publican en tiempo diferido en la Base de Datos Hidrológica Integrada (DBHI) accesible a través del sitio web de la Subsecretaría de Recursos Hídricos de la Nación (Subsecretaría de Recursos Hídricos, 2013). Para la obtención a tiempo real de las lecturas de escala actualmente se procede a contactar al observador por vía telefónica.

Tabla 2: Ecuaciones de la curva de gasto de la sección Rosario del Tala del río Gualeguay

\begin{tabular}{|c|c|c|}
\hline Control & Nivel & Ecuación \\
\hline Cauce & $<7,06$ & $Q\left[\mathrm{~m}^{3} / \mathrm{s}\right]=13,87 \mathrm{H}[\mathrm{m}]^{1,83}$ \\
Planicie & $\geq 7,06$ & $Q\left[\mathrm{~m}^{3} / \mathrm{s}\right]=\frac{H[\mathrm{~m}]^{6,84}}{1286,91}$ \\
\hline
\end{tabular}




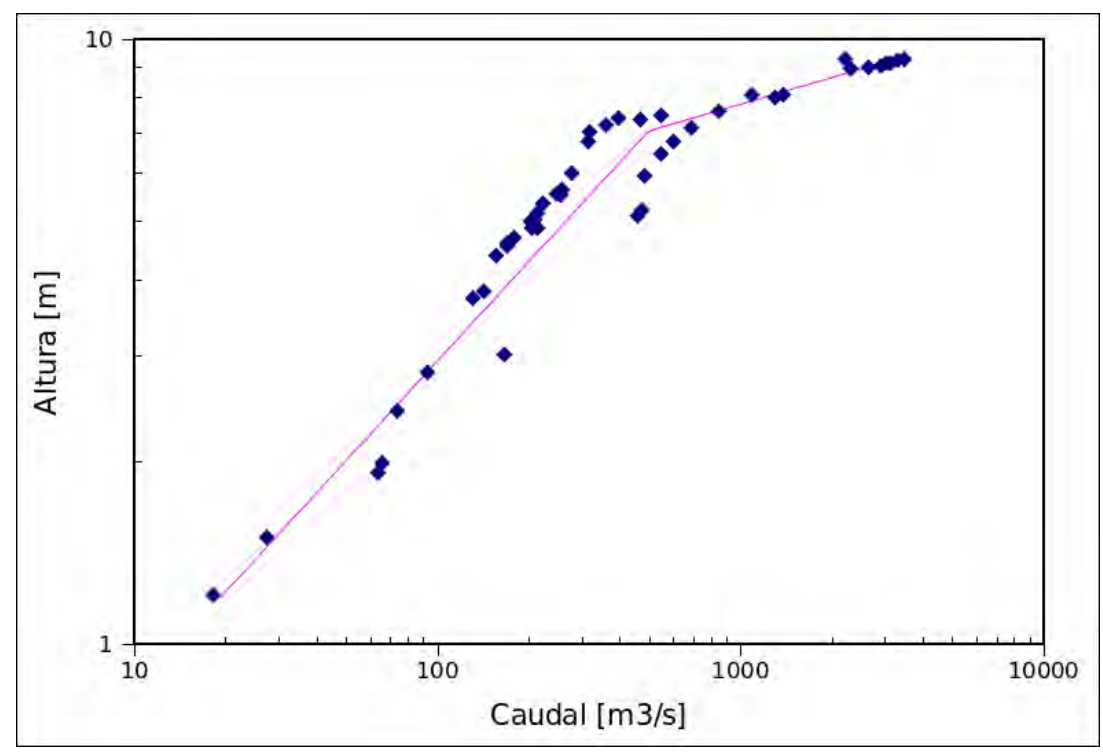

Figura 11: Puntos: pares altura-caudal. Línea: curva de gasto

\subsubsection{Humedad del suelo}

Como dato de humedad del suelo se utilizaron estimaciones producidas a partir de sensores remotos pasivos de microondas. Estos sensores miden la radiancia de la superficie terrestre en un determinado segmento de la banda de espectro electromagnético conocido como las microondas (con longitudes de onda aproximadamente entre un metro y un milímetro), la cual es función de la emisividad y la temperatura de la superficie observada. A su vez, la emisividad varía en función de los cambios en las propiedades dieléctricas del suelo que resultan de los cambios en el contenido de agua (Goniadzki et al., 2011). Sin embargo, la emisividad total resulta de muchas contribuciones, de las cuales las más importantes provienen de la cobertura vegetal y la rugosidad del terreno. Por lo tanto, los algoritmos de recuperación de la humedad del suelo mediante sensores remotos utilizan variables auxiliares que den cuenta de la rugosidad del suelo, la temperatura real y la cobertura vegetal. Dichas variables auxiliares se pueden derivar de mediciones remotas de los mismos $u$ otros instrumentos, o pueden ser capas estáticas derivadas de otras fuentes. Las diversas fuentes de variabilidad de la señal observada, sumado a la relativa novedad de esta tecnología y a la dificultad de calibrar y validar estas estimaciones a escala global hace que los productos posean un elevado grado de incertidumbre.

Diversos sensores remotos pasivos de microondas han operado, operan actualmente o se proyectan para el futuro próximo. Éstos difieren en su frecuencia radiométrica de operación y en su resolución espacial y temporal. La frecuencia radiométrica determina la profundidad del perfil del suelo de la cual el sensor recibe la señal de temperatura de brillo, siendo preferibles las frecuencias bajas (altas longitudes de onda) con las cuales la profundidad sondeada es mayor y la influencia de la vegetación es menor. La resolución espacial incide en la precisión del dato cuando las unidades espaciales que se desea observar son de similar o inferior tamaño que la unidad espacial mínima de la observación. La resolución temporal incide en la frecuencia de las observaciones, lo cual condiciona el impacto potencial de la simulación en modo actualizado. En el presente trabajo se utilizaron tres estimaciones de humedad del suelo provenientes de distintos sensores remotos, todos de nivel 3 (alto nivel de procesamiento, 
productos de grilla de valores interpolados), las cuales se describen a continuación.

Tabla 3: Características de los productos de humedad del suelo utilizados

\begin{tabular}{|c|c|c|c|}
\hline Sensor & MIRAS & AQUARIUS & AMSR2 \\
\hline Plataforma & SMOS (ESA) & SAC-D (CONAE/NASA) & GCOM-W1 (JAXA) \\
\hline Revisita promedio & 0,87 días & 2,32 días & 0,65 días \\
\hline Resolución espacial & $1 / 4^{\circ}$ & $1^{\circ}$ & $1 / 4^{\circ}$ \\
\hline Cobertura espacial & global & global & global \\
\hline Cobertura temporal & desde 2010-01-15 & desde 2011-08-27 & desde 2012-07-03 \\
\hline Producto SM utilizado & Nivel 3 & Nivel 3 & Nivel 3 \\
\hline Bandas $^{2}$ & $1,4 \mathrm{GHz}$ & $1,414 \mathrm{GHz}$ & 6,9 y $10,65 \mathrm{GHz}$ \\
\hline Error (meta/máx.) & $3 \% / 10 \%$ & $3 \% / 5 \%$ & $5 \% / 10 \%$ \\
\hline
\end{tabular}

SMOS Se utilizó el producto $\mathrm{P} 11 \mathrm{P}$ del radiómetro interferométrico de microondas MIRAS Microwave Imaging Radiometer with Aperture Synthesis) de la misión SMOS (Soil Moisture and Ocean Salinity satellite, ESA) , el cual opera a $1,4 \mathrm{GHz}$ (banda $\mathrm{L}$ ) a bordo de la plataforma SMOS de órbita heliosincrónica cuasipolar. Con la información capturada diariamente se producen dos mapas globales correspondientes a las pasadas ascendente (matutina) y descendente (vespertina). El producto posee una resolución espacial de $\sim 25 \mathrm{~km}$ y un periodo de revisita máximo de 3 días y promedio de 0,87 para la cuenca del presente estudio. El valor de humedad del suelo se expresa en contenido volumétrico de agua sobre el volumen total de suelo $\left[\mathrm{m}^{3} / \mathrm{m}^{3}\right]$, y se considera representativo de un espesor de suelo comprendido entre los $0,2-5,0 \mathrm{~cm}$ de profundidad (Manfreda et al., 2013). Cada valor viene acompañado de un índice de calidad del dato, expresado en las mismas unidades. El producto se publica en un repositorio FTP de libre acceso (SM-ESL team, 2012) con un retraso aproximado de 10 días.

Aquarius Se utilizó el producto de humedad del suelo global diario grillado de nivel 3 del radiómetro de microondas pasivo Aquarius de NASA a bordo del Satélite Aplicaciones Científicas (SAC-D, de la Comisión Nacional de Actividades Espaciales, CONAE) de órbita heliosincrónica cuasipolar. Su resolución espacial es de 1 grado geográfico y la revisita promedio para esta cuenca es de 2,32 días. La serie comienza en septiembre de 2011, el dato se ofrece en unidades volumétricas $\left[\mathrm{m}^{3} / \mathrm{m}^{3}\right]$ y se encuentra disponble a través de un portal FTP de libre acceso (Bindlish y Jackson, 2013). El instrumento Aquarius incluye tres radiómetros y un escaterómetro. Los radiómetros miden la temperatura de brillo a $1,414 \mathrm{GHz}$ en las polarizaciones horizontal y vertical (TH y TV). El escaterómetro es un radar de microondas que mide la retrodispersión y se lo utiliza en este caso para realizar correcciones debido a la rugosidad del terreno. El algoritmo de Aquarius utiliza observaciones de temperatura de brillo en banda $L(1,414 \mathrm{MHz})$ en polarización horizontal debido a la mayor sensitividad de este canal a la humedad del suelo. El enfoque se basa un modelo de transferencia radiativa simplificado desarrollado bajo el supuesto de que la vegetación y el suelo tienen la misma temperatura (Jackson, 1993). El dato resultante, en unidades volumétricas, se considera representativo de un espesor entre $0,2-5,0 \mathrm{~cm}$ de suelo. Se utilizó la versión 3.0 del producto. 
AMSR2 Se utilizó el producto L3 del instrumento AMSR2 (Advanced Microwave Scanning Radiometer 2) a bordo de la plataforma GCOM-W1 (Global Change Observation MissionWater 1) de JAXA (Japan Aerospace Exploration Agency) (Njoku, 2007). El instrumento es un radiómetro de microondas pasivo de 12 canales en 6 frecuencias entre 6,9 y $89,0 \mathrm{GHz}$, réplica del instrumento AMSRE, el cual operó de 2002 a 2011 a bordo de la platafoma Aqua. La radiación polarizada horizontal y verticalmente se mide por separado para cada frecuencia. La revisita de la plataforma permite un máximo de dos capturas diarias (una ascendente, próxima al mediodía del lugar, y una descendente, próxima a la medianoche) para un mismo sitio, dando una revisita promedio de 0,65 días para esta cuenca. El producto utilizado se basa en información de temperatura de brillo a $10,7 \mathrm{GHz}$ (banda $\mathrm{X}$ ) con una resolución espacial media de $38 \mathrm{~km}$. El producto de grilla global de $0,25 \times 0,25$ grados geográficos para el periodo iniciado en agosto de 2012 se publica a tiempo cuasi-real y es accesible libremente a través de un portal HTTP. El dato representa el contenido gravimétrico de agua (peso de agua/volumen total) en el horizonte superficial del suelo $(\sim 1 \mathrm{~cm})$.

En la Tabla 3 se presentan las características básicas de los productos de humedad del suelo mencionados precedentemente.

Los valores de humedad del suelo media areal para la cuenca estudiada en los tres casos se obtuvieron mediante la media aritmética de los valores de los píxeles contenidos parcial o totalmente en el área de la cuenca. Para cada producto, como estimación del error se consideró el error de observación informado por el respectivo proveedor.

\subsubsection{Pronóstico cuantitativo de precipitación}

En una sesión de pronóstico hidrológico, los registros de las forzantes observadas se utilizan para alimentar el modelo hasta un cierto paso de tiempo, a partir del cual comienza el horizonte de pronóstico, para el cual es necesario alimentar el modelo con predicciones. Para ello actualmente se utilizan modelos meteorológicos distribuidos tanto globales como locales, los cuales usualmente actualizan sus condiciones iniciales a partir de observaciones de sensores remotos. Debido a la enorme complejidad de los fenómenos meteorológicos, la eficiencia de los modelos disminuye notablemente conforme nos alejamos del instante inicial. A su vez, debe entenderse que la precisión del pronóstico aumenta conforme agregamos tanto espacial como temporalmente el dato, es decir que el error de pronóstico de un intervalo de 3 hs para una cuenca pequeña es mayor que el de un intervalo de 24 hs para una cuenca grande.

En este estudio se utilizó el pronóstico cuantitativo de precipitación del modelo meteorológico ETA adaptado para el extremo sur de Sudamérica por el grupo de Modelado Numérico del Departamento de Procesos Automatizados del Servicio Meteorológico Nacional. El mismo posee 38 niveles en la vertical y $25 \mathrm{~km}$ de resolución espacial, y pronostica temperatura, humedad específica, viento horizontal, presión de superficie, energía cinética turbulenta, agua y hielo de nube, con un paso fundamental de integración de 90 segundos. A partir del exceso de humedad en cada celda se pronostica la precipitación tanto en gran escala como convectiva, cada 3 horas discriminada en varias categorías (nieve, hielo, lluvia gelante y lluvia). Se realizan dos corridas diarias: a las 00 y 12 hora local, las cuales extienden un pronóstico de hasta 132 hs (5 días y medio) (Suaya, 2004). El mismo se obtiene a tiempo cuasi-real a través de una 
plataforma FTP de acceso restringido ${ }^{3}$.

Luego de agregar temporal y espacialmente los valores de una corrida ETA SMN dada, se obtiene la forzante de precipitación para un horizonte de pronóstico de 5 días. Debe entenderse que los valores pronosticados a partir de una corrida ETA SMN para una fecha dada difieren de los valores pronosticados por la corrida subsiguiente (o precedente), ya que el modelo modifica sus condiciones iniciales en base a observaciones de sensores remotos, observaciones in-situ y corridas previas, por lo que siempre debe utilizarse el vector de valores correspondiente a la corrida más reciente. En la figura 12 se muestra un ejemplo de producto ETA SMN agregado a paso diario.

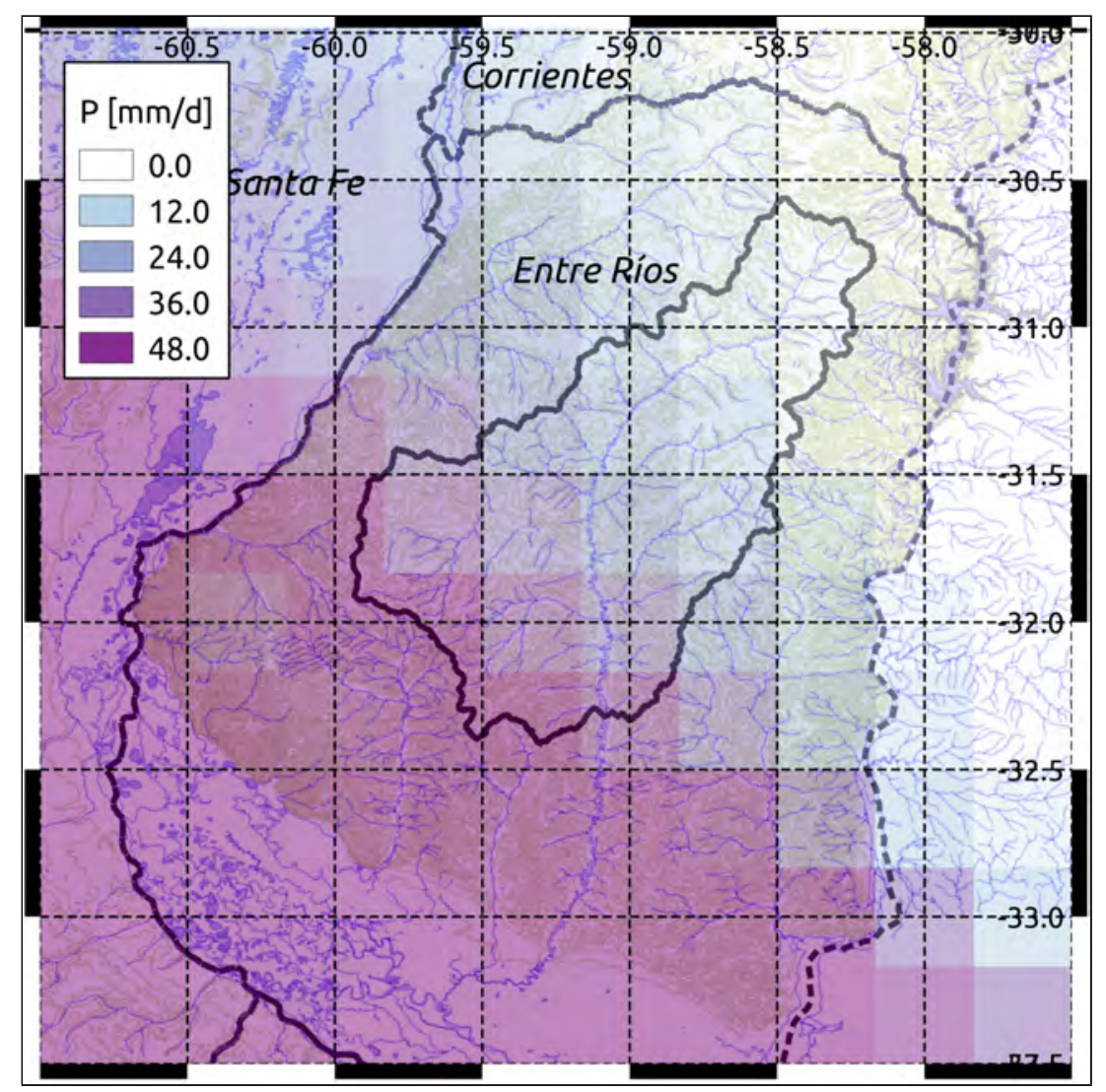

Figura 12: Ejemplo de pronóstico cuantitativo de precipitación ETA SMN [mm/día], agregado a paso diario. Capas base: (IGN, 2019)

\subsection{Base de datos hidrometeorológicos}

Se elaboró una base de datos bajo el sistema POSTGRESQL (Wikipedia, 2007) para almacenar de manera ordenada las variables necesarias para la corrida de los modelos hidrológicos. Adicionalmente se elaboraron rutinas de programación para mantenerla actualizada. Finalmente se elaboraron rutinas de extracción y procesamiento de los datos para elaborar los vectores de datos de entrada para los distintos modelos hidrológicos de pronóstico. Todas las rutinas se elaboraron en base a software libre de código abierto.

La base de datos consiste en dos tipos de tabla:

- tablas de objetos espaciales (estaciones meteorológicas y limnimétricas), y

\footnotetext{
${ }^{3} \mathrm{El}$ acceso a los datos se obtuvo mediante un convenio interinstitucional INA - SMN
} 
- tablas de observaciones (registros).

Cada registro debe estar referenciado a un objeto existente en la tabla de objetos espaciales correspondiente, y no puede haber dos registros de la misma variable con la misma fecha y hora referidos al mismo objeto espacial. Los registros areales (precipitación media areal, humedad del suelo media areal, evapotranspiración potencial media areal), fueron referidos a la estación limnimétrica que marca el cierre de la cuenca vertiente correspondiente. En la Tabla 4 se ilustra la estructura de la base de datos: cada tabla de la columna 'registros' refiere a la tabla de objetos espaciales ubicada a su izquierda. Esta estructura ha permitido trabajar simultáneamente con diversos modelos en diversas cuencas o secciones de interés, y con distintas fuentes de datos de entrada.

Tabla 4: Estructura de la base de datos hidrometeorológica

\begin{tabular}{|c|c|c|c|}
\hline \multicolumn{2}{|c|}{ Objetos espaciales } & \multicolumn{2}{|c|}{ Registros } \\
\hline tablas & campos & tablas & campos \\
\hline $\begin{array}{l}\text { estaciones meteorológ- } \\
\text { icas }\end{array}$ & coordenadas & valores diarios & $\begin{array}{l}\text { estación } \\
\text { tasa de precipitación } \\
\text { fecha } \\
\text { otras variables meteo- } \\
\text { rológicas }\end{array}$ \\
\hline \multirow{6}{*}{$\begin{array}{l}\text { estaciones limnimétric- } \\
\text { as }\end{array}$} & \multirow{6}{*}{ coordenadas } & $\begin{array}{l}\text { lecturas de es- } \\
\text { cala }\end{array}$ & $\begin{array}{l}\text { estación } \\
\text { altura } \\
\text { caudal (según curva } \\
\text { de gasto) } \\
\text { fecha y hora }\end{array}$ \\
\hline & & aforos & $\begin{array}{l}\text { estación } \\
\text { altura } \\
\text { caudal } \\
\text { fecha y hora }\end{array}$ \\
\hline & & PMAD $^{1}$ campo & $\begin{array}{l}\text { estación } \\
\text { tasa de precipitación } \\
\text { fecha }\end{array}$ \\
\hline & & $\mathrm{PMAD}^{1}$ satelital & $\begin{array}{l}\text { estación } \\
\text { tasa de precipitación } \\
\text { fecha }\end{array}$ \\
\hline & & $\mathrm{PMAD}^{1} \mathrm{QPF}^{3}$ & $\begin{array}{l}\text { estación } \\
\text { tasa de precipitación } \\
\text { fecha }\end{array}$ \\
\hline & & ETPD ${ }^{2}$ climática & $\begin{array}{l}\text { estación } \\
\text { tasa de } \\
\text { evapotranspiración } \\
\text { día del año }\end{array}$ \\
\hline
\end{tabular}

\footnotetext{
${ }^{1}$ Precipitación media areal diaria

${ }^{2}$ Evapotranspiración potencial diaria

${ }^{3}$ Pronóstico cuantitativo de precipitación
} 


\subsection{Modelación hidrológica continua}

En el presente trabajo se utilizaron modelos conceptuales agregados, los cuales se describen a continuación.

Sacramento Simplificado Este modelo presenta dos componentes con una formulación diferencial para modelar la secuencia de procesos de precipitación-escorrentía y traslación del hidrograma (Georgakakos y Baumer, 1996). El primer componente simula el balance de humedad en una columna de suelo resultante de los flujos a través de la interfaz sueloatmósfera. La columna se divide en dos capas, una superior de respuesta más rápida y una inferior de respuesta más lenta. La precipitación constituye el aporte de humedad a este componente, mientras que las pérdidas son debidas a la evapotranspiración, el escurrimiento superficial y subterráneo y la recarga del acuífero.

El segundo componente simula el proceso de traslación del hidrograma a lo largo de la red de drenaje por medio de una cascada de dos embalses lineales conceptuales iguales a la salida de la cuenca. La entrada a la cascada es la salida del primer componente (el volumen generado por el modelo de precipitación-escorrentía). El hidrograma de salida de la cascada es la salida final del modelo.

Las ecuaciones que gobiernan los procesos, siguiendo la nomenclatura de Guetter (Guetter, 2000), son las siguientes (2 a 5):

$$
\begin{gathered}
\frac{d X_{1}}{d t}=P-S R-P C-E T_{1}-I N T \\
\frac{d X_{2}}{d t}=P C-E T_{2}-G W \\
\frac{d X_{3}}{d t}=(S R+B F)-\alpha X_{3} \\
\frac{d X_{4}}{d t}=\alpha X_{3}-\alpha X_{4}
\end{gathered}
$$

donde:

$X_{1} / X_{2}$ : Volumen de agua en la capa superior/inferior del suelo $[L]$ (variables de estado),

$X_{3}$ y $X_{4}$ : Almacenamientos en los reservorios lineales $[L]$ (variables de estado),

$P$ : Intensidad de la precipitación $[L / T]$,

$S R$ : Escurrimiento superficial $[L / T]$,

$P C$ : Tasa de percolación $[L / T]$,

$E T_{1} / E T_{2}$ : Tasa de evapotranspiración de la capa superior/inferior del suelo $[L / T]$,

$I N T$ : Aporte al flujo base desde la capa superior del suelo $[L / T]$,

$G W$ : Aporte al flujo base y recarga del acuífero desde la capa inferior del suelo $[L / T]$,

$\alpha$ : Inversa de la costante de recesión de los embalses lineales $[1 / T]$, y

$B F$ : Flujo base $[L / T]$

El escurrimiento superficial es una respuesta directa de la precipitación, producida solamente por la capa superior. Se calcula según la ecuación 6:

$$
S R=P \cdot\left(\frac{X_{1}}{X_{1}^{0}}\right)^{m_{1}}
$$

donde: 
$X_{1}^{0}$ : Capacidad de la capa superior del suelo $[L]$,

$m_{1}$ : Exponente del escurrimiento superficial [adimensional].

La evapotranspiración de la capa superior se calcula como el producto de la evapotranspiración potencial y la disponibilidad de agua, según la ecuación 7:

$$
E T_{1}=E T P \cdot\left(\frac{X_{1}}{X_{1}^{0}}\right)
$$

donde:

ETP: Evapotranspiración potencial para ese paso. La percolación, como la transferencia de agua de la capa superior a la capa inferior, se calcula como una función no lineal de los almacenamientos en ambas capas, según la ecuación 8:

$$
P C=C_{3} \cdot X_{2}^{0} \cdot\left(1+C_{2} \cdot\left(1-\frac{X_{2}}{X_{2}^{0}}\right)^{m_{2}}\right) \cdot\left(\frac{X_{1}}{X_{1}^{0}}\right)
$$

donde:

$X_{2}^{0}$ : Capacidad de la capa inferior del suelo $[L]$,

$C_{3}$ : Tasa de recesión del flujo base $[1 / T]$,

$\mathrm{C}_{2}$ : Coeficiente de la función de percolación [adimensional],

$m_{2}$ : Exponente de la función de percolación [adimensional].

El aporte de la capa superior al flujo base se considera propocional a la primera variable de estado según la ecuación 9:

$$
I N T=C_{1} X_{1}
$$

donde $C_{1}$ es el coeficiente de recesión [1/T]

La transpiración desde la capa inferior del suelo se calcula según la ecuación 10:

$$
E T_{2}=\left(E T P-E T_{1}\right) \cdot\left(\frac{X_{2}}{X_{2}^{0}}\right)^{m_{3}}
$$

donde $m_{3}$ es el exponente de la función de transpiración [adimensional].

$G W$ se calcula según la ecuación 11:

$$
G W=C_{3} \cdot X_{2}
$$

El flujo base se calcula según la ecuación 12:

$$
B F=(1+\mu)^{-1} \cdot G W+I N T
$$

Donde:

$\mu$ [adimensional] es un parámetro del modelo tal que $G W /(1+\mu)$ contribuye al flujo base mientras que $G W \cdot \mu /(1+\mu)$ es la recarga al acuífero.

Finalmente, el caudal de salida de la cuenca se calcula como una función lineal del almacenamiento en el segundo embalse de la cascada, según la ecuación 13:

$$
Q_{4}=\alpha X_{4}
$$

En la figura 13 se presentan en forma esquemática las relaciones funcionales que componen 
el modelo.

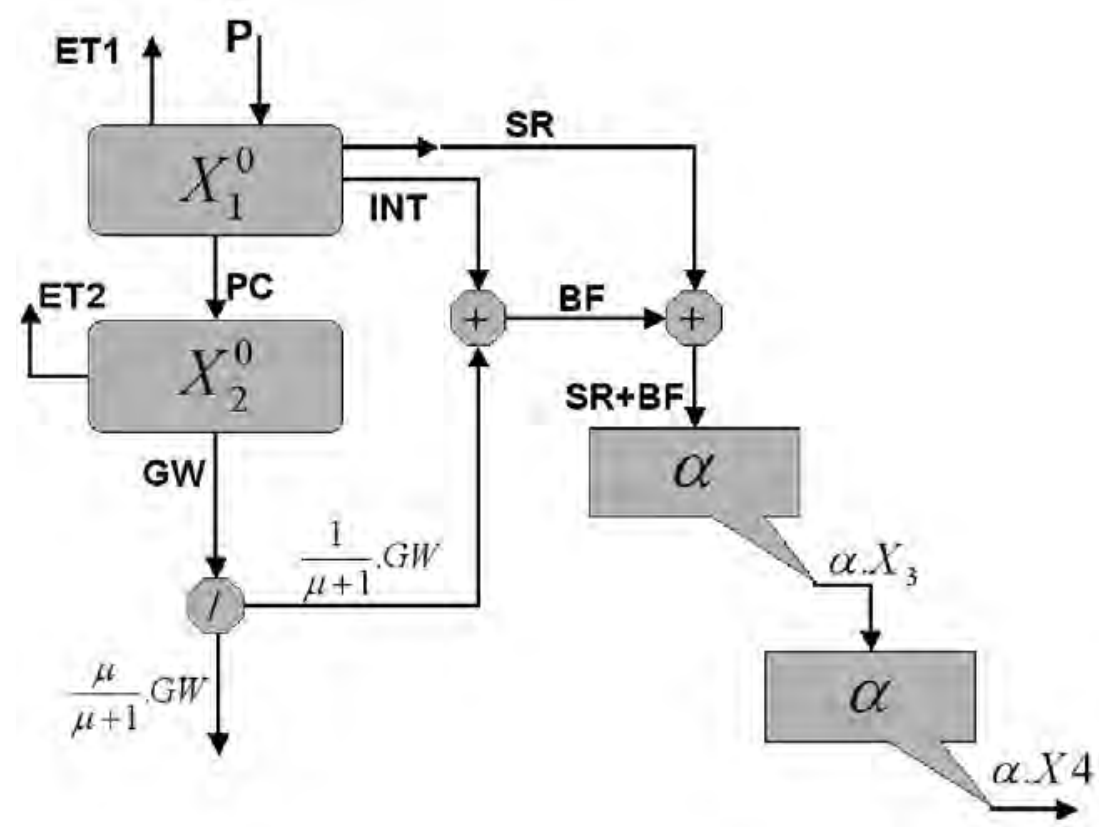

Figura 13: Representación esquemática del modelo Sacramento (Uriburu Quirno, 2011)

El sistema de ecuaciones diferenciales se resolvió numéricamente mediante Runge-Kutta de orden 4 (Wikipedia, 2014e). Sabiendo que

$$
\frac{\mathrm{d}[X]}{\mathrm{d} t}=f\left(t,[X]_{0}\right) \quad \mathrm{y} \quad[X]\left(t_{0}\right)=[X]_{0}
$$

donde $[X]$ es el vector de estados del modelo, $t$ es el tiempo, $[X]_{0}$ es el vector de estados inicial (conocido) y $t_{0}$ el tiempo inicial, planteamos

$$
\begin{aligned}
{[X]_{n+1} } & =[X]_{n}+h / 6\left(k_{1}+2 k_{2}+2 k_{3}+k_{4}\right) \\
t_{n+1} & =t_{n}+h
\end{aligned}
$$

donde $n=0,1,2,3 \ldots, h$ es el paso de tiempo y

$$
\begin{aligned}
& k_{1}=f\left(t_{n},[X]_{n}\right), \\
& k_{2}=f\left(t_{n}+h / 2,[X]_{n}+h / 2 k_{1}\right), \\
& k_{3}=f\left(t_{n}+h / 2,[X]_{n}+h / 2 k_{2}\right), \\
& k_{4}=f\left(t_{n}+h,[X]_{n}+h k_{3}\right) .
\end{aligned}
$$

GRP modificado (GR4P) El modelo GRP (Tangara, 2005) (Génie Rural pour la Prévision de crues) es un modelo lluvia-escorrentía global simple de 4 parámetros derivado del modelo GR4J. Su funcionamiento se comprende como un encadenamiento de una función 
de producción y una de propagación y atenuación (Berthet, 2010). La modificación realizada al GR4J consiste en el reemplazo del embalse cuadrático a la salida de la componente de propagación por una cadena de embalses lineales, de manera de linealizar la relación entre las variables de estado del modelo y los caudales, haciendo posible la asimilación de estos últimos mediante filtrado de Kalman.

La función de producción sirve para calcular la precipitación efectiva, y se trata de un módulo de cálculo de la humedad de la cuenca (enfoque conocido como SMA, Soil Moisture Accounting). En la componente de producción, la precipitación neta $P_{t}^{n}\left(P_{t}^{n}=P_{t}-E T P_{t}\right.$ si $P_{t}>=E T P_{t}$, en otro caso $\left.P_{t}^{n}=0\right)$ donde $t$ es el índice de tiempo, se divide en infiltración $P_{t}^{s}$ y escorrentía directa $P_{t}^{n}-P_{t}^{s}$ según la ecuación 18.

$$
P_{t}^{s}=a\left(1-\left(S_{t-1} / a\right)^{2}\right) \frac{\tanh \left(P_{t}^{n} / a\right)}{1+\left(S_{t-1} / a\right) \tanh \left(P_{t}^{n} / a\right)},
$$

donde $a$ es la capacidad de almacenaje en el suelo (parámetro libre) y $S$ la lámina de agua almacenada en el suelo (variable de estado). La evapotranspiración $E_{t}^{s}$ se calcula según la ecuación 19

$$
E_{t}^{s}=S_{t-1}\left(2-S_{t-1} / a\right) \frac{\tanh \left(\left(E T P_{t}-P_{t}\right) / a\right)}{1+\left(1-S_{t-1} / a\right) \tanh \left(\left(E T P_{t}-P_{t}\right) / a\right)}
$$

Al estado del suelo resultante, calculado según la ecuación 20:

$$
S_{t}^{+}=S_{t-1}+P_{t}^{s}-E_{t}^{s}
$$

se le aplica la ecuación de percolación 21:

$$
\operatorname{Perc}_{t}=S_{t}^{+}\left(1-\left(1+\left(\frac{4}{9} \frac{S_{t}^{+}}{a}\right)^{4}\right)^{-1 / 4}\right)
$$

El almacenamiento en el suelo final se calcula según la ecuación $22:$

$$
S_{t}=S_{t}^{+}-\operatorname{Perc}_{t}
$$

La escorrentía directa se conduce junto con la percolación hacia la componente de propagación luego de aplicarse un factor de ajuste multiplicativo $m$ (parámetro libre) según la ecuación 23:

$$
P R T_{t}=m\left(\operatorname{Perc}_{t}+P_{t}^{n}-P_{t}^{s}\right)
$$

En la componente de propagación, la precipitación efectiva $P R T_{t}$ se convoluciona a través de un hidrograma unitario cuyas ordenadas $\lambda_{k}$ se calculan según la ecuación 24:

$$
\lambda_{k}=H U A(k)-H U A(k-1)
$$


donde $H U A$ es la función del hidrograma unitario acumulado definida en la ecuación 25:

$$
\begin{array}{rc}
H U A(k)=0 & \text { si } k<=0 \\
k^{5 / 2} & \text { si } 0<k<=t^{h u} \\
H U A(k)=1 & \text { si } k>t^{h u}
\end{array}
$$

donde $t^{h u}$ es el tiempo base del hidrograma unitario (parámetro libre). Luego la salida del hidrograma unitario se calcula según la ecuación 26 :

$$
Q_{t}^{h u}=\sum_{k=0}^{t^{h u+1}} \lambda_{k} P R T_{t-k}
$$

Este caudal alimenta una cadena de dos embalses lineales iguales en serie ( $R 1$ y $R 2)$ con coeficiente de recesión $r$ (parámetro libre), según las ecuaciones 27:

$$
\begin{aligned}
R 1_{t}^{+} & =R 1_{t-1}+Q^{h u}, \\
Q 1_{t} & =R 1_{t}^{+} r, \\
R 2_{t}^{+} & =R 2_{t-1}+Q 1_{t}, \\
\hat{Q} & =R 2_{t}^{+} r, \\
R 1_{t} & =R 1_{t}^{+}-Q 1_{t}, \\
R 2_{t} & =R 2_{t}^{+}-\hat{Q}
\end{aligned}
$$

Véase un esquema del modelo en la Figura 14. 


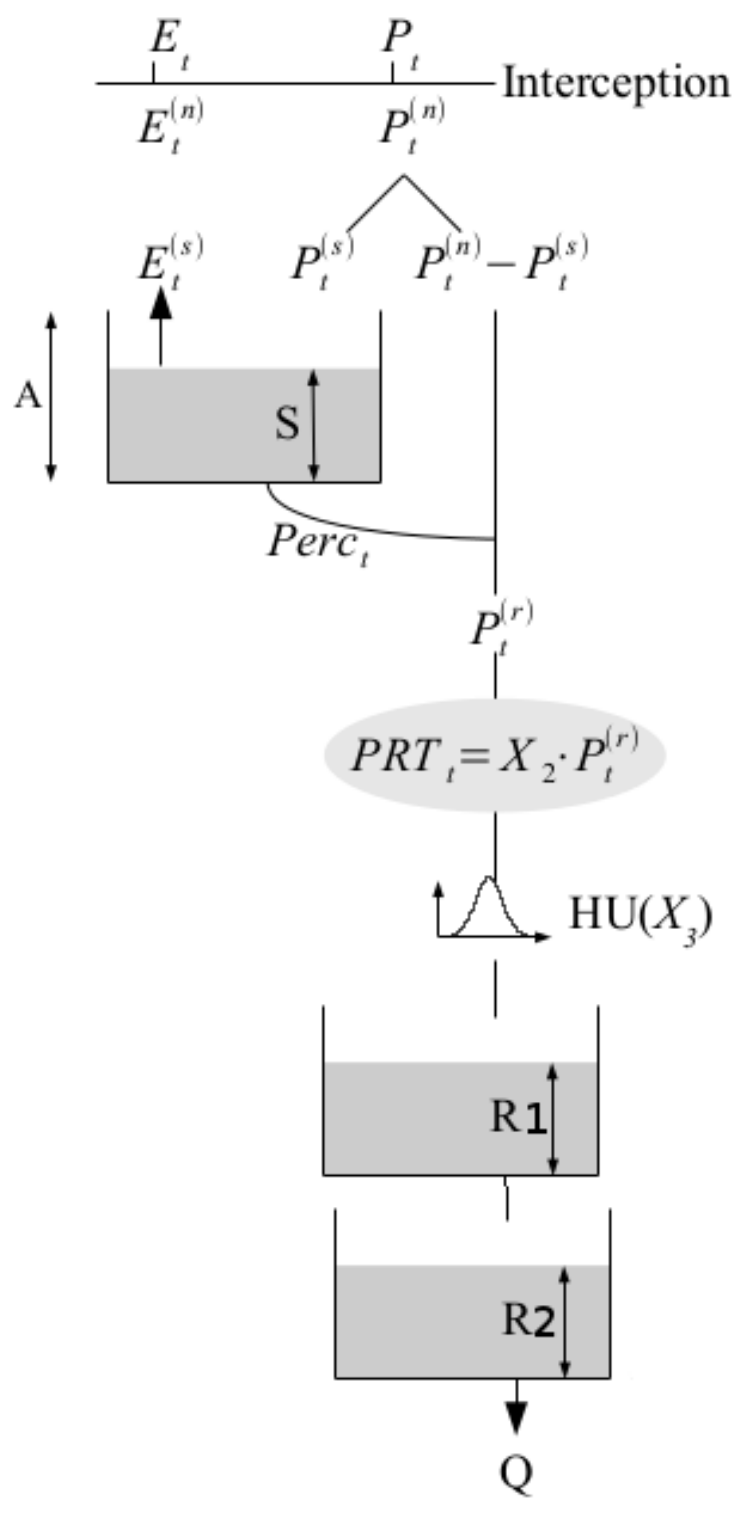

Figura 14: Representación esquemática del modelo GR4P. Modificado de Tangara (2005)

\subsection{Calibración de los modelos y verificación}

Previo a la fase operativa, los modelos deben ser calibrados y verificados contra los valores observados en la cuenca de estudio. La calibración significa buscar el conjunto de parámetros del modelo de modo que los valores predichos coincidan lo mejor posible con los observados. El grado de ajuste del modelo generalmente se evalúa mediante una función objetivo tal como un error cuadrático ponderado, la cual se busca minimizar mediante alguna técnica de optimización. Opcionalmente, algunos parámetros del modelo, en lugar de someterse a calibración, pueden estimarse empíricamente a partir de información auxiliar.

La calibración se realizó en forma automática mediante el método Downhill Simplex de optimización numérica elaborado por Nelder y Mead, según se lo explica en Mathews y Fink (2004). Como función objetivo se utilizó el error cuadrático ponderado por el valor de caudal observado, de modo tal de dar mayor importancia al ajuste de valores altos de caudal (ecuación 
Figura 15: Rango de valores iniciales de los parámetros. Izq.: Sacramento, der.: GR4P

\begin{tabular}{|c|c|c|c|c|c|}
\hline par. & mín. & máx. & & & \\
\hline$x_{0}^{1}$ & 30 & 300 & & & \\
\hline$x_{0}^{2}$ & 30 & 600 & & & \\
\hline$m_{1}$ & 1 & 3 & par. & mín. & máx. \\
\hline$c_{1}$ & 0,01 & 0,03 & $X_{0}$ & 5 & 200 \\
\hline$c_{2}$ & 150 & 500 & $X_{1}$ & 0,001 & 0,99 \\
\hline$c_{3}$ & 0,00044 & 0,002 & $X_{2}$ & 0 & 1 \\
\hline$\mu$ & 0,4 & 6 & $X_{3}$ & 1,1 & 10 \\
\hline$\alpha$ & 0,1 & 0,6 & & & \\
\hline$m_{2}$ & 0,5 & 2,2 & & & \\
\hline$m_{3}$ & 1 & 5 & & & \\
\hline
\end{tabular}

28).

$$
F_{o b j}=\sum_{i=1}^{N} W T_{i}\left(Q_{o b s, i}-Q_{p r e d, i}\right)^{2}
$$

El peso se calculó de la siguiente manera (Borús et al., 2004):

$$
W T_{i}=\frac{\left[Q_{o b s, i}+4 \bar{Q}\right]}{5 \bar{Q}}
$$

Donde:

$W T_{i}$ es el factor de ponderación,

$\bar{Q}$ es el caudal medio observado en el periodo de calibración.

A través del algoritmo de optimización se procura encontrar un conjunto de parámetros que minimice la función objetivo. Partiendo de $N+1$ conjuntos iniciales de parámetros ( $N$ :cantidad de parámetros) formando un politopo de $N+1$ vértices (llamado simplex) en el espacio de parámetros $N$-dimensional, el algoritmo calcula $F_{o b j}$ para los mismos y luego, mediante operaciones geométricas (reflexión, expansión y contracción), explora la vecindad del espacio de parámetros para encontrar un nuevo punto de prueba y reemplazar uno de los viejos puntos por el nuevo si éste lo supera en $F_{o b j}$. La operación se repite en forma iterativa por una cantidad definida de pasos, en los cuales el simplex se va desplazando hasta encontrar un valle de la superficie de respuesta, donde se contrae hasta localizar un punto mínimo de $F_{o b j}$.

Haciendo pruebas preliminares se observó que alrededor de las 100 iteraciones en la mayoría de los casos se encontraba un valle. Por lo tanto se fijó un máximo de 150 iteraciones. Además, debido a que la superficie de respuesta no se conoce a priori y puede ser muy compleja, presentando más de un valle en distintas regiones del espacio de parámetros, es recomendable repetir el algoritmo con distintos simplex iniciales. Por lo tanto se repitió el algoritmo 50 veces partiendo de simplex generados aleatoriamente dentro de los rangos definidos en la Figura 15. Se descartaron los conjuntos de parámetros con valores fuera un rango aceptable y se escogió el de menor $F_{o b j}$. Toda la operación se repitió para los 4 modelos (sac+CAMPO, sac+3B42RT, gr4p+CAMPO, gr4p+3B42RT).

El grado de consistencia de un modelo generalmente se evalúa verificando el desempeño del modelo, sin cambiar los parámetros escogidos, en un conjunto de datos independiente 
diferente del utilizado para la calibración. Por lo tanto, generalmente se divide el periodo total de datos disponibles en dos tercios para la calibración y el tercio restante para la verificación. Para que el modelo se considere lo suficientemente preciso, el grado de ajuste para el periodo de verificación no debe ser significativamente menor que para el periodo de calibración.

Se seleccionó un conjunto de índices de eficiencia para evaluar los modelos aplicados. Los mismos se detallan en la Tabla 5.

Tabla 5: Índices de eficiencia

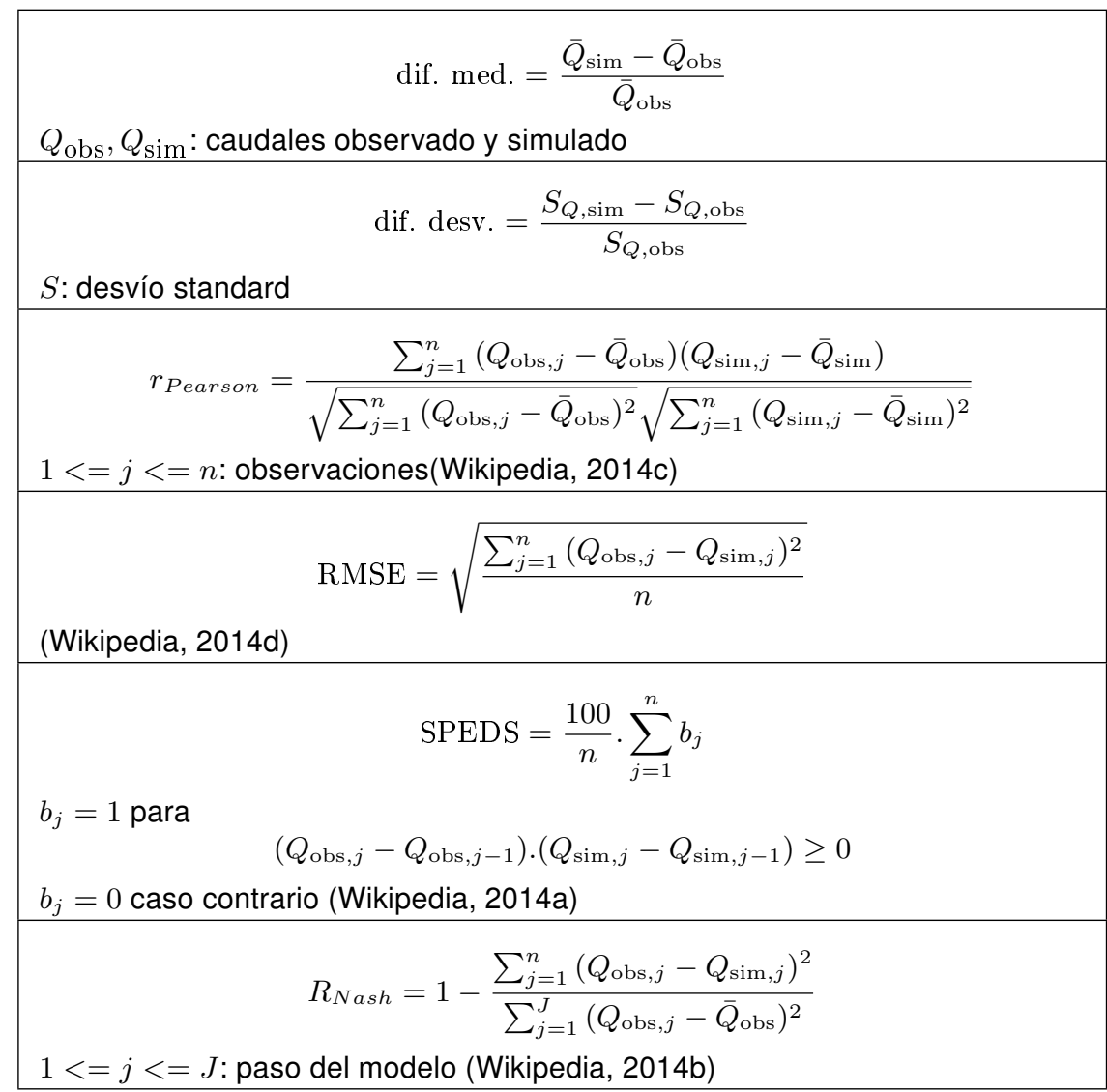

Se seleccionó para calibración y verificación de los modelos matemáticos el periodo de disponibilidad de los datos satelitales de precipitación TRMM 3b42RT, es decir de marzo de 2000 a diciembre de 2014. Los primeros dos de cada tres años consecutivos se utilizaron para calibración y el tercero se utilizó para verificación (véase la Tabla 6). Para los experimentos de asimilación de datos se utilizó el periodo de septiembre de 2012 a enero de 2015, en el cual se poseen registros de las tres fuentes de datos de humedad del suelo utilizadas.

Tabla 6: Periodo de calibración y verificación de los modelos hidrológicos

\begin{tabular}{|c|c|}
\hline Calibración & Verificación \\
\hline $2000-2001$ & 2002 \\
$2003-2004$ & 2005 \\
$2006-2007$ & 2008 \\
$2009-2010$ & 2011 \\
$2012-2013$ & 2014 \\
\hline
\end{tabular}




\subsection{Actualización de las variables de estado mediante asimilación de datos}

Ningún modelo ofrece una descripción totalmente satisfactoria de la naturaleza debido principalmente a tres factores:

- ningún modelo matemático es perfecto y sus parámetros no pueden determinarse de manera absoluta,

- existen forzantes desconocidas que no podemos controlar o modelar determinísticamente, $y$

- los sensores no proveen mediciones exactas, sino que introducen su propias distorsiones (Goniadzki et al., 2011).

Frecuentemente distintos dispositivos generan información acerca de la misma variable de estado del sistema, y uno debe entonces preguntarse cómo generar una mejor estimación de la variable de interés a partir de información parcialmente redundante (Goniadzki et al., 2011). La asimilación de datos es una técnica utilizada para extraer información valiosa contenida tanto en datos medidos como en los modelos existentes teniendo en consideración sus incertidumbres (Goniadzki et al., 2011). Ésta combina observaciones actuales (o pasadas) del estado del sistema con los resultados de un modelo matemático para producir un análisis, el cual se considera una mejor estimación del estado actual del sistema (Goniadzki et al., 2011).

Un procedimiento de actualización para la predicción de caudales busca reducir los errores entre la salida del modelo y los correspondientes valores posteriormente observados, para producir pronósticos mejorados a tiempo real (Uriburu Quirno, 2011). La corrección de los estados del sistema utilizando valores observados de descarga y humedad del suelo próximos al comienzo del horizonte de pronóstico se considera beneficioso, no necesariamente porque se espere que sean más precisos que los estados predichos por el modelo, sino porque la estructura del error de ambas fuentes de datos es diferente (Wagner et al., 2009). Por lo tanto, una combinación de ellos puede tener menos sesgo y menos error aleatorio que cualquiera de ellos individualmente (Parajka et al., 2009). Este procedimiento, denominado asimilación de datos, se basa en el supuesto de que una mejor simulación de los estados del sistema en el paso de tiempo $t$ también mejorará la precisión de los estados del modelo en los pasos de tiempo $t+1, t+2$,etc (Aubert et al., 2003).

De los diferentes mecanismos de actualización utilizados en pronóstico hidrológico, la metodología de actualización de los estados parece ser la mejor adaptada a sistemas no lineales (Aubert et al., 2003). Esta metodología consiste en corregir internamente el valor de las variables de estado del modelo cuando se dispone de una observación. Como se ve en la figura 16, cuando se dispone de una observación, el valor de la variable de estado correspondiente se corrige parcialmente obteniendo un valor a posteriori más cercano a la observación, el cual el modelo toma como nueva condición inicial a partir de la cual evoluciona libremente hasta encontrarse con nuevas observaciones. El cálculo del factor de corrección es un punto importante (Aubert et al., 2003). En este trabajo se utilizó la técnica de Filtro de Kalman en Ensamble, la cual toma en cuenta los errores estimados del modelo y de las observaciones para determinar dicho factor. 


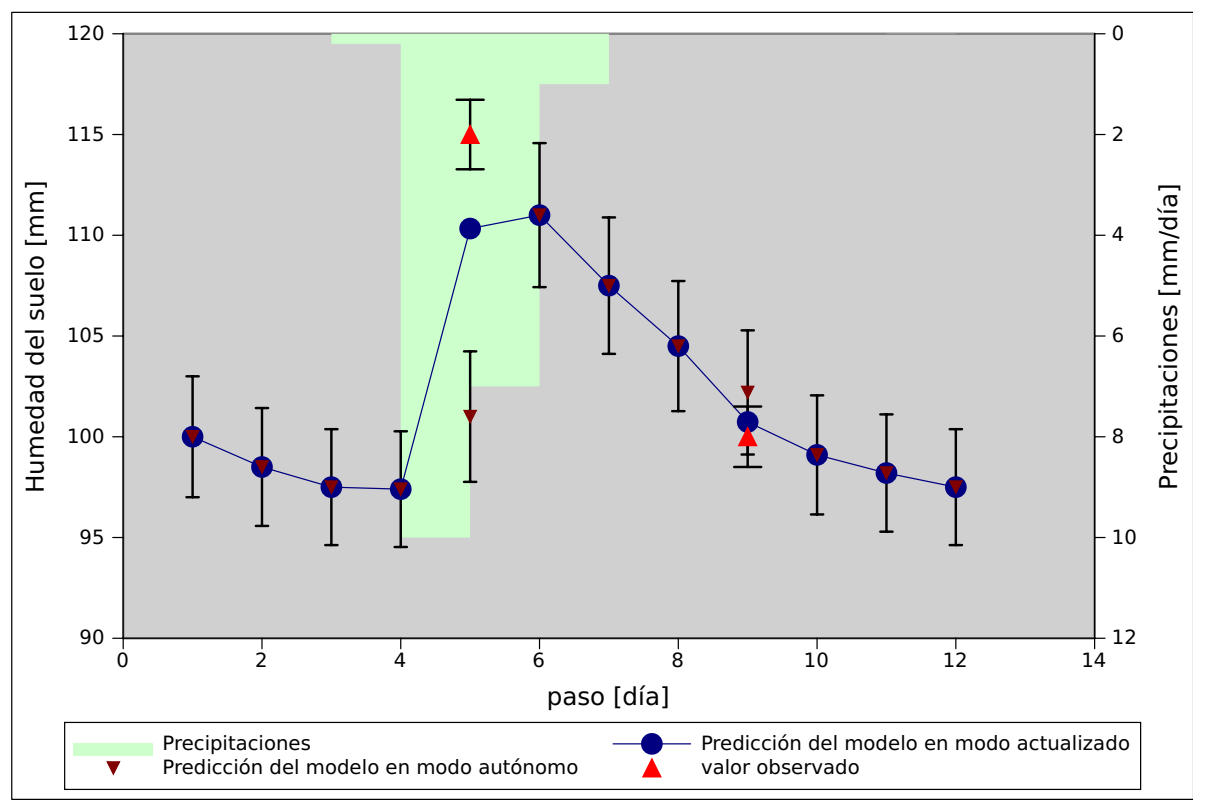

Figura 16: Diagrama esquemático de la asimilación de datos

\subsubsection{Filtro de Kalman en ensamble}

El filtro de Kalman es un conjunto de ecuaciones matemáticas que implementan un estimador de tipo predictor-corrector que minimiza la covarianza del error de la estimación cuando se cumplen ciertos supuestos (linealidad y distribuciones gaussianas) (Goniadzki et al., 2011).

El filtro de Kalman de ensamble es una implementación Monte-Carlo para sistemas más complejos. El estado del sistema se representa usando una colección de vectores de estado, llamada ensamble, cuya covarianza sirve como medida del error del modelo (Uriburu Quirno, 2011).

El modelo consta de dos fases: predicción y corrección. La predicción consiste en producir para cada réplica de Monte-Carlo $i$ (miembro del ensamble) un estimado de las variables de estado para el paso $j\left(S_{i, j}^{-}\right)$a partir de los valores de las variables de estado del paso anterior corregidos $\left(S_{i, j-1}^{+}\right)$y de las forzantes del modelo entre $j-1$ y $j\left(P_{j}, E T P_{j}\right)$. Estas últimas se perturban sumando un término aleatorio de distribución normal cuyas varianzas son los errores de medición o simulación de las mismas $\left(v_{i, j}^{P}, v_{i, j}^{E T P}\right)$. A su vez al resultado se le puede sumar otro término aleatorio en representación de la varianza propia del modelo $\left(v_{i, j}^{\text {mod }}\right)$. El resultado de la predicción se obtiene mediante la ecuación 30 :

$$
S_{i, j}^{-}=S_{i, j-1}^{+}+\Delta S_{i, j}\left(S_{i, j-1}^{+}, P_{j}+v_{i, j}^{P}, E T P_{j}+v_{i, j}^{E T P}\right)+v_{i, j}^{\text {mod }}
$$

donde los superíndices $-\mathrm{y}+$ indican respectivamente magnitudes sin corregir y corregidas. Al hacer avanzar al modelo en cada réplica con datos de entrada distintos, se espera que el ensamble presente una cierta dispersión. Las covarianzas de las variables de estado (matriz $C_{j}$ ) se utilizan como medida del error de la predicción. El factor de corrección (la ganancia del filtro de Kalman, $K G$ ) se calcula según la ecuación 31 :

$$
K G_{j}=\left[C_{j} \cdot H^{T}\right] \cdot\left[H \cdot C_{j} \cdot H^{T}+R\right]^{-1}
$$


donde $H$ es la matriz que transforma el espacio de los estados en el de las observaciones, $H^{T}$ es la matriz transpuesta de $H, R$ es la matriz de covarianza de los errores de las observaciones que se usarán para corregir, la cual tiene la siguiente forma 32 :

$$
R=\left(\begin{array}{cc}
R_{s m}^{0} & 0 \\
0 & R_{q}^{0}
\end{array}\right)
$$

donde $R_{s m}^{0}$ y $R_{q}^{0}$ son las varianzas de los errores de medición de humedad en el suelo y caudales respectivamente (se consideran independientes). La matriz $K G_{j}$ resultante, junto con los valores de humedad del suelo y caudal observados $\left(s m_{j}\right.$ y $\left.q_{j}\right)$, nos permiten corregir el estado del sistema mediante la ecuación 33:

$$
S_{i, j}^{+}=S_{i, j}^{-}+K G_{j} \cdot\left[\left(s m_{j}, q_{j}\right)+\left(v_{i, j}^{s m}, v_{i, j}^{q}\right)-H . S_{i, j}\right]
$$

donde $v_{i, j}^{s m}$ y $v_{i, j}^{q}$ son ruido gaussiano de media cero con varianzas $R_{s m}^{0}$ y $R_{q}^{0}$. Las predicciones finales del estado del sistema se obtienen promediando todas las réplicas del ensamble.

Como se indica en la ecuación 33, todos los elementos del vector de estados del modelo $S_{i, j}$ se corrigen cuando se dispone de observaciones (de humedad del suelo o caudal). Sin embargo, es posible limitar el impacto de la asimilación a un subconjunto de los estados del modelo. Esto puede resultar conveniente en algunos casos.

Se evaluó el impacto de la asimilación de datos de humedad del suelo satelital sobre la eficiencia en la simulación de caudales. A través del filtrado de Kalman en ensamble, se asimilaron los productos de humedad del suelo de los instrumentos SMOS, Aquarius y AMSR2 a los dos modelos hidrológicos de la cuenca del río Gualeguay precedentemente calibrados $^{4}$. Las características esenciales de los productos utilizados se muestran en la tabla 3, mientras que en los gráficos 17 y 18 y la Tabla 8 se comparan las series de humedad del suelo media areal de las tres fuentes. La asimilación de datos se utilizó para corregir las variables de estado de los modelos linealmente relacionadas con la variable observada (Tabla 9) teniendo en cuenta sus errores relativos como se indica en la ecuación 33. Se asumieron los errores de observación informados por los proveedores, mientras que el error del modelo se estimó como la varianza muestral del ensamble de Kalman. Se introdujo variabilidad en el ensamble adicionando ruido gaussiano de media cero a las forzantes de los modelos, con varianzas iguales a sus errores de observación estimados (véase Tabla 7). Cada combinación de producto de humedad del suelo/modelo se evaluó separadamente. Adicionalmente, se evaluó la eficiencia de los modelos con asimilación de caudales y sin asimilación. En cada caso la eficiencia de los modelos se calculó como la suma del cuadrado de las diferencias entre caudales simulados y observados asumiendo distintos horizontes de pronóstico ( 0 a 3 días) para el periodo 7-2012 a 12-2014.

Tabla 7: Varianzas del error asumidas para las forzantes de los modelos

\begin{tabular}{|c|c|c|}
\hline Forzante & tipo & $\hat{S}$ \\
\hline $\mathrm{P}$ & multiplicativo & 0,25 \\
\hline ETP & aditivo & $1 \mathrm{~mm}$ \\
\hline
\end{tabular}

\footnotetext{
${ }^{4}$ La calibración de los modelos se realiza en modo autónomo, es decir, sin asimilación de datos
} 


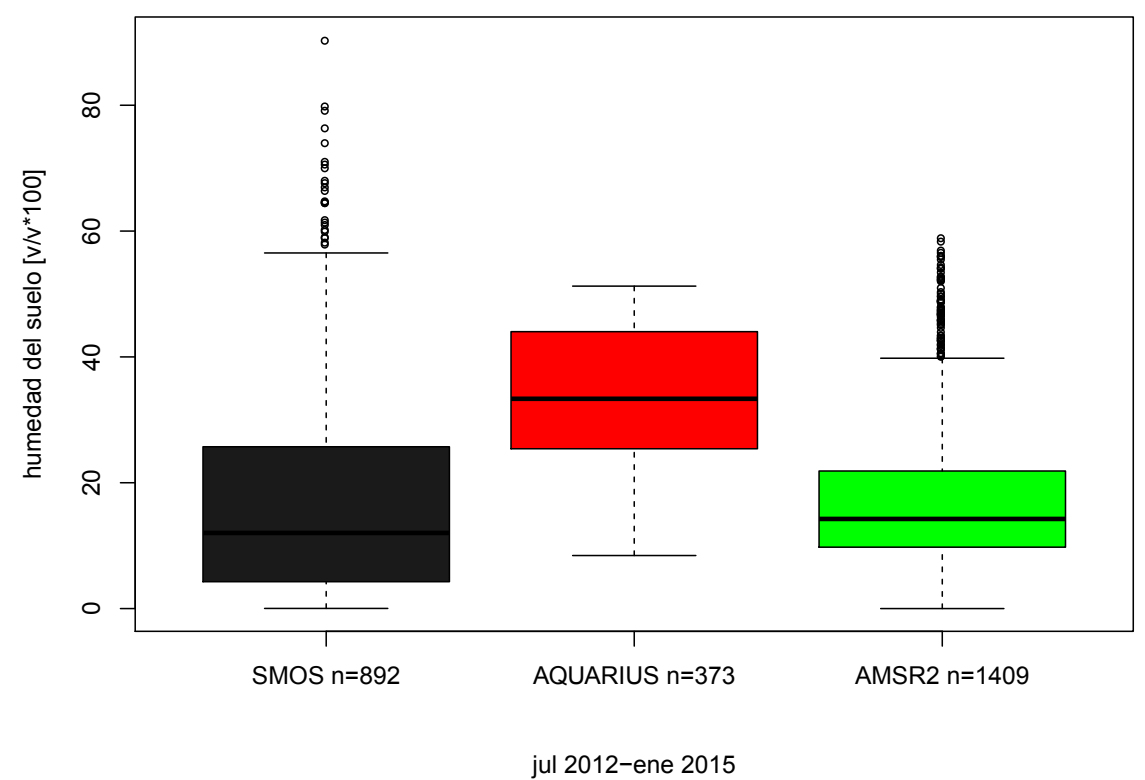

Figura 17: Gráfico de caja y patillas de las series de humedad del suelo media areal

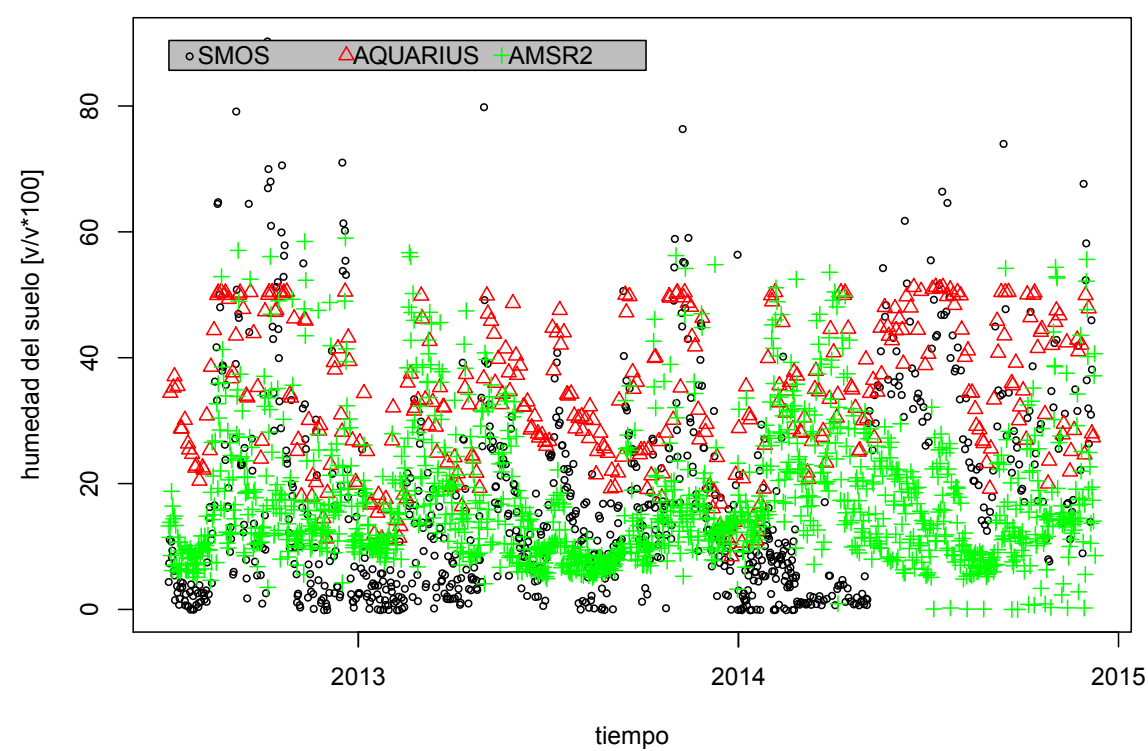

Figura 18: Humedad del suelo media areal en función del tiempo 
Tabla 8: Resumen estadístico de las series de humedad del suelo media areal

\begin{tabular}{|l|l|l|l|}
\hline Producto & Aquarius & SMOS & AMSR2 \\
\hline$\overline{s m}$ & 0,3378 & 0,1709 & 0,1742 \\
Mediana & 0,3334 & 0,1202 & 0,1425 \\
$\sigma$ & 0,1114 & 0,1613 & 0,1087 \\
n obs. & 373 & 892 & 1409 \\
\hline
\end{tabular}

Para equiparar los estados simulados por los modelos con las observaciones, se utilizaron relaciones lineales que se muestran en la Tabla 9, donde $\theta_{s}$ es la porosidad total del horizonte superficial del suelo, $\theta_{r}$ es la humedad residual del suelo, $A\left[\mathrm{~km}^{2}\right]$ es el área de la cuenca, y las demás variables se definieron precedentemente en 5.4. La porosidad efectiva y la humedad residual se estimaron utilizando los percentiles 98 y 2 respectivamente de cada serie de humedad del suelo media areal. Por lo tanto difieren según el producto de humedad del suelo utilizado (véase Tabla 10).

Tabla 9: Ecuaciones de transformación entre variables de estado de los modelos y sus correlatos observados

\begin{tabular}{|c|c|c|}
\hline Modelo/Variable & SM & Q \\
\hline Sacramento & $\hat{s} m_{i, j}[1]=\frac{X_{1, i, j}}{X_{i, j}^{0}}\left(\theta_{s}-\theta_{r}\right)+\theta_{r}$ & $\hat{q}_{i, j}\left[\mathrm{~m}^{3} / s\right]=\alpha X_{4, i, j} \frac{A}{86,4}$ \\
\hline GR4P & $\hat{s} m_{i, j}[1]=\frac{s_{i, j}}{a}\left(\theta_{s}-\theta_{r}\right)+\theta_{r}$ & $\hat{q}_{i, j}\left[\mathrm{~m}^{3} / s\right]=r R 2_{j} \frac{A}{86,4}$ \\
\hline
\end{tabular}

Tabla 10: parámetros de porosidad

\begin{tabular}{|l|l|l|}
\hline Producto & $\theta_{s}$ & $\theta_{r}$ \\
\hline Aquarius & 0,5043 & 0,1094 \\
\hline SMOS & 0,56373 & 0,0017 \\
\hline AMSR2 & 0,4898 & 0,0462 \\
\hline
\end{tabular}

Como se evidencia en los gráficos 17 y 18, las diversas fuentes de datos de humedad del suelo muestran rangos y dinámicas distintas, lo cual puede explicarse dadas las diferentes características radiométricas entre los instrumentos y los modelos de recuperación de la variable utilizados. Sin embargo, como se afirma en (Crow et al., 2005c), para lograr una eficiente asimilación los datos observados y simulados deben corresponder a una misma climatología. Por otro lado, se ha verificado que estos sensores capturan la señal de los primeros centímetros del perfil del suelo (AMSR2: $1,5 \mathrm{~cm}$, SMOS, Aquarius: $5 \mathrm{~cm}$ ), mientras que el espesor de la zona no saturada de la cuenca es mucho más profunda. Por lo tanto, para las corridas con asimilación de humedad del suelo se recalibraron los modelos de manera tal de hacer coincidir lo mejor posible la dinámica de la variable observada y la simulada. Esto se logró mediante calibración automática utilizando el mismo periodo que en la sección 6.1 pero restringiendo el parámetro correspondiente al contenido máximo de agua de la primera capa de suelo (SAC-EnKF: $X_{0}^{1}$, GR4P: $a$ ) y luego comparando las trazas de humedad del suelo 
observada y simulada hasta encontrar un grado de coincidencia satisfactorio. Como resultado se obtuvieron los conjuntos de parámetros que se muestran en las Tablas 11 y 12.

Tabla 11: Parámetros del modelo SAC-EnKF

\begin{tabular}{|l|l|l|l|}
\hline Producto & Aquarius & SMOS & AMSR2 \\
\hline$x_{0}^{1}$ & 90,35 & 38,06 & 26,50 \\
$x_{0}^{2}$ & 26,35 & 109,00 & 94,85 \\
$m 1$ & 11,194 & 3,442 & 4,234 \\
$c 1$ & 0,00360 & 0,02346 & $10^{-9}$ \\
$c 2$ & 1656,1 & 273,1 & 565,7 \\
$c 3$ & 0,000185 & 0,002476 & 0,001327 \\
$\mu$ & 9,8202 & 1,2663 & 7,8395 \\
$\alpha$ & 0,2143 & 0,2188 & 0,2109 \\
$m 2$ & 1,3599 & 0,6272 & 0,6296 \\
$m 3$ & 0,4512 & 1,0192 & 0,6801 \\
\hline
\end{tabular}

Tabla 12: Parámetros del modelo GRP-EnKF

\begin{tabular}{|l|l|l|l|}
\hline Producto & Aquarius & SMOS & AMSR2 \\
\hline$a$ & 46,03 & 16,928 & 16,928 \\
$r$ & 0,1489 & 0,2343 & 0,2343 \\
$m$ & 0,7153 & 0,8745 & 0,8745 \\
$t^{h u}$ & 3,9402 & 7,0091 & 7,0091 \\
\hline
\end{tabular}

En cuanto a la asimilación de caudales, el error de la observación se extrajo de la serie de aforos, cuyo dominio se dividió en siete intervalos para los cuales se calculó el error medio respecto de la curva de gasto. Los valores obtenidos se presentan en la Tabla 13.

Tabla 13: Error observacional de caudal

\begin{tabular}{|c|c|c|c|c|c|c|}
\hline$Q_{o b s}\left[m^{3} / s\right]$ & $<162,65$ & $<262,12$ & $<362,00$ & $<462,00$ & $<823,00$ & $\geq 823,00$ \\
\hline$\hat{\sigma}^{2}\left[\left(m^{3} / s\right)^{2}\right]$ & 82,6 & 12669 & 21621 & 24471 & 24802 & 247359 \\
\hline
\end{tabular}

\subsection{Uso operativo para pronóstico hidrológico}

Para el pronóstico hidrológico a tiempo real pueden combinarse datos meteorológicos de distintas fuentes. El periodo que abarca desde el momento en que se realiza el pronóstico hasta el momento para el cual se realiza el pronóstico se denomina horizonte de pronóstico. La simulación comienza en algún punto en el pasado para el cual se conocen (o se asumen) las condiciones de la cuenca (condición inicial). A partir de esa fecha el modelo necesita ser alimentado con observaciones meteorológicas y pronósticos meteorológicos, para la parte inicial (calentamiento) y futura (horizonte de pronóstico) del periodo de simulación, respectivamente. Naturalmente, la incertidumbre del pronóstico aumenta a medida que uno extrapola hacia el futuro (por ejemplo, incrementando el horizonte de pronóstico). Debido a que los pronósticos meteorológicos tienen un grado de incertidumbre elevado, frecuentemente 
se utilizan salidas de diversos modelos de pronóstico meteorológico formando un ensamble para producir un pronóstico probabilístico en lugar de uno determinístico.

La longitud del horizonte de pronóstico debe ser escogida con cuidado. No debe ser demasiado larga ya que la confiabilidad del pronóstico cuantitativo de precipitación decrece rápidamente luego de unos pocos días. Por otro lado, debe ser lo suficientemente larga para dar un tiempo de respuesta adecuado a los actores involucrados en la zona potencialmente afectada. Por lo tanto, en este trabajo se utilizó un horizonte de pronóstico de hasta tres días. La eficiencia del pronóstico hidrológico se evaluó en forma independiente para uno, dos y tres días de anticipación.

Los requerimientos técnicos para la puesta en operación del sistema de pronóstico hidrológico propuesto son:

1. un sistema de recolección de datos a tiempo real para recibir y procesar la información hidro-meteorológica relevante (precipitaciones, descarga, humedad en el suelo),

2. acceso a las salidas de modelos de predicción meteorológica,

3. un sistema para combinar información de diversas fuentes,

4. uno o más modelos hidrológicos para estimar la descarga total en la salida de la cuenca, y en el caso que resulte factible

5. un sistema de actualización a tiempo real para mejorar las estimaciones de descarga, basado en la asimilación de datos observados para la actualización de los estados del sistema.

Cada uno de estos requerimientos se satisfizo mediante el desarrollo de módulos independientes en una platafoma GNU (Linux) utilizando software libre de código abierto. Se utilizaron los lenguajes de programación Perl y Bash para la automatización de procesos (descarga de datos, actualización de base de datos, preparación de datos de entrada, corrida de modelos), y las librerías GDAL y GRASS como herramientas de procesamiento espacial. Se optó por el lenguaje $R$ para la generación automatizada de salidas gráficas. El lenguaje SQL se utilizó para crear y mantener actualizada la base de datos POSTGRESQL que contiene tanto los datos de entrada como las salidas de los modelos. 


\section{Experimentos y Resultados}

\subsection{Modelación matemática sin asimilación de datos (modo autónomo)}

Se calibraron y verificaron los modelos hidrológicos SAC y GR4P, en sus dos variantes: utilizando mediciones de campo de precipitación (CAMPO) y utilizando estimaciones de precipitación mediante sensores remotos (3B42RT). Se utilizó el algoritmo de optimización Downhill Simplex(Mathews y Fink, 2004) como se describe en la sección 5.5. Se utilizó el periodo 2000-2014, reservando cada tercer año para verificación. En la Tabla 14 se muestran los indicadores de eficiencia obtenidos. Las Tablas 15 y 16 muestran los parámetros finalmente adoptados. En las figuras 20 a 39 del Anexo I se grafican los hidrogramas y hietogramas observados e hidrogramas simulados.

Los hidrogramas simulados utilizando como entrada precipitaciones de campo resultaron adecuados para los fines propuestos, aunque se observa cierto grado de subestimación del caudal de los eventos de crecida más importantes, y frecuente sobreestimación de eventos de menor importancia.

Los resultados muestran que para fines de modelación hidrológica de la cuenca estudiada la estimación satelital de la precipitación media areal diaria a tiempo real (3B42RT) no alcanza a igualar la calidad de la estimación por métodos convencionales, a pesar de la baja densidad espacial de las mediciones pluviométricas en campo (especialmente en el periodo 2000-2006). Sin embargo, los resultados son aceptables, y no debe descartarse su utilización para cuencas donde no se dispone de mediciones pluviométricas o donde las mismas no se encuentren disponibles a tiempo real. Siendo este último el caso, es posible adoptar un esquema de uso secuencial de ambas fuentes de dato de precipitación, en el cual se alimenta el modelo con datos de campo hasta la última fecha disponible, y a partir de la misma hasta el presente se alimenta con el dato satelital. A medida que se capturan datos de precipitación de campo, éstos reemplazan a los satelitales.

Tabla 14: Parámetros de calibración (verificación) e indicadores de eficiencia del ajuste

\begin{tabular}{|c|c|c|c|c|c|c|c|c|}
\hline & \multicolumn{4}{|c|}{ Sacramento Simplificado } & \multicolumn{4}{|c|}{ GR4P } \\
\hline & \multicolumn{2}{|c|}{ CAMPO } & \multicolumn{2}{|c|}{ 3B42RT } & \multicolumn{2}{|c|}{ CAMPO } & \multicolumn{2}{|c|}{ 3B42RT } \\
\hline n cal. (ver.) & & & & 3585 & 1461) & & & \\
\hline dif. med. & 18,2 & $(4,2) \%$ & 15,6 & $(8,9) \%$ & 19,6 & $(0,6) \%$ & 8,7 & $(3,1) \%$ \\
\hline dif. des. & $-12,4$ & $(-19,9) \%$ & 331,6 & $(335,1) \%$ & $-8,0$ & $(-16,8) \%$ & 331,1 & $(324,5) \%$ \\
\hline $\operatorname{RMSE}\left[\mathrm{m}^{3} / \mathrm{s}\right]$ & 209,0 & $(203,0)$ & 260,2 & $(326,5)$ & 240,5 & $(233,6)$ & 289,3 & $(348,5)$ \\
\hline$r_{\text {Pearson }}$ & 0,86 & $(0,88)$ & 0,76 & $(0,64)$ & 0,81 & $(0,83)$ & 0,7 & $(0,58)$ \\
\hline$R_{\text {Nash }}$ & 0,736 & $(0,760)$ & 0,575 & $(0,381)$ & 0,637 & $(0,683)$ & 0,474 & $(0,294)$ \\
\hline SPEDS & 81,8 & $(75,2)$ & 78,9 & $(76,1)$ & 67,7 & $(63,9)$ & 65,7 & $(62,8)$ \\
\hline
\end{tabular}


Tabla 15: Parámetros del modelo Sacramento Modificado

\begin{tabular}{|c|c|c|c|}
\hline parámetro & unidad & CAMPO & 3B42RT \\
\hline$X 1_{0}$ & $\mathrm{~mm}$ & 70,2577 & 73,03 \\
$X 2_{0}$ & $\mathrm{~mm}$ & 60,44 & 103,5 \\
$m 1$ & 1 & 4,029 & 2,377 \\
$c 1$ & día $^{-1}$ & 0,0227 & 0,00704 \\
$c 2$ & 1 & 288,33 & 349,195 \\
$c 3$ & 1 & 0,00156 & 0,001 \\
$\mu$ & 1 & 2,684 & 4,522 \\
$\alpha$ & día $^{-1}$ & 0,23255 & 0,185 \\
$m 2$ & 1 & 0,567 & 0,529 \\
$m 3$ & 1 & 4,96 & 0,3887 \\
\hline
\end{tabular}

Tabla 16: Parámetros del modelo GR4P

\begin{tabular}{|c|c|c|c|}
\hline parámetro & unidad & CAMPO & 3B42RT \\
\hline$a$ & $\mathrm{~mm}$ & 278,024 & 385,44 \\
$r$ & día $^{-1}$ & 0,704 & 1,9418 \\
$m$ & 1 & 0,829 & 0,887 \\
$t^{h u}$ & día & 8,238 & 17,504 \\
\hline
\end{tabular}

\subsection{Modelación matemática con asimilación de datos (modo actualizado)}

Se realizaron corridas de los modelos SAC y GRP para la cuenca de estudio con asimilación de datos utilizando los parámetros de las Tablas 11 y 12. Se asimiló humedad del suelo de tres fuentes satelitales y caudal observado en corridas separadas. Se evaluó la eficiencia de la simulación con horizontes de pronóstico de entre 1 y 3 días en forma separada. En la Tabla 17 se muestran los coeficientes de eficiencia de Nash-Sutcliffe de todas las combinaciones de asimilación/modelo/horizonte de pronóstico ${ }^{5}$. En la Figura 19 se ilustra la metodología de evaluación de la eficiencia de los modelos en modo actualizado. Para todas las corridas se utilizó precipitación observada en campo tanto para el periodo de calentamiento como para el horizonte de pronóstico ya que el objetivo de esta etapa fue evaluar el impacto de la asimilación de datos (en la siguiente sección se evalúa el impacto de la incorporación de la salida de un modelo de pronóstico cuantitativo de precipitación). El periodo de simulación fue de 2012-7-1 a 2015-01-31. En los gráficos 40 a 47 del Anexo II se muestran los hidrogramas simulados con asimilación de datos con un horizonte de pronóstico de 3 días, comparado con el hidrograma en modo autónomo y el hidrograma observado.

\footnotetext{
${ }^{5}$ Dicho coeficiente (véase Tabla 5 ) tiene un rango de $-\infty$ a 1 , donde $E=1$ indica un ajuste perfecto, $E=0$ indica un pronóstico igual de preciso que la media de los caudales observados, y $E<0$ ocurre cuando la media de los caudales observados es mejor predictor que el modelo
} 
Tabla 17: Coeficientes de eficiencia de Nash-Sutcliffe de la simulación de caudales con y sin asimilación de datos

\begin{tabular}{|l|l|l|l|l|l|l|}
\hline & \multicolumn{3}{|c|}{ SACRAMENTO } & \multicolumn{3}{c|}{ GRP } \\
\hline Horiz. de prono. & 1 día & 2 días & 3 días & 1 día & 2 días & 3 días \\
\hline Actual. SM con SMOS & 0,55 & 0,55 & 0,55 & 0,62 & 0,62 & 0,61 \\
\hline Actual. SM con AQUARIUS & 0,51 & 0,51 & 0,51 & 0,58 & 0,58 & 0,58 \\
\hline Actual. SM con AMSR2 & 0,61 & 0,61 & 0,61 & 0,60 & 0,60 & 0,60 \\
\hline Actual. Q con caudal obs. & 0,81 & 0,76 & 0,72 & 0,96 & 0,89 & 0,84 \\
\hline Sin actualizar & \multicolumn{3}{|c|}{0,62} & \multicolumn{3}{c|}{0,58} \\
\hline
\end{tabular}



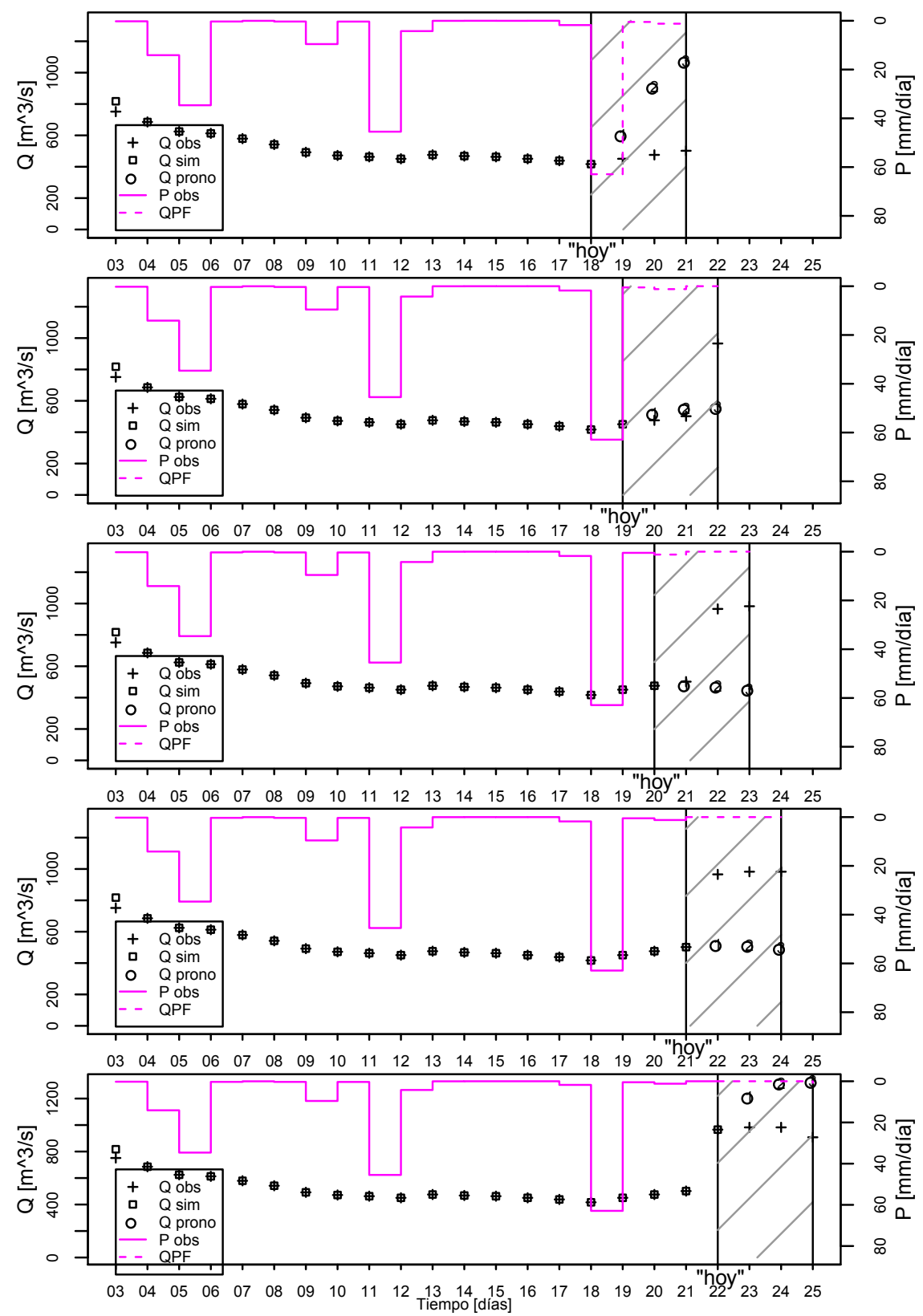

Figura 19: Esquema de evaluación de la eficiencia del pronóstico en modo actualizado. Se corrió el modelo asimilando datos (modo actualizado) hasta la fecha de emisión del pronóstico ("hoy"), y en modo autónomo más allá de la misma (área sombreada). La operación se repitió para cada fecha del periodo de simulación. La eficiencia del pronóstico a 1, 2 y 3 días se evaluó por separado (véase Tabla 5). Tanto en el periodo de calentamiento como en el horizonte de pronóstico se alimentó el modelo con precipitaciones observadas en campo.

Observando los resultados (Tabla 17), no se evidencia un impacto significativo de la asimilación de observaciones satelitales de humedad del suelo sobre la eficiencia de los caudales simulados. Se observan algunas diferencias en los hidrogramas simulados, pero las mejoras logradas en algunos eventos se ve compensada por mayores errores en otros eventos. Algunas posibles causas de esto se proponen en la sección 7.

En cuanto a la asimilación de datos de caudal, se evidencia un impacto positivo en la eficiencia del pronóstico en ambos modelos, lo cual se explica si se tiene en cuenta el grado de autocorrelación temporal de la serie de caudal. Sin embargo, se evidencia también que 
dicho impacto en la eficiencia disminuye notablemente al aumentar el horizonte de pronóstico. Aún así, para el horizonte de pronóstico de 3 días el impacto sigue siendo significativo.

\subsection{Modelación matemática con pronóstico cuantitativo de precipitación}

Se simuló la operación de los modelos hidrológicos en modo autónomo con la utilización de un pronóstico cuantitativo de precipitación. Se evaluó la eficiencia del pronóstico de caudal alimentando el modelo Sacramento a partir de la fecha de pronóstico con la precipitación media areal del modelo ETA SMN a 5 días, completando hasta 9 días de horizonte de pronóstico con valores nulos de precipitación. Para comparar se realizó una corrida con un vector de precipitación pronosticado nulo para todo el periodo de pronóstico. Las eficiencias a entre 1 y 9 días de horizonte de pronóstico de evaluaron independientemente.

Se observó que la eficiencia del pronóstico de caudal hasta los 5 días se mantiene aproximadamente constante y no es sensible al vector de precipitaciones utilizado, lo cual se explica al considerar que dicho periodo coincide aproximadamente con el tiempo de respuesta hidrológico de la cuenca. Se observó que entre los 6 y 9 días la eficiencia disminuye en ambos casos, siendo menor la disminución en caso de utilizarse QPF pronosticado. En las Tablas 18 y 19 se muestran los indicadores de eficiencia.

Tabla 18: Indicadores de eficiencia de la simulación de caudales en modo autónomo con pronóstico de precipitación ETA-SMN

\begin{tabular}{|c|c|c|c|c|c|c|c|}
\hline Horiz.[días] & $\mathrm{n}$ & dif. media & dif. desvío & $\mathrm{RMSE}\left[\mathrm{m}^{3} / s\right]$ & $\mathrm{r}$ & $R_{\text {Nash }}$ & SPEDS \\
\hline $\mathbf{0}$ & 4011 & $50,7 \%$ & $-1,5 \%$ & 216,2 & 0,82 & 0,599 & 78,3 \\
\hline $\mathbf{1}$ & 3811 & $52,6 \%$ & $-0,6 \%$ & 218,0 & 0,84 & 0,612 & 76,9 \\
\hline $\mathbf{3}$ & 3810 & $50,2 \%$ & $-2,3 \%$ & 214,5 & 0,84 & 0,625 & 75,7 \\
\hline 3 & 3806 & $47,0 \%$ & $-5,2 \%$ & 211,5 & 0,84 & 0,636 & 74,7 \\
\hline 4 & 3348 & $45,3 \%$ & $-7,5 \%$ & 209,4 & 0,83 & 0,686 & 73,8 \\
\hline 5 & 3336 & $42,4 \%$ & $-10,9 \%$ & 216,4 & 0,81 & 0,666 & 72,7 \\
\hline 6 & 3336 & $38,2 \%$ & $-14,8 \%$ & 226,0 & 0,79 & 0,635 & 70,5 \\
\hline 7 & 3335 & $32,1 \%$ & $-19,9 \%$ & 236,1 & 0,75 & 0,602 & 67,5 \\
\hline 8 & 3336 & $24,9 \%$ & $-25,7 \%$ & 247,3 & 0,72 & 0,564 & 66,1 \\
\hline 9 & 3337 & $17,0 \%$ & $-31,9 \%$ & 258,2 & 0,68 & 0,524 & 65,1 \\
\hline
\end{tabular}


Tabla 19: Indicadores de eficiencia de la simulación de caudales con precipitación nula para el horizonte de pronóstico

\begin{tabular}{|c|c|c|c|c|c|c|c|}
\hline Horiz. prono. & $\mathrm{n}$ & dif. media & dif. desvío & RMSE & $\mathrm{r}$ & $R_{\text {Nash }}$ & SPEDS \\
\hline 0 & 4011 & $50,7 \%$ & $-1,5 \%$ & 216,2 & 0,82 & 0,599 & 78,3 \\
\hline 1 & 3813 & $51,6 \%$ & $-1,2 \%$ & 216,9 & 0,84 & 0,616 & 76,9 \\
\hline 2 & 3812 & $46,5 \%$ & $-4,6 \%$ & 211,4 & 0,84 & 0,635 & 75,3 \\
\hline 3 & 3808 & $39,3 \%$ & $-9,8 \%$ & 207,5 & 0,84 & 0,649 & 74,0 \\
\hline 4 & 3350 & $32,1 \%$ & $-15,3 \%$ & 205,9 & 0,82 & 0,696 & 73,3 \\
\hline 5 & 3337 & $23,3 \%$ & $-22,2 \%$ & 215,6 & 0,80 & 0,668 & 72,5 \\
\hline 6 & 3337 & $13,9 \%$ & $-29,5 \%$ & 230,9 & 0,76 & 0,619 & 72,0 \\
\hline 7 & 3336 & $4,6 \%$ & $-36,5 \%$ & 249,1 & 0,71 & 0,557 & 70,5 \\
\hline 8 & 3337 & $-4,4 \%$ & $-43,3 \%$ & 266,6 & 0,65 & 0,493 & 69,3 \\
\hline 9 & 3338 & $-12,9 \%$ & $-49,5 \%$ & 281,3 & 0,60 & 0,435 & 68,5 \\
\hline
\end{tabular}




\section{Conclusiones}

Se logró implementar operativamente un sistema de pronóstico hidrológico para la cuenca del río Gualeguay, incluyendo dos modelos hidrológicos a paso diario, una base de datos relacional, módulos de captura de datos de sensores remotos e in situ, un módulo de asimilación de datos de caudal y humedad del suelo, módulos de graficación y tabulación de los resultados y un módulo de calibración y validación mediante Downhill Simplex, utilizando exclusivamente software libre de código abierto en una plataforma de base GNU (Linux).

Los resultados obtenidos aportan evidencia para sostener que la modelación hidrológica agregada a paso diario utilizando modelos parsimoniosos existentes en la literatura constituye una herramienta adecuada para la anticipación de crecidas ribereñas en cursos de agua de llanura con áreas de aporte extensas. Se resalta la importancia de contar con observaciones de caudal in situ (lecturas diarias de escala más aforos que cubran todo el rango de alturas) para la sección de interés, sin las cuales este tipo de enfoque resulta impracticable, junto con una red pluviométrica de densidad adecuada para el cálculo de la precipitación media areal diaria del área de aporte (cuenca hidrográfica). Asimismo, la incorporación de nuevas estaciones de monitoreo hidrométrico en otras secciones dentro de la misma cuenca permitiría avanzar en la discretización del sistema y así ganar conocimiento sobre su comportamiento.

Se observó que el producto satelital de estimación de precipitación 3B42RT puede resultar adecuado para los fines propuestos, pero resulta en una estimación de la precipitación media areal de calidad inferior a la estimación resultante de la red pluviométrica. Puede evaluarse su utilización como complemento de las observaciones en campo o en cuencas donde no se dispone de mediciones pluviométricas o para rellenar la serie donde las mismas no se encuentren disponibles a tiempo real. Asimismo, se evidencia la necesidad de medir más y mejor la precipitación in situ, densificando las redes pluviométricas, asegurando la disponibilidad del dato a tiempo real y manteniendo prácticas eficientes de control de calidad del dato. Esto permitiría, entre otras cosas,

- tanto verificar como calibrar localmente productos satelitales de precipitación y modelos de pronóstico meteorológico,

- obtener una mejor representación espacial del campo de precipitaciones,

- obtener una mejor estimación de la precipitación media areal en las distintas subcuencas,

- avanzar hacia un esquema semi-distribuido de modelación hidrológica.

En cuanto a la asimilación de datos mediante filtrado de Kalman en ensamble, no se obtuvo una mejora en la eficiencia utilizando humedad del suelo estimada satelitalmente para corregir los estados de los modelos. La humedad del suelo media areal observada por las tres fuentes utilizadas y las simulada por los dos modelos mostraron descriptores estadísticos y dinámicas distintas, lo cual puede indicar que existen discordancias entre los distintos productos satelitales y los modelos en cuanto a la conceptualización de la variable. Es decir que, a pesar de que todos definen a la humedad del suelo de la misma manera, la forma en la que en cada caso se calcula le confiere características singulares al campo de observaciones. Debido a estas discrepancias, como se señala en (Massari et al., 2015), la eficiencia de la asimilación de datos no sólo se relaciona con la calidad de la estimación de 
humedad del suelo, sino también a factores metodológicos y morfoclimáticos. A esto se suma la dificultad de realizar una calibración contra valores de humedad del suelo in-situ debido, entre otros factores, a

- la escasez de sitios de medición de humedad del suelo, y

- la dificultad de equiparar la escala de las observaciones in situ a la escala del dato satelital,

Adicionalmente, existe una limitación de estos sensores remotos en cuanto a la profundidad que alcanza a penetrar la señal en el suelo, lo cual puede inducir a errores a la hora de asimilar dicho dato a una variable de estado de un modelo que representa el estado de saturación de un espesor de suelo mayor. Probablemente deberá mejorarse la interpretación del dato satelital y adaptarse ad hoc la estructura de los modelos para lograr un aprovechamiento óptimo de esta nueva fuente de información. Por ejemplo, un enfoque alternativo puede ser utilizar directamente el dato radiométrico de los sensores como proxy del estado de humedad de la cuenca y asociarlo al vector de estados del modelo mediante algún vínculo empírico, o asimilar el valor satelital de humedad del suelo a un proxy de la humedad del suelo simulado para la cuenca (véase por ejemplo (Crow et al., 2005a)). Otro enfoque consiste en estimar la humedad del perfil de suelo completo a partir de la estimación superficial a través de, por ejemplo, métodos de asimilación variacionales (véase por ejemplo (Calvet y Noilhan, 2000)).

La asimilación de datos de caudal observado in situ produjo mejoras en los índices de eficiencia de los modelos para horizontes de pronóstico de entre 1 y 3 días. Más allá de los 3 días no se observaron mejoras, probablemente debido a que a partir de dicho intervalo la autocorrelación temporal de los caudales se vuelve poco significativa. Debido a que la asimilación de datos altera el balance de masa de los modelos (rompiendo la conservación de masa) se recomienda realizar el pronóstico a más de 3 días en modo autónomo. Un enfoque para contrarrestar este efecto consiste en incorporar una restricción de conservación de masa, como se describe en (Li et al., 2012).

Por último, se mostró que los pronósticos con horizontes de hasta 5 días no se ven significativamente afectados por el vector de pronóstico de precipitación utilizado, lo cual indicaría que la precipitación media areal en los 5 días previos no repercute significativamente en los caudales observados a la salida. Esto se explica si se tienen en cuenta las dimensiones y pendiente media de la cuenca, pero debe entenderse sólo como un valor medio, ya que eventos de precipitación más cercanos a la salida de la cuenca repercutirán antes en los caudales que eventos distribuidos homogéneamente o concentrados en las nacientes. Es una de las limitaciones de los modelos agregados la incapacidad de representar estas diferencias. En cambio, para pronósticos a entre 6 y 9 días se mostró que la incorporación del pronóstico cuantitativo de precipitación ETA SMN a 5 días mejora sensiblemente la eficiencia con respecto a un pronóstico de precipitación impuesto como nulo. Por lo tanto, la importancia de contar con un pronóstico cuantitativo de precipitación preciso reside en que nos permite extender en el tiempo los pronósticos hidrológicos.

En resumen, el trabajo mostró que utilizando técnicas de modelación bien conocidas, herramientas informáticas simples y una infraestructura básica, se obtuvieron pronósticos hidrológicos adecuados para un horizonte temporal útil para la gestión del riesgo de crecidas ribereñas. Las diversas alternativas ensayadas muestran un abanico de posibilidades de 
mejora en función del surgimiento de nuevas fuentes de información, mientras que para el funcionamiento básico de sistema se demostró que los datos necesarios son escasos y de fácil adquisición. Esto habilita a replicar fácilmente este abordaje en otros sistemas hídricos con características y necesidades similares.

\section{Agradecimientos}

Mi más sincero agradecimiento a mis compañeros del INA, a mis padres, a mis hermanas, a mi director y mi codirectora de tesis. 


\section{Bibliografía}

Ameghino, F. (1984). Las secas y las inundaciones en la provincia de Buenos Aires. Ministerio de Asuntos Agrarios de la provincia de Buenos Aires, 5 edición.

Aubert, D., C., L., y Oudin, L. (2003). Sequential assimilation of soil moisture and streamflow data in a conceptual rainfall-runnoff model. J. Hydrol., 280:145-161.

Berthet, L. (2010). Prévision des crues au pas de temps horaire: pour une meilleure assimilation de l'information de débit dans un modèle hydrologique. PhD thesis, AgroParisTech.

Beven, K. (2001). Rainfall-Runoff Modelling. The Primer. John Wiley and Sons, Ltd, Chichester, England.

Bindlish, R. y Jackson, T. (2013). Aquarius level-3 gridded 1-degree daily soil moisture. version 2. Boulder, Colorado USA: NASA DAAC at the National Snow and Ice Data Center. http: //dx.doi.org/10.5067/Aquarius/AQ3_DYSM.002.

Borús, J., Uriburu Quirno, M., Goniadzki, D., y Vila, D. (2004). Hydrologic modeling for flood warning and reservoir management. Instituto Nacional del Agua. Ezeiza, Argentina.

Brocca, L., Melone, F., Moramarco, T., y Stelluti, M. (2005). Soil water content monitoring in an experimental basin in central italy. En Tropeano, D., Arattano, M., Maraga, F., y Pellissero, C., editores, Progress in Surface and Subsurface Water Studies at the plot and Small Basin Scale, páginas 48-51. IDEANET Press, Turin.

Brocca, L., Moramarco, T., Melone, F., Wagner, W., Hasenauer, S., y Hahn, S. (2012). Assimilation of surface- and root-zone ascat soil moisture products into rainfall-runoff modeling. IEEE Transactions on Geoscience and Remote Sensing, 50(7):2542-2554.

Calvet, J.-C. y Noilhan, J. (2000). From near-surface to root-zone soil moisture using year-round data. Journal of Hydrometeorology, 1(5):393-411.

Cerana, J., Wilson, M., De Battista, J., Noir, J., y Quintero, C. (2006). Estabilidad estructural de los vertisoles de Entre Ríos en un sistema arrocero regado con agua subterránea. Revista de Investigaciones Agropecuarias, INTA, 35(1):87-106.

Crow, W. T., Bindlish, R., y Jackson, T. J. (2005a). The added value of spaceborne passive microwave soil moisture retrievals for forecasting rainfall-runoff partitioning. Geophysical Research Letters, 32:L18401.

Crow, W. T., Dongryeol, R., y Famiglietti, J. S. (2005b). Upscaling of field-scale soil moisture measurements using distributed land surface modeling. Advances in Water Resources, 28:114.

Crow, W. T., Koster, R. D., H., R. R., y Sharif, H. O. (2005c). Relevance of time-varying and time-invariant retrieval error sources on the utility of spaceborne soil moisture products. Geophysical Research Letters, 32. 
Fertonani, M. y Prendes, H. (1984). Hidrología en áreas de llanura: aspectos conceptuales, teóricos y meteorológicos. En Fuschini Mejía, M. C., editor, Hidrología de Grandes Llanuras. Comité Nacional Argentino para el Programa Hidrológico Internacional y UNESCO.

Fuentes Godo, P. (1984). Las áreas inundables. En Fuschini Mejía, M. C., editor, Hidrología de Grandes Llanuras. Comité Nacional Argentino para el Programa Hidrológico Internacional y UNESCO.

GCOS-138 (2010). Implementation plan for the global observing system for climate in support of the unfccc (2010 update). http://www.wmo.int/pages/prog/gcos/Publications/ gcos-138.pdf. Accedido el 6/12/2013.

Georgakakos, K., Rajaram, H., y Li, S. (1988). On improved operational hydrologic forecasting of streamflows. Informe técnico 325, IIHR. lowa Institute of Hydraulic Research, The University of lowa, lowa City, lowa, 52242.

Georgakakos, K. P. (1987). Real-time flash flood prediction. Journal of Geophysical research, 92:9615-9629.

Georgakakos, K. P. y Baumer, O. W. (1996). Measurement and utilization of on-site soil moisture data. Journal of Hydrology, 184:131-152.

Giordano, L. (2011). Cuenca del río Gualeguay en Rosario del Tala. Proceso de transformación lluvia total-escorrentía total. Desarrollo de herramientas de alerta y pronóstico hidrológico. Instituto Nacional del Agua. Ezeiza, Argentina.

Goniadzki, D., Thibeault, M., Lozza, H., Uriburu Quirno, M., y Dadamia, D. (2011). SACD/Aquarius Announcement of Opportunity. Assimilation of Soil Moisture Estimates into FlowForecasting Hydrologic Models. Instituto Nacional del Agua. Ezeiza, Argentina.

GRASS Development Team (2012). Geographic Resources Analysis Support System (GRASS GIS) Software. Open Source Geospatial Foundation. http://grass.osgeo.org.

Guetter, A. K. (2000). Hydrological Modeling and Hydrological Warning Systems. Lecture Notes. Advanced Course in Numerical Modeling. Hydrological Modeling, Lima, Peru, 0314/julio/2000.

Huffman, G. J., Stocker, E. F., Adler, R. F., Bolvin, D. T., y Nelkin, E. J. (2009). TRMM version 6 real-time multi-satellite precipitation analysis data set. Información digital. ftp://trmmopen . gsfc.nasa.gov/pub/merged/. NASA/GSFC, Greenbelt, MD, EEUU.

IGN (2019). Capas SIG. Instituto Geográfico Nacional de la República Argentina.

Jackson, T. J. (1993). Measuring surface soil moisture using passive microwave remote sensing. Hydrological Processes, 7:139-152.

Li, B., Toll, D., Zhan, X., y B., C. (2012). Improving estimated soil moisture fields through assimilation of AMSR-E soil moisture retrievals with an ensemble kalman filter and a mass conservation constraint. Hydrology and Earth System Sciences, 16(105):105-119. 
Manfreda, S., Fiorentino, M., Samela, C., Magiotta, M. R., Brocca, L., y Moramarco, T. (2013). A physically based approach for the estimation of root-zone soil moisture from surface measurements: application of the AMMA database. Hydrology Days, páginas 47-56.

Massari, C., Brocca, L., Tarpanelli, A., y Moramarco, T. (2015). Data assimilation of satellite soil moisture into rainfall-runoff modelling: A complex recipe? Remote Sensing, 9(7):1140311433.

Mathews, J. H. y Fink, K. K. (2004). Numerical Methods Using Matlab. Prentice-Hall Inc., Upper Saddle River, New Jersey, EEUU, 4th edición.

Nemec, J. (1986). Hydrological Forecasting. Kluwer Academic Publishers Group, Holanda.

Njoku, E. (2007). AMSR-E/Aqua L2B Surface Soil Moisture, Ancillary Parms, \& QC EASEGrids v002. Información digital. Actualizado diariamente. Boulder, Colorado EEUU: National Snow and Ice Data Center.

O'Connor, K. (2007). WMO Manual on Flood Forecasting and Warning. http://www.wmo. int/pages/prog/hwrp/publications/flood_forecasting_warning/WMO $\% 201072$ en. pdf. Capítulo 3.

Oudin, L., Hervieu, F., Michel, C., Perrin, C., Andréassian, V., Anctil, F., y Loumagne, C. (2005). Which potential evapotranspiration input for a lumped rainfall-runoff model? Part 2-Towards a simple and efficient potential evapotranspiration model for rainfall-runoff modelling. Journal of Hydrology, 303:290-306.

Panigatti, J. L., Cruzate, G., Tasi, H., y Bedendo, D. (2002). Suelos y ambientes de Entre Ríos.

Parajka, J., Naeimi, V., Blöschl, G., y Komma, J. (2009). Matching ERS scatterometer based soil moisture patterns with simulations of a conceptual dual layer hydrologic model over Austria. Hydrology and Earth System Sciences, 13(2):259-271.

Sala, J. M. (1984). La problemática en la investigaciones geohidrológicas en grandes llanuras con escasa información. En Fuschini Mejía, M. C., editor, Hidrología de Grandes Llanuras. Comité Nacional Argentino para el Programa Hidrológico Internacional y UNESCO.

SM-ESL team (2012). Catds level 4 data product description. Centre Aval de Traitement des Données SMOS. http://www. catds.fr/Products/Products-access.

Suaya, M. (2004). Primera evaluación objetiva de los pronósticos operativos de los modelos ETA-SMN y GFS-NCEP durante el año 2003. Tesis de licenciatura en ciencias de la atmósfera, Facultad de Ciencias Exactas y Naturales, UBA, Argentina.

Subsecretaría de Recursos Hídricos (2013). Base de datos hidrológica integrada. Información digital. Sistema Nacional de Información Hídrica, SSRH, Ministerio de Planificación Federal, Inversión Pública y Servicios, República Argentina.

Tangara, M. (2005). Nouvelle méthode de prévision de crue utilisant un modèle pluie-débit global. Tesis de doctorado, École Pratique des Hautes Études de Paris, Francia. 
Thornthwaite, C. W. (1948). An approach toward a rational classification of climate. Geographical Review, 38(1):55-94.

Uriburu Quirno, M. (2011). Risk and Hydrological Emergency Management. Algorithm Theoretical Basis Document. PIATURA SAOCOM. Comisión Nacional de Actividades Espaciales. Buenos Aires, Argentina.

USGS (2006). Shuttle radar topography mission. Información digital. Publicado por: Global Land Cover Facility, University of Maryland, EEUU.

Wagner, W., Naeimi, V., Scipal, K., De Jeu, R., y Martínez-Fernández, J. (2007). Soil moisture from operational meteorological satellites. Hydrogeology Journal, 15(1):121-131.

Wagner, W., Verhoest, N. E. C., Ludwig, R., y Tedesco, M. (2009). Remote sensing in hydrological sciences. Hydrology and Earth System Sciences, 13(6):813-817.

Wikipedia (2007). Postgresql - wikipedia, the free encyclopedia. [Online; accedido el 22/oct/2014].

Wikipedia (2014a). Directional symmetry (time series) - wikipedia, the free encyclopedia. [Online; accedido el 22/oct/2014].

Wikipedia (2014b). Nash-sutcliffe model efficiency coefficient - wikipedia, the free encyclopedia. [Online; accedido el 22/oct/2014].

Wikipedia (2014c). Pearson correlation coefficient — wikipedia, the free encyclopedia. [Online; accedido el 22/oct/2014].

Wikipedia (2014d). Root-mean-square deviation — wikipedia, the free encyclopedia. [Online; accedido el 22/oct/2014].

Wikipedia (2014e). Runge-kutta methods - wikipedia, the free encyclopedia. [Online; accedido el 22/oct/2014].

WMO (2008). WMO Guide to Hydrological Practices. Organización Meteorológica Mundial, sexta edición. Capítulo 3. 
10. ANEXO I 


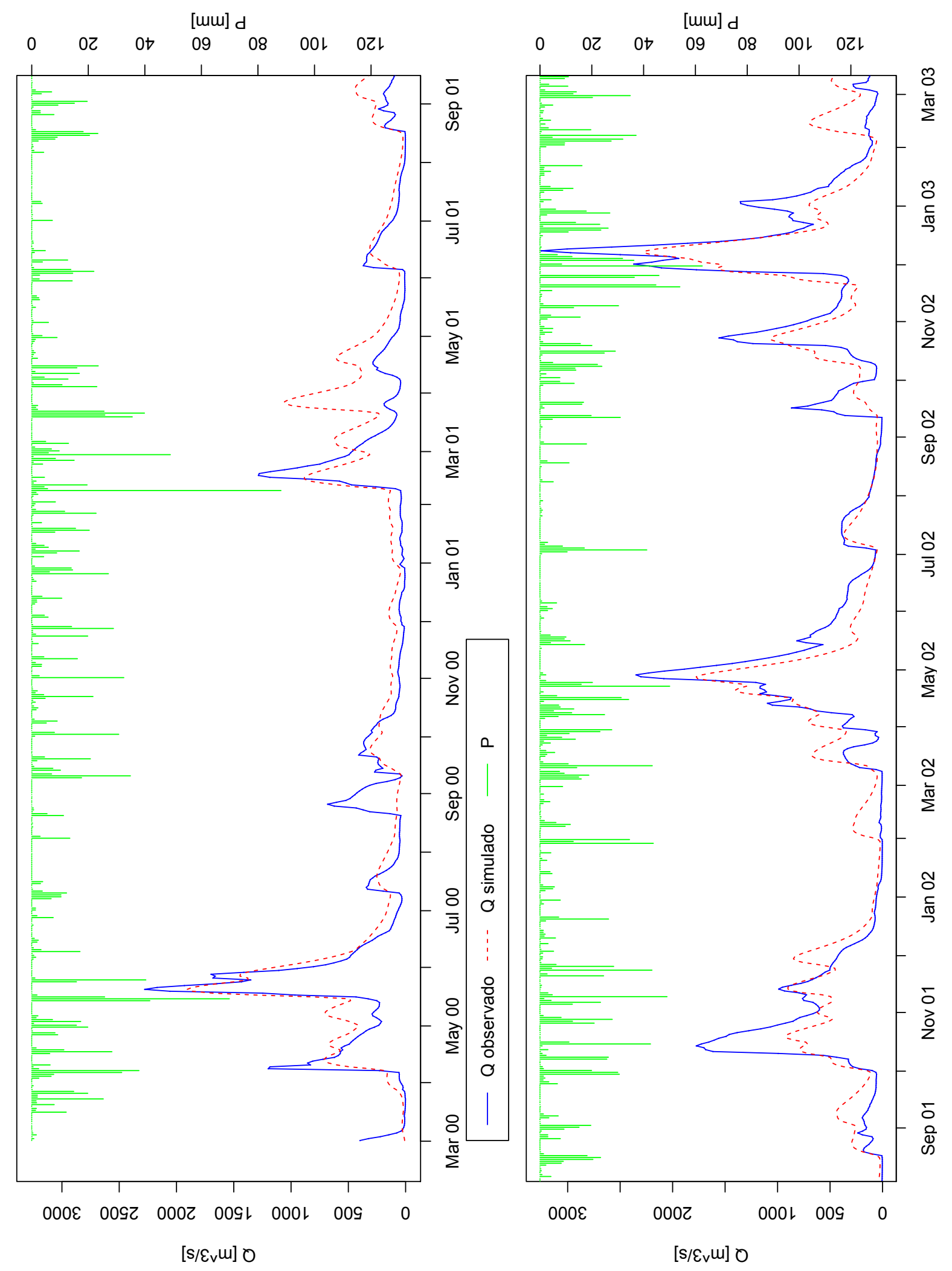

Figura 20: Hidrograma observado y simulado. Modelo SAC, precipitaciones de campo 


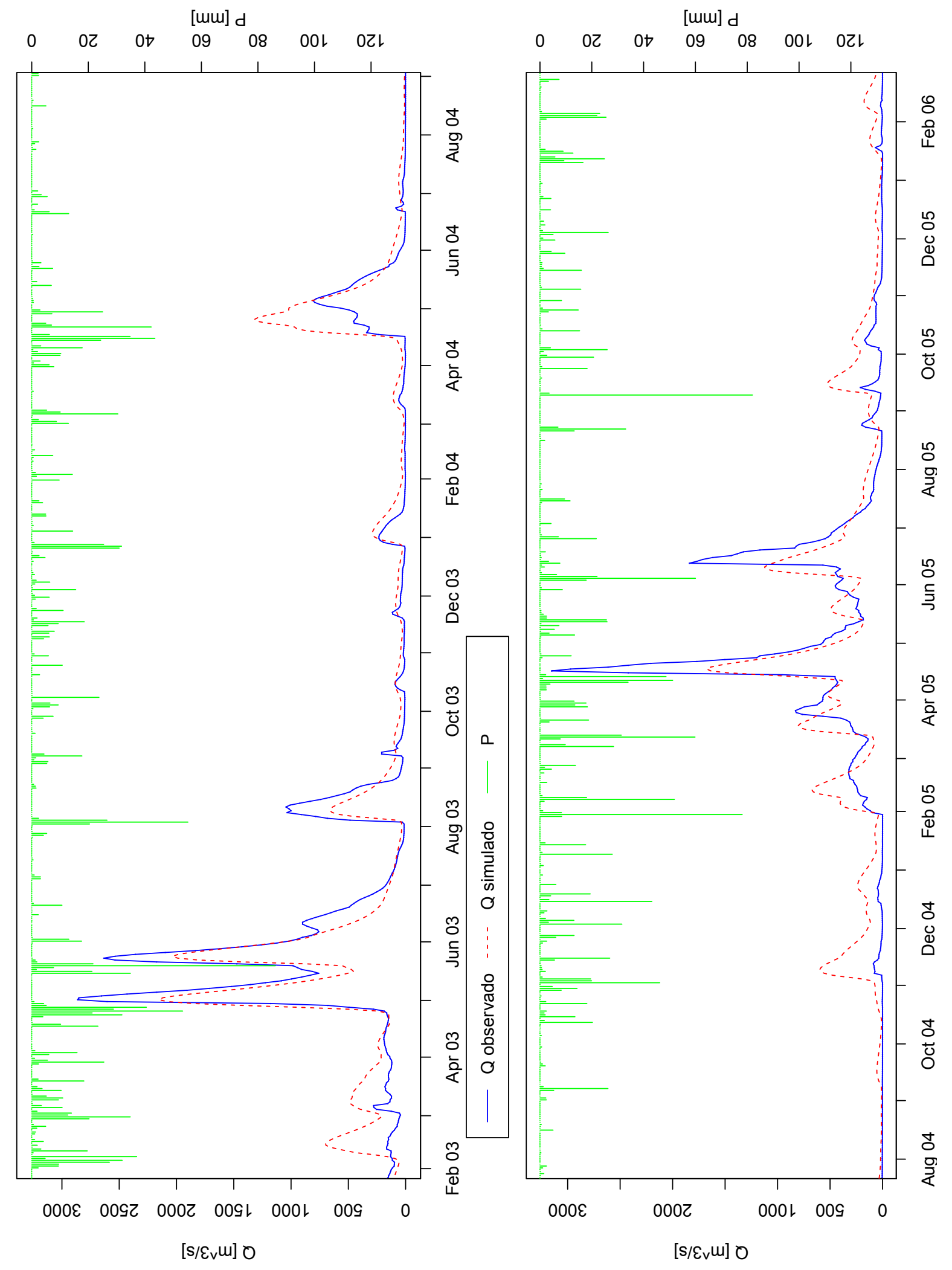

Figura 21: Hidrograma observado y simulado. Modelo SAC, precipitaciones de campo 


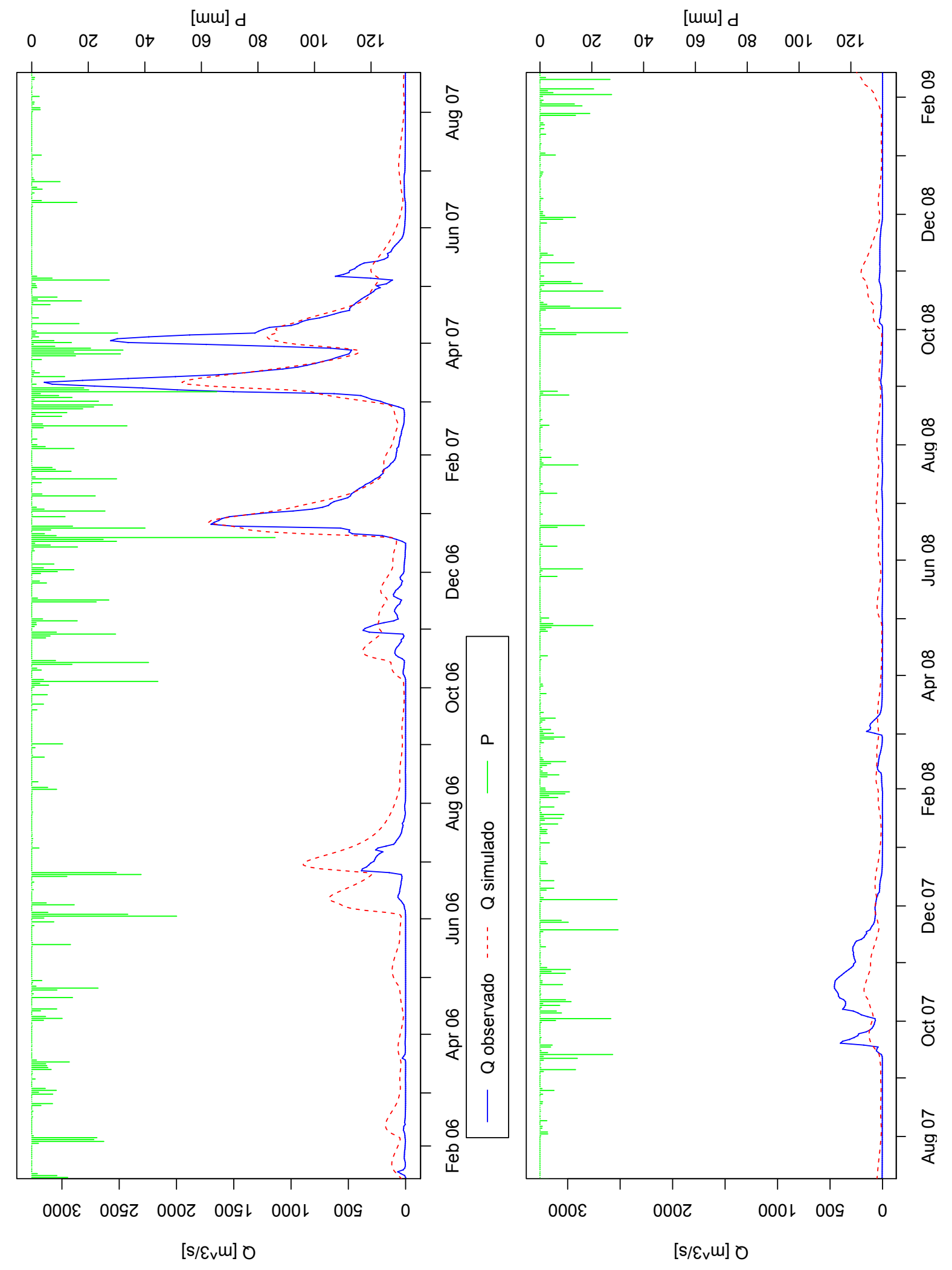

Figura 22: Hidrograma observado y simulado. Modelo SAC, precipitaciones de campo 


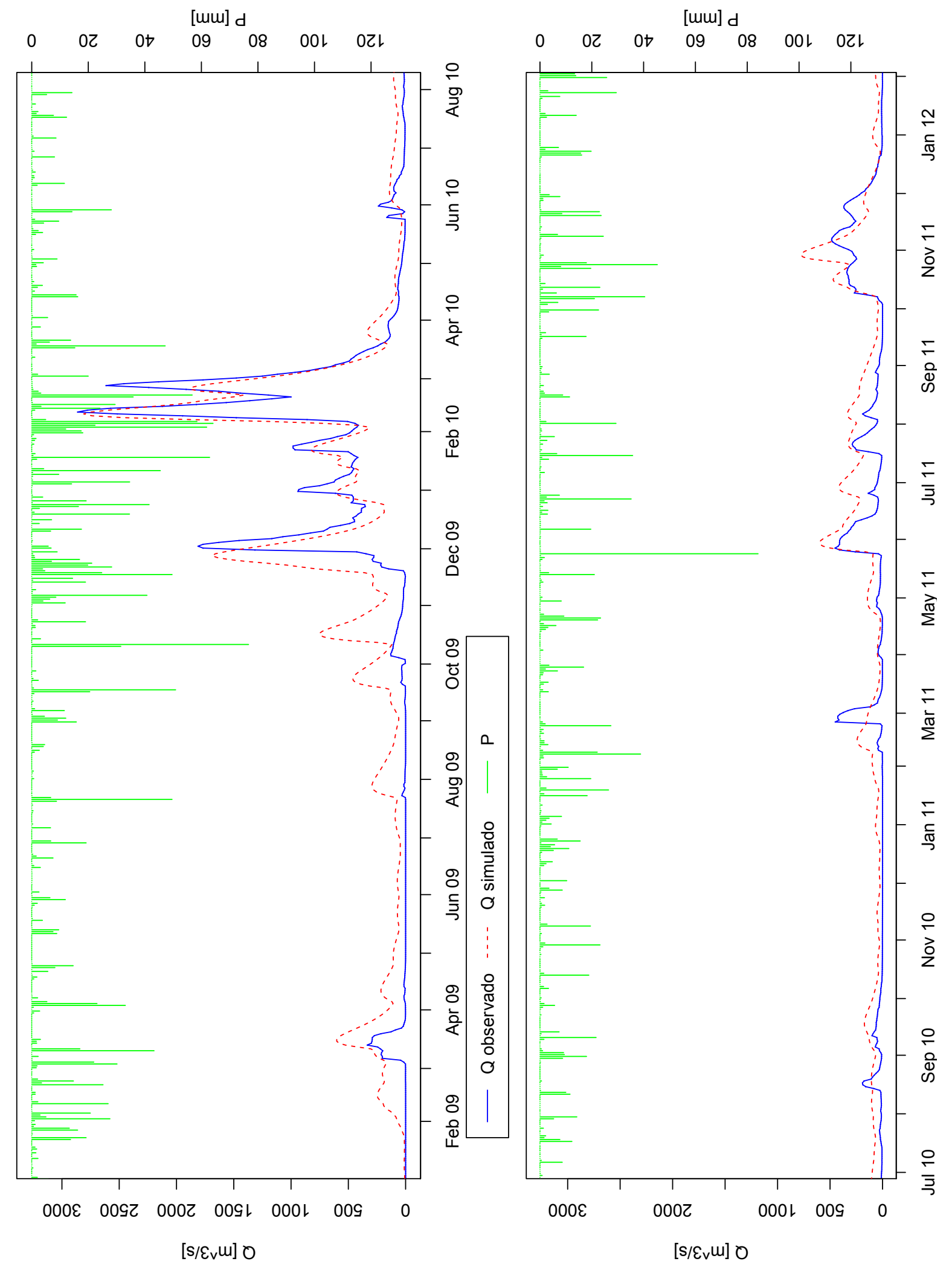

Figura 23: Hidrograma observado y simulado. Modelo SAC, precipitaciones de campo 


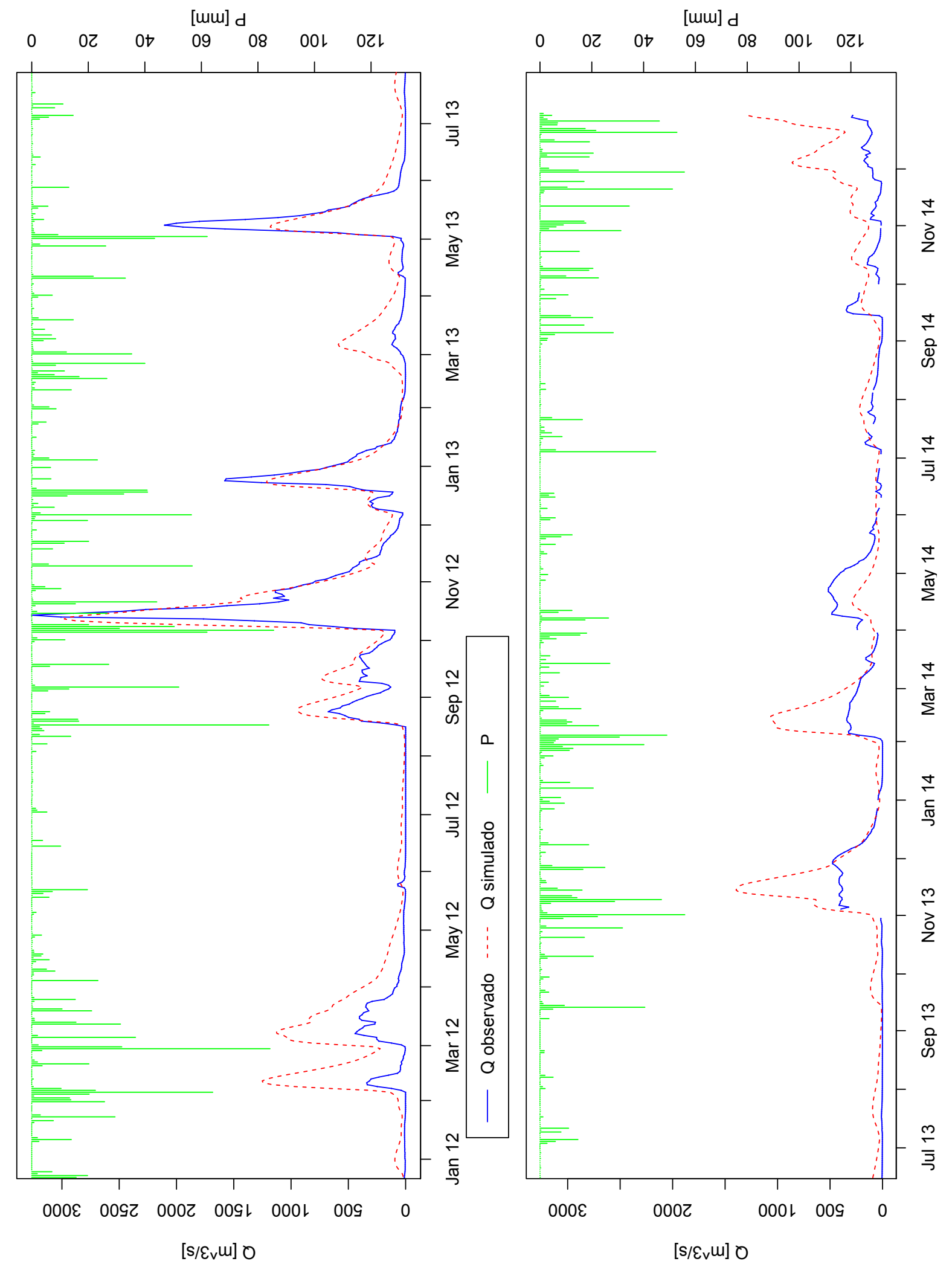

Figura 24: Hidrograma observado y simulado. Modelo SAC, precipitaciones de campo 


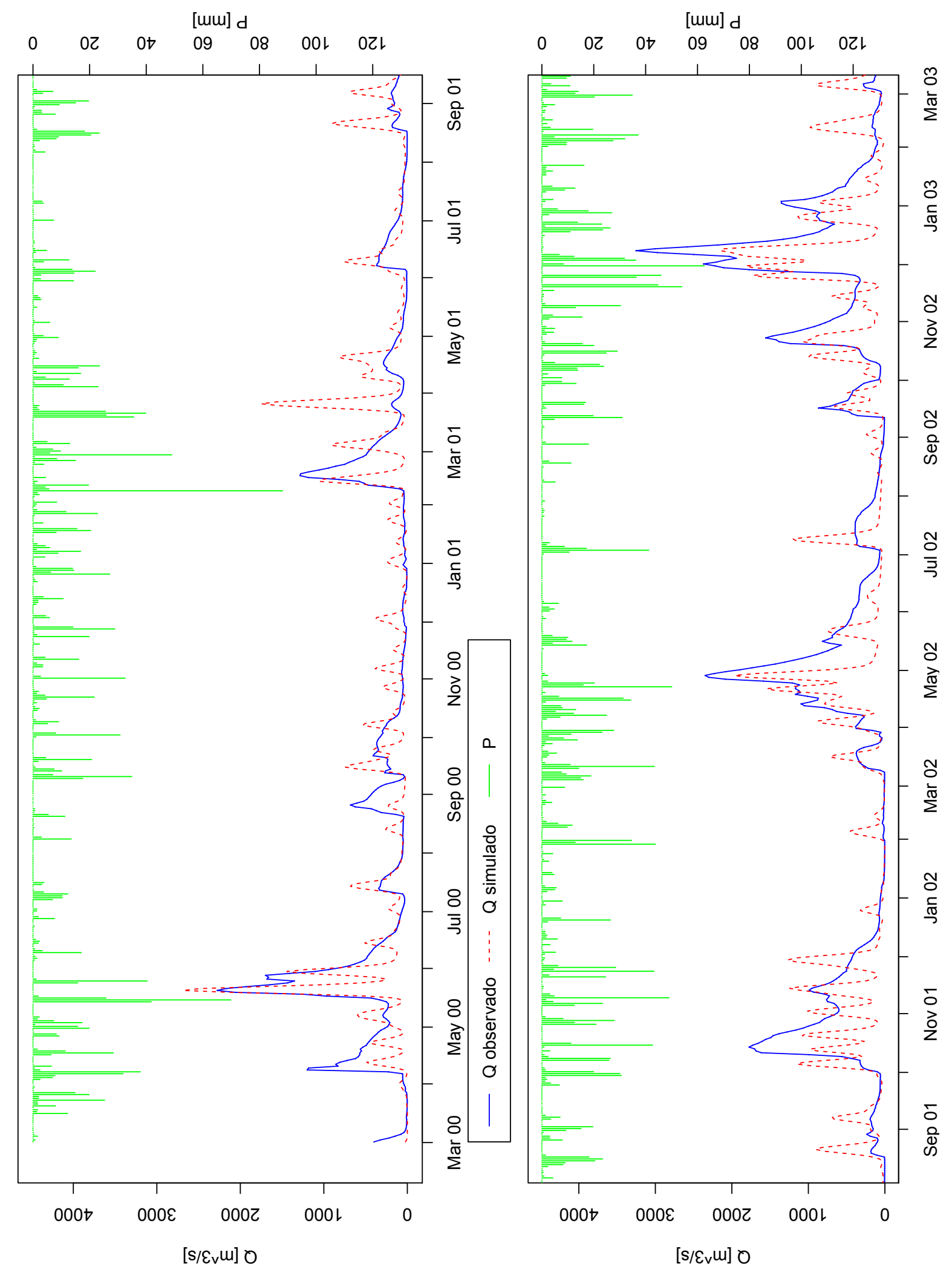

Figura 25: Hidrograma observado y simulado. Modelo GR4P, precipitaciones de campo 


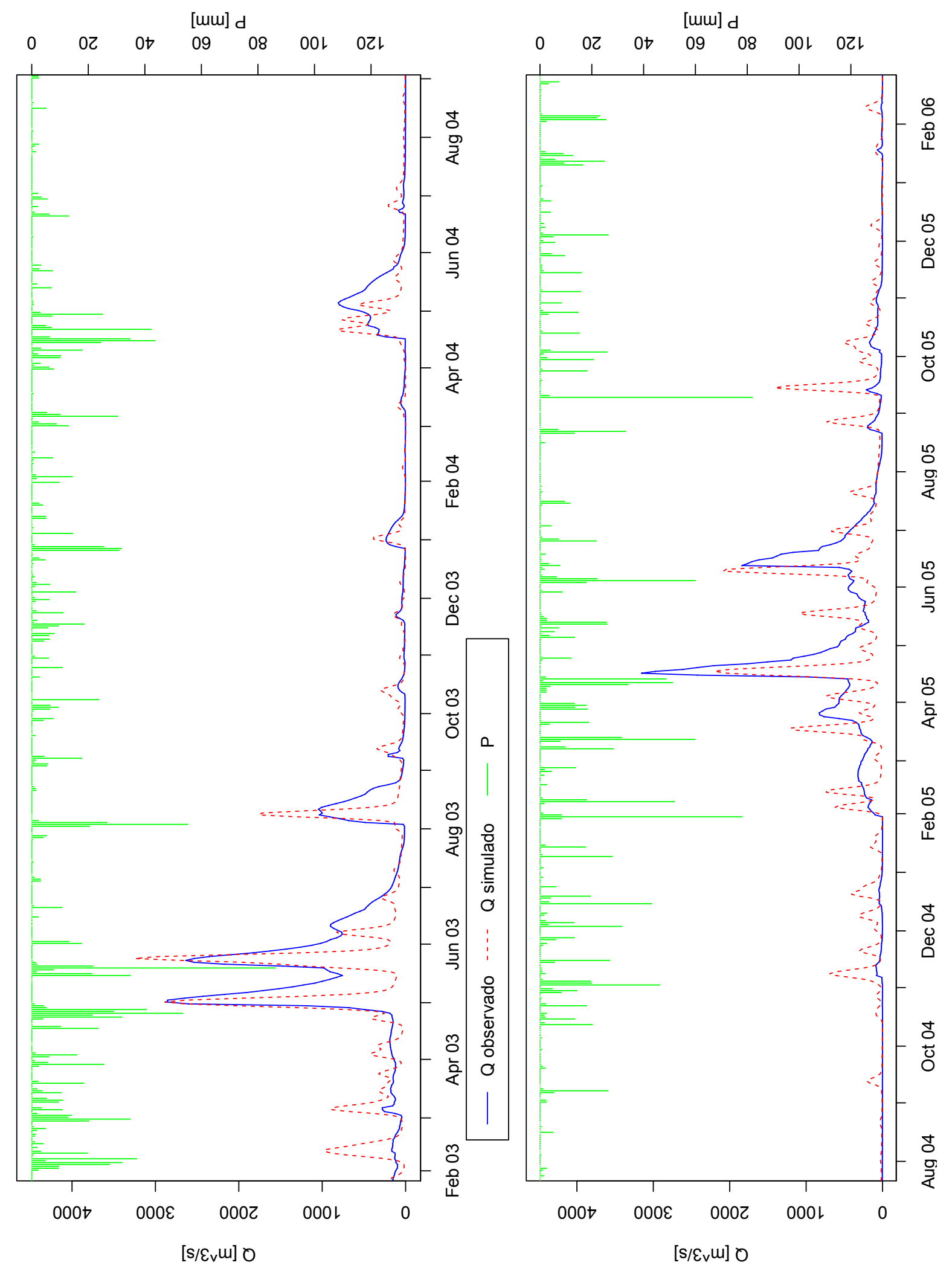

Figura 26: Hidrograma observado y simulado. Modelo GR4P, precipitaciones de campo 


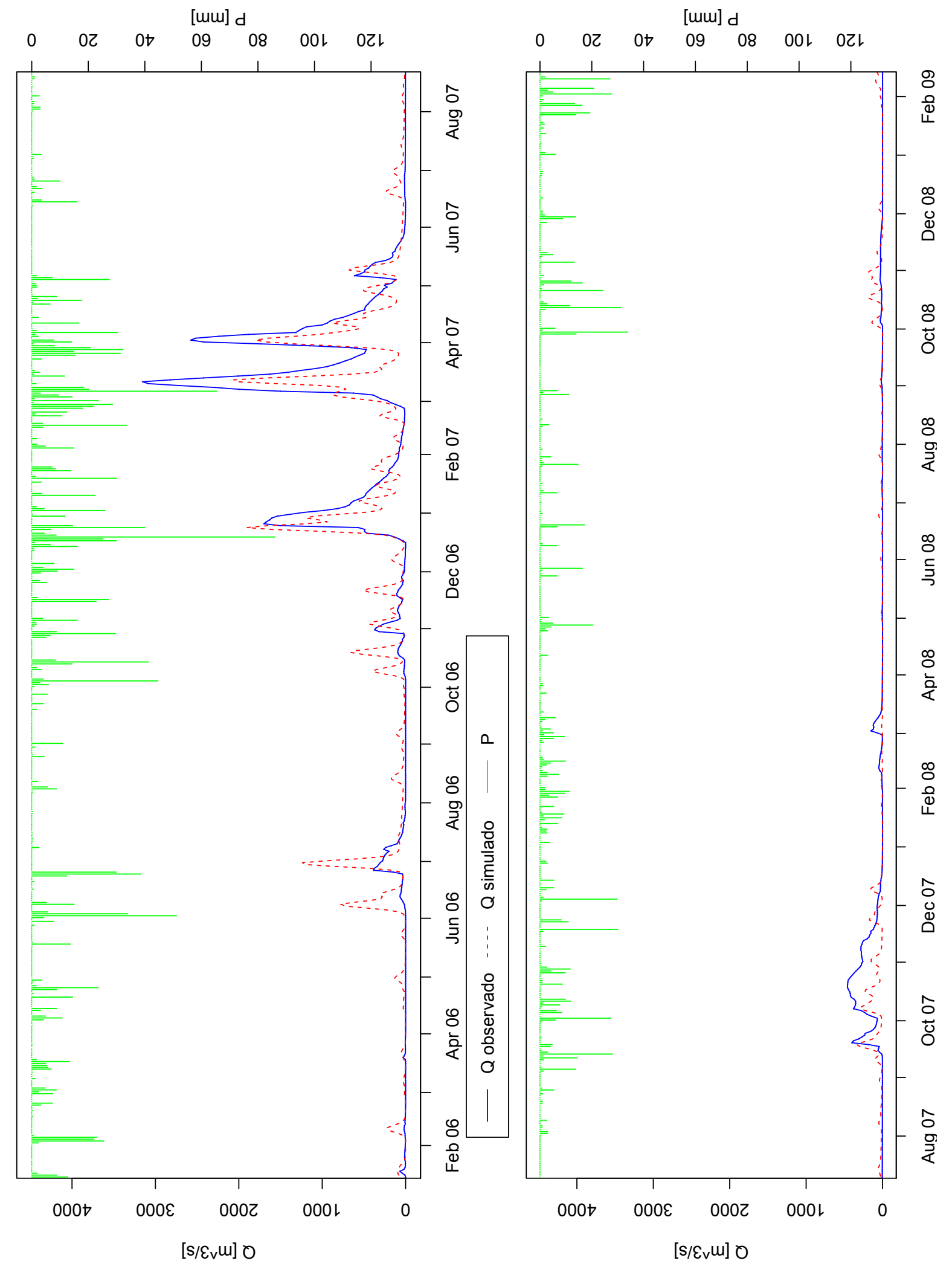

Figura 27: Hidrograma observado y simulado. Modelo GR4P, precipitaciones de campo 


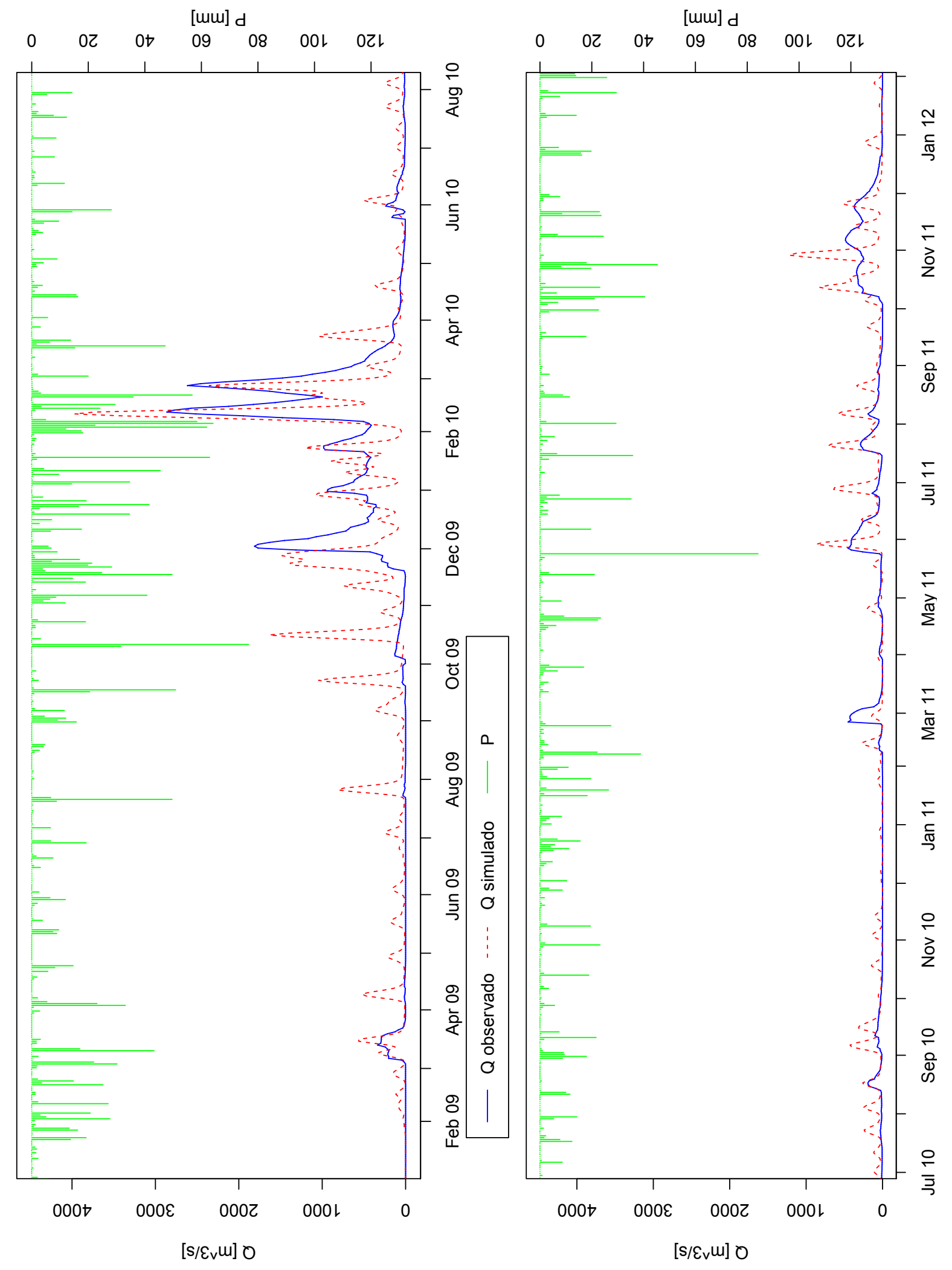

Figura 28: Hidrograma observado y simulado. Modelo GR4P, precipitaciones de campo 


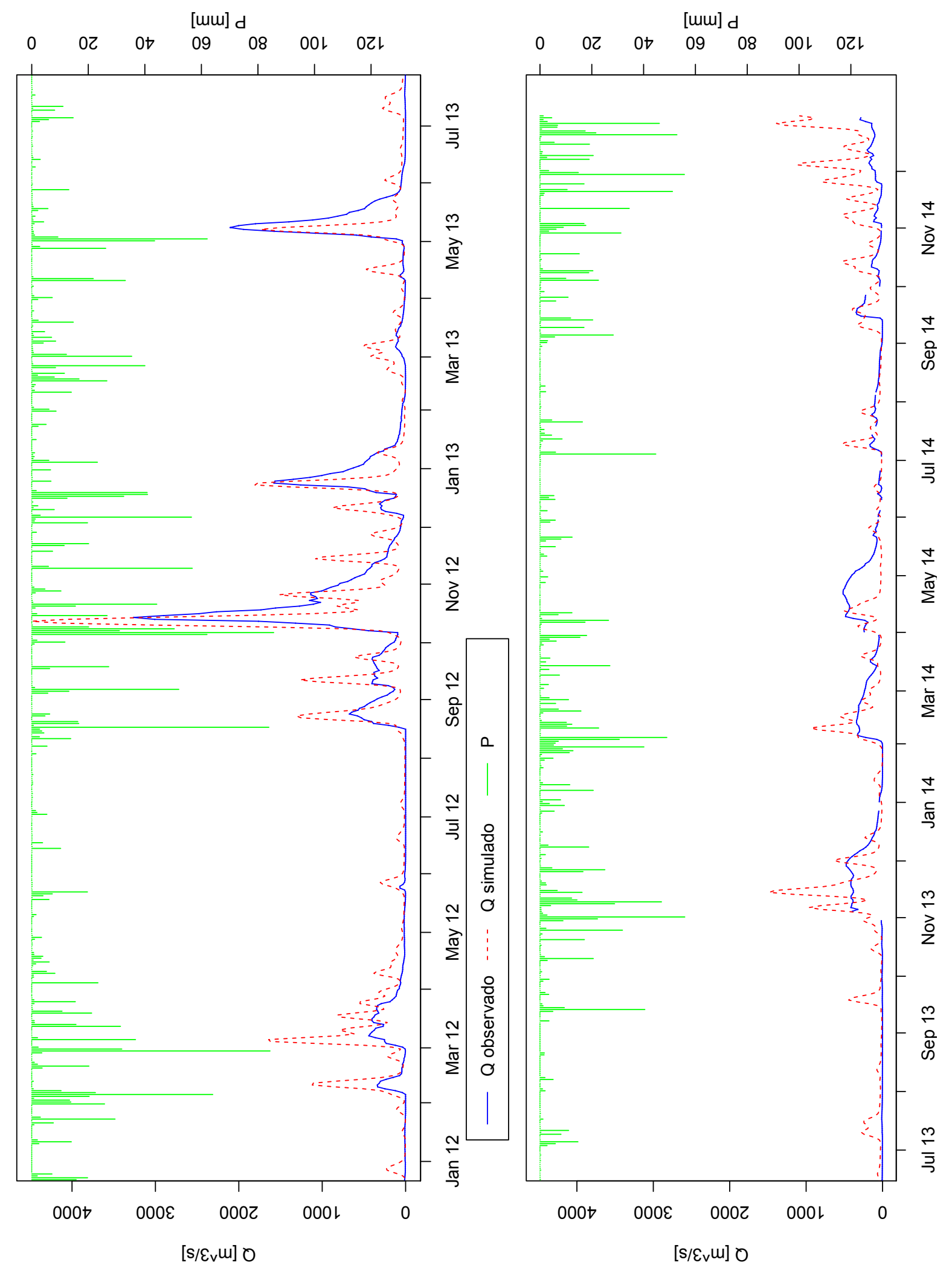

Figura 29: Hidrograma observado y simulado. Modelo GR4P, precipitaciones de campo 


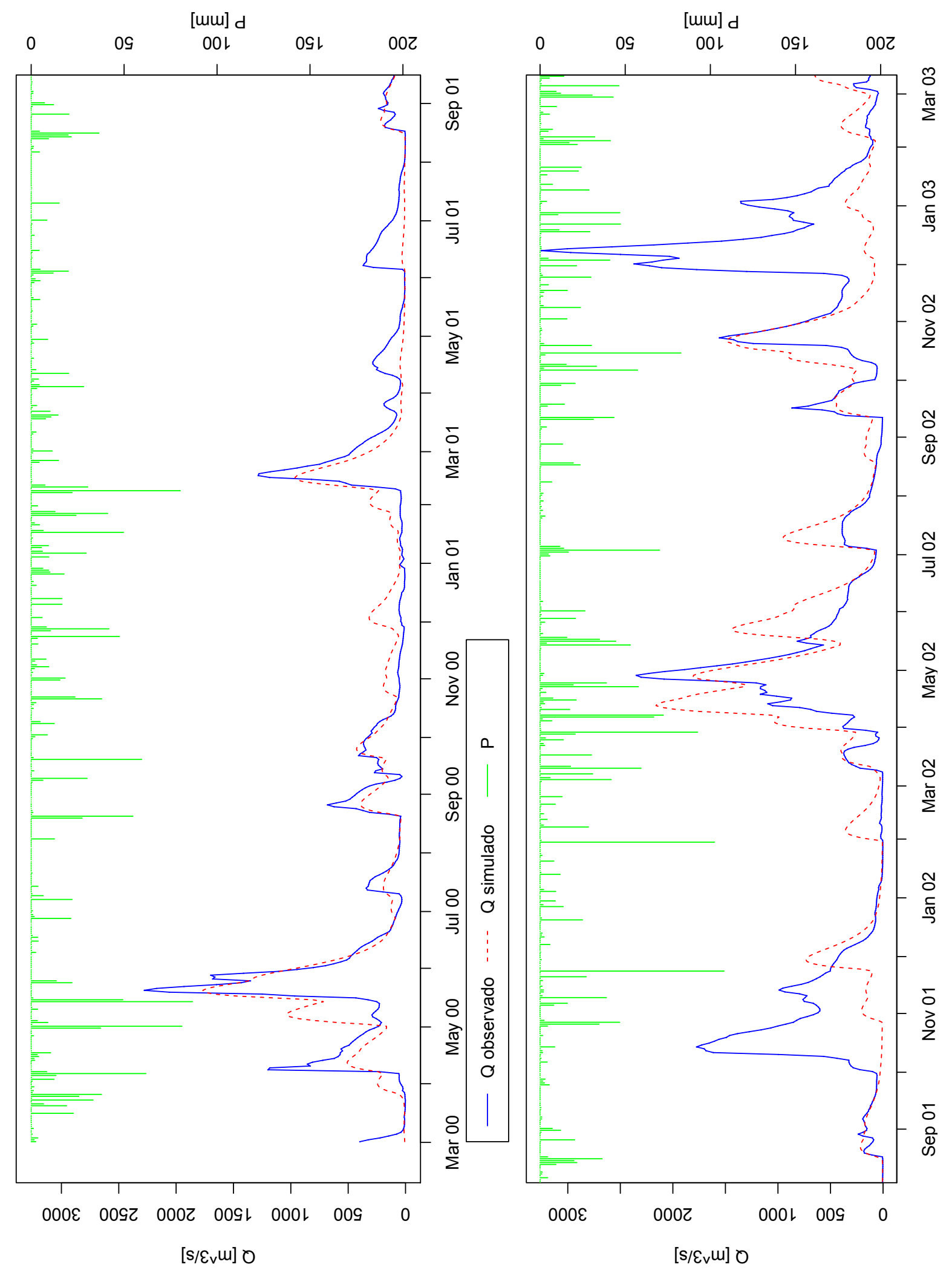

Figura 30: Hidrograma observado y simulado. Modelo SAC, precipitaciones satelitales 


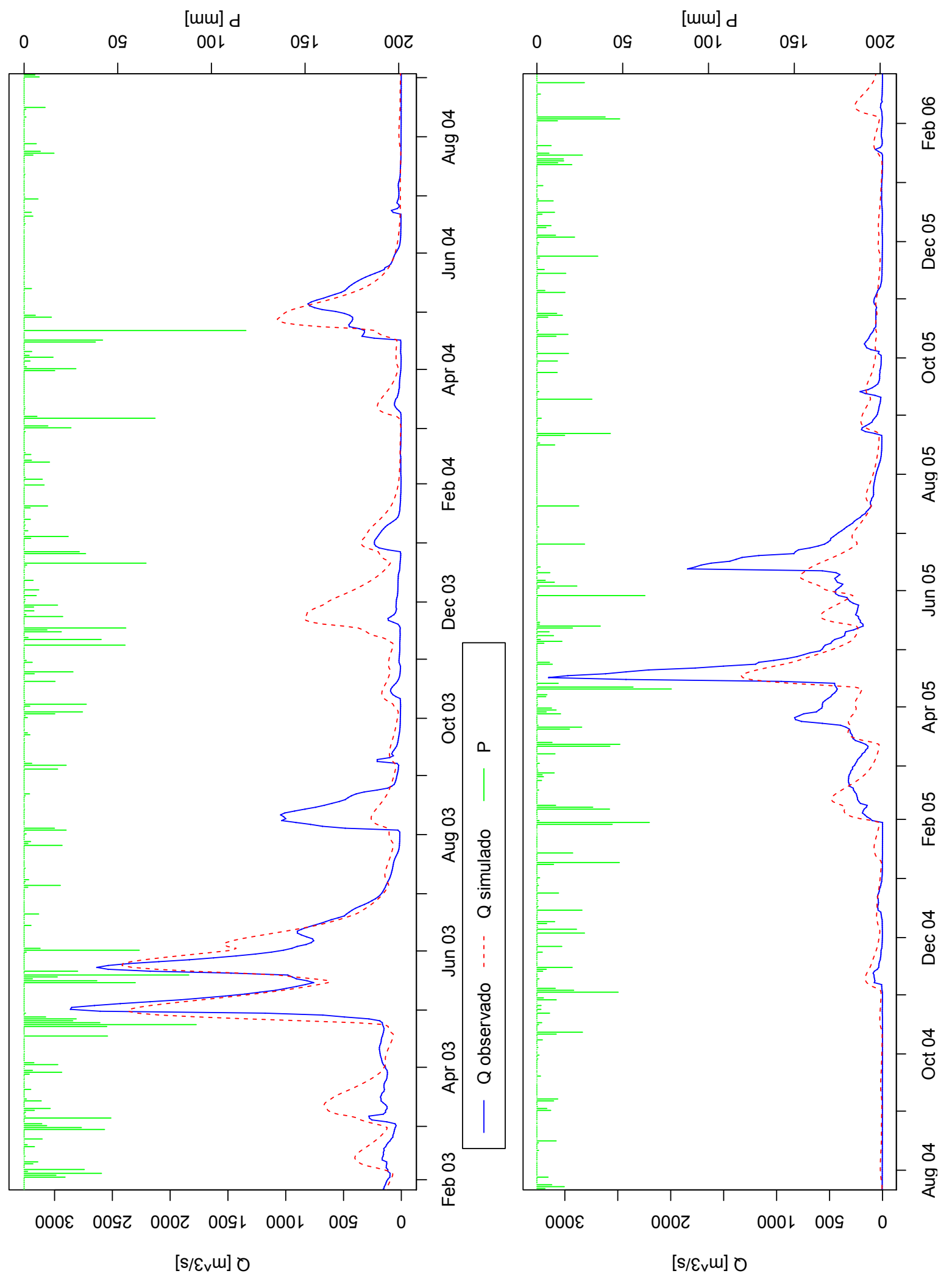

Figura 31: Hidrograma observado y simulado. Modelo SAC, precipitaciones satelitales 


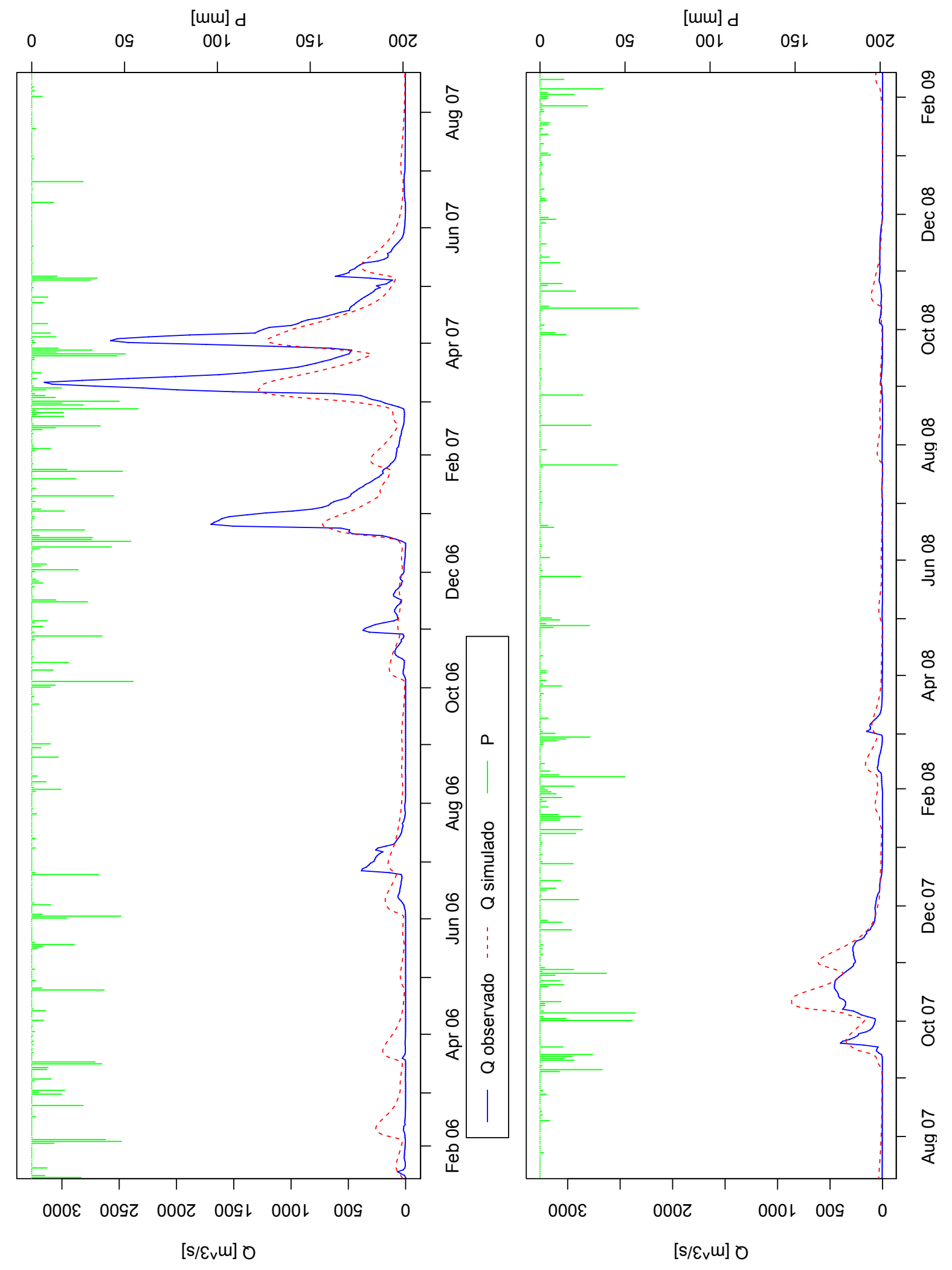

Figura 32: Hidrograma observado y simulado. Modelo SAC, precipitaciones satelitales 


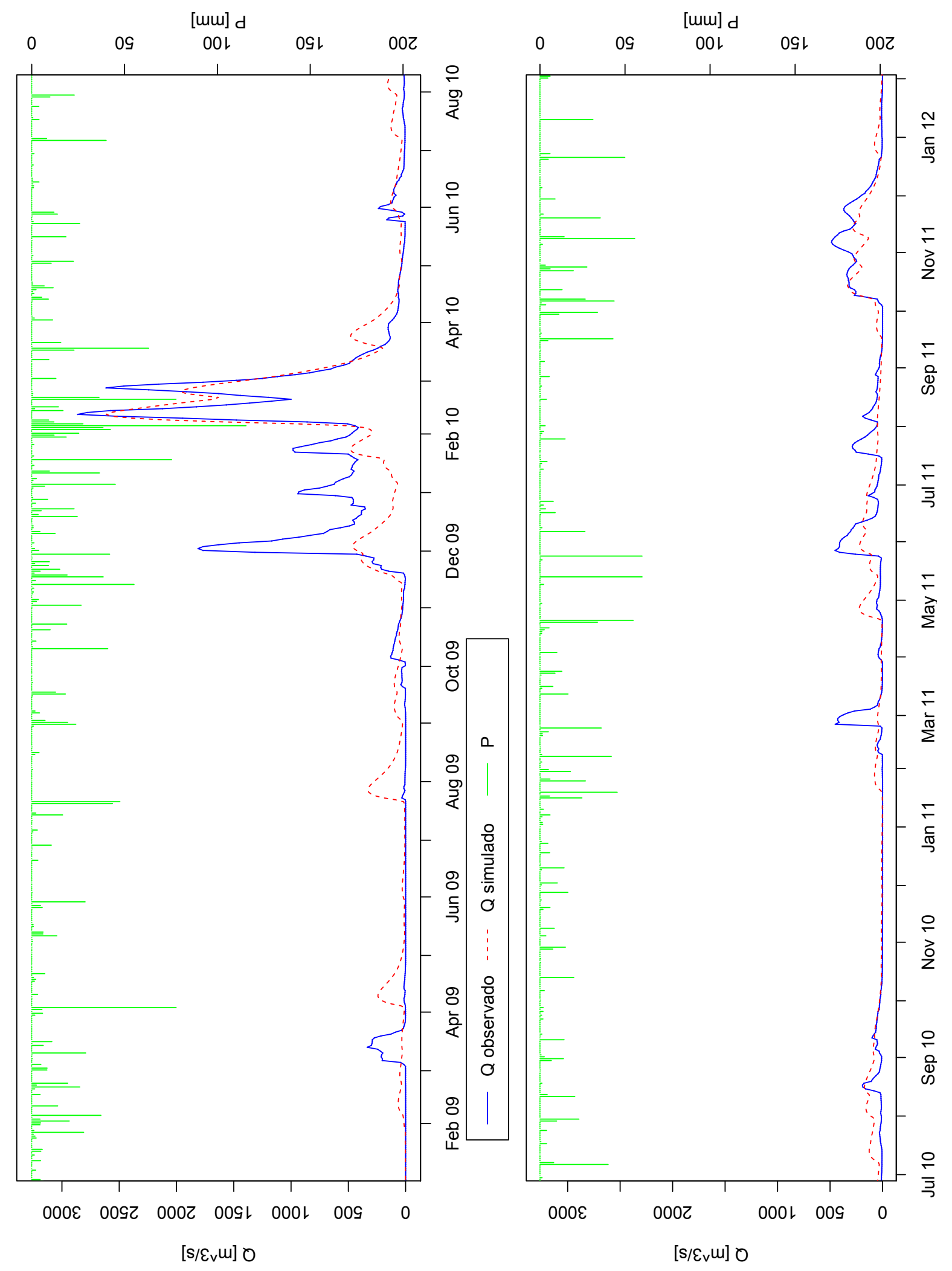

Figura 33: Hidrograma observado y simulado. Modelo SAC, precipitaciones satelitales 


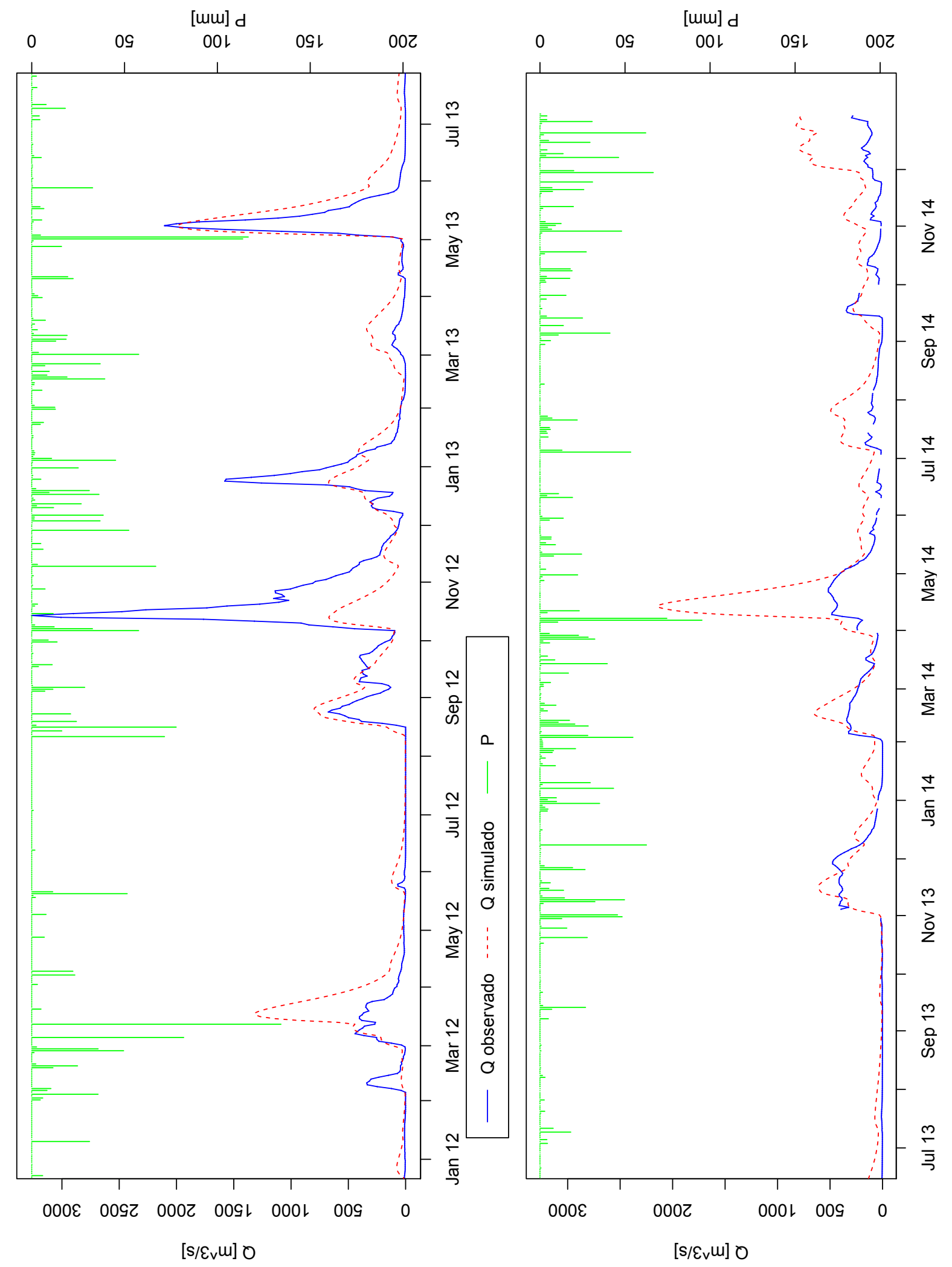

Figura 34: Hidrograma observado y simulado. Modelo SAC, precipitaciones satelitales 


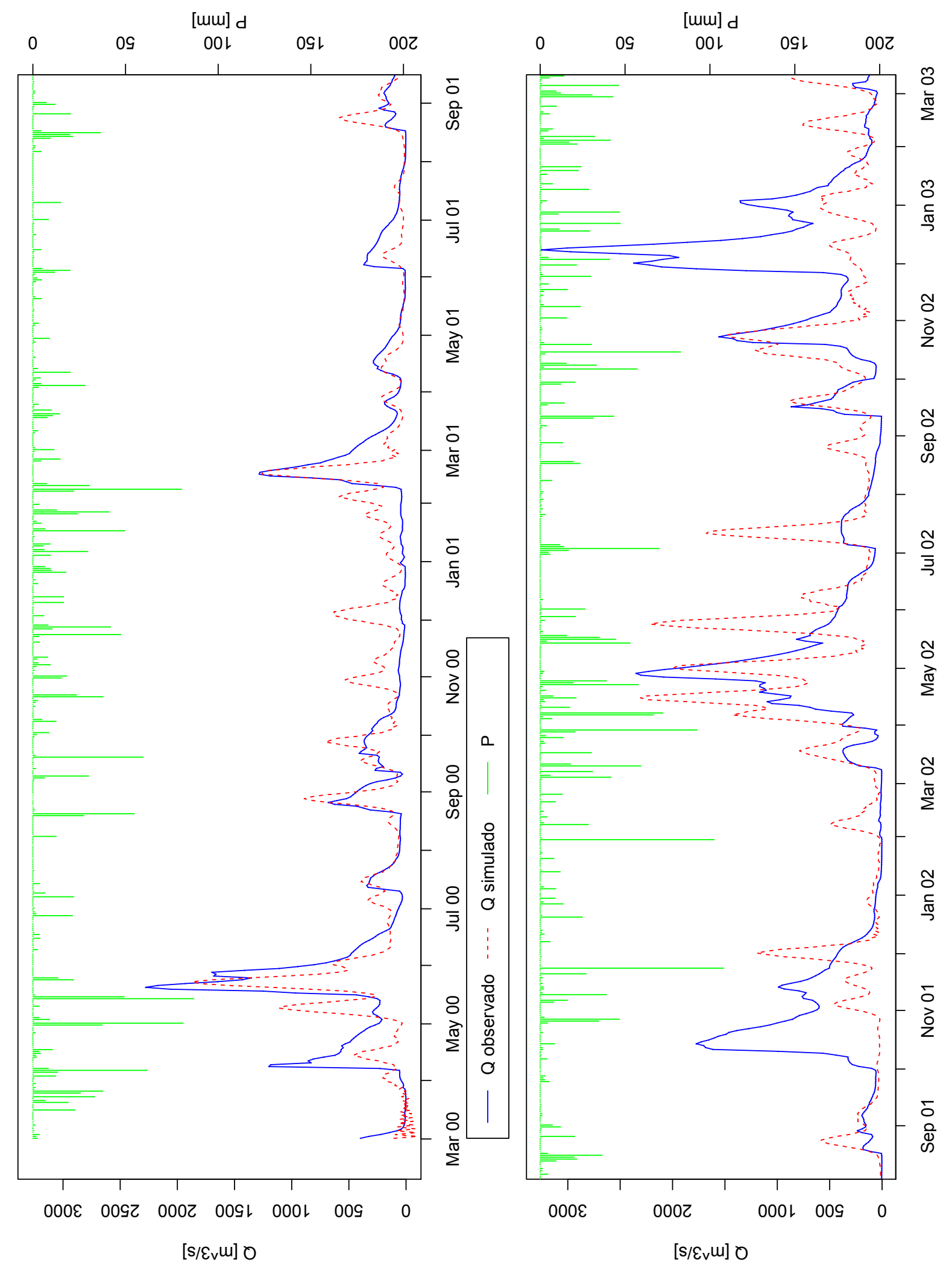

Figura 35: Hidrograma observado y simulado. Modelo GR4P, precipitaciones satelitales 


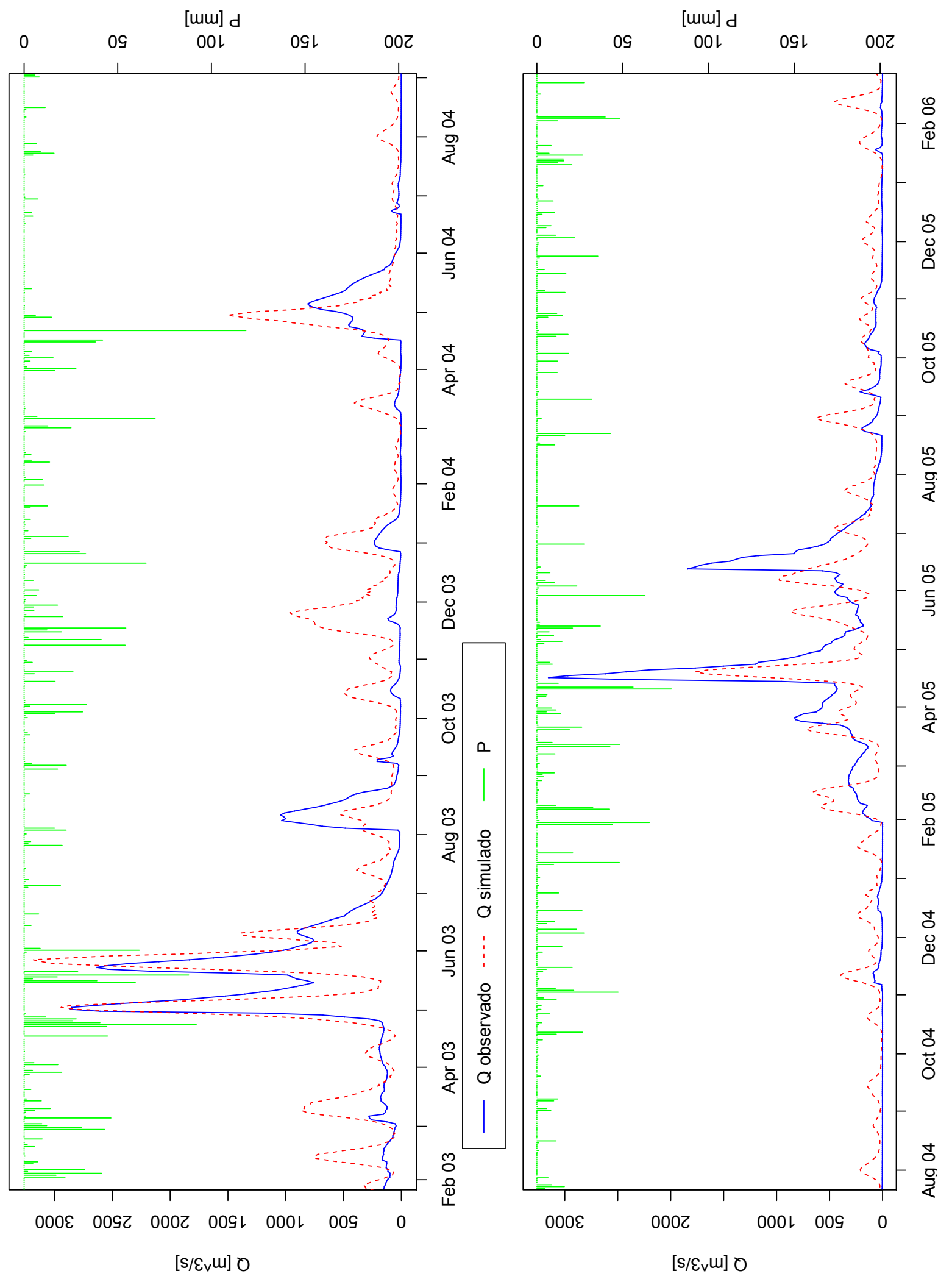

Figura 36: Hidrograma observado y simulado. Modelo GR4P, precipitaciones satelitales 


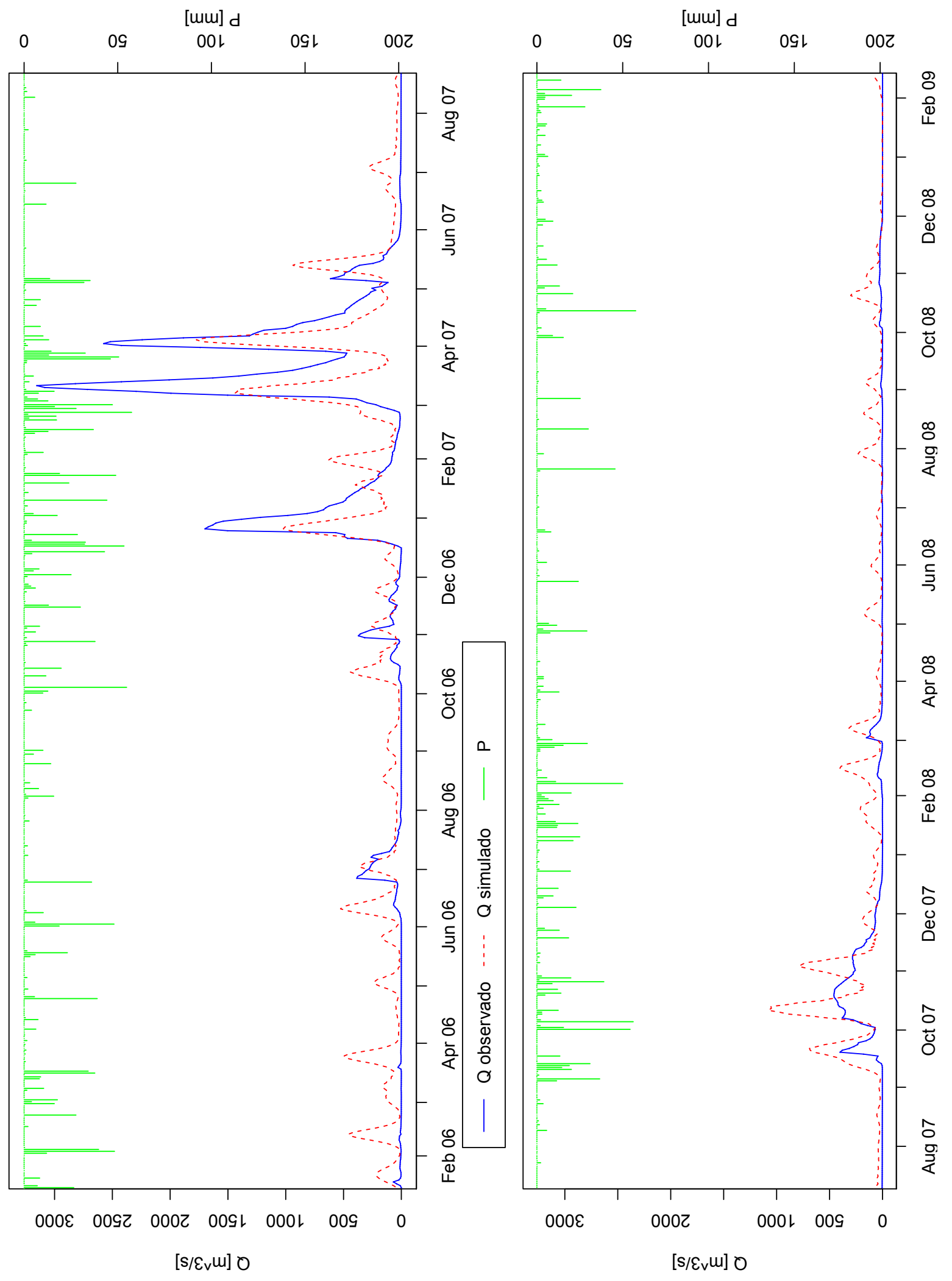

Figura 37: Hidrograma observado y simulado. Modelo GR4P, precipitaciones satelitales 


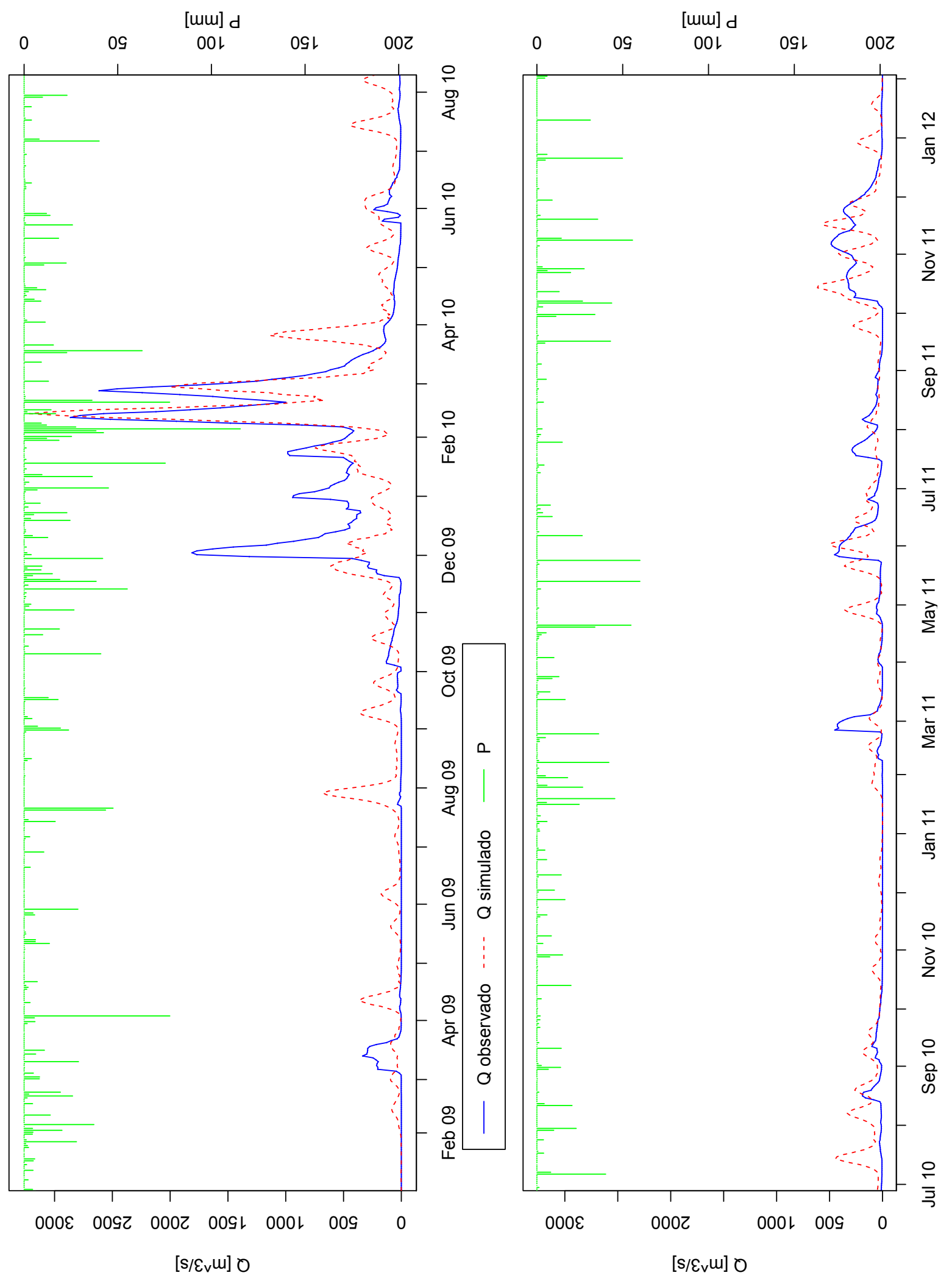

Figura 38: Hidrograma observado y simulado. Modelo GR4P, precipitaciones satelitales 


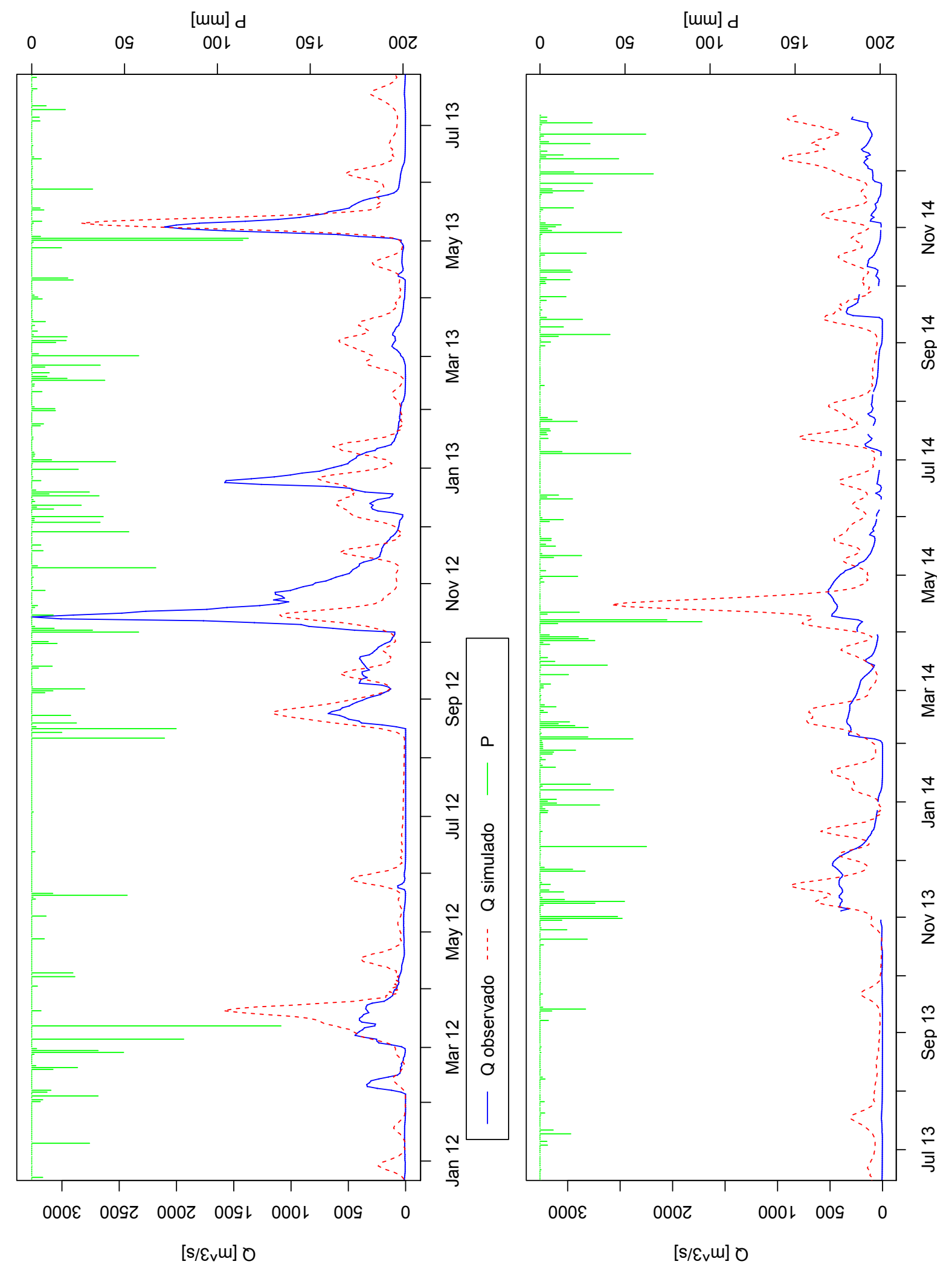

Figura 39: Hidrograma observado y simulado. Modelo GR4P, precipitaciones satelitales 
11. ANEXO II 


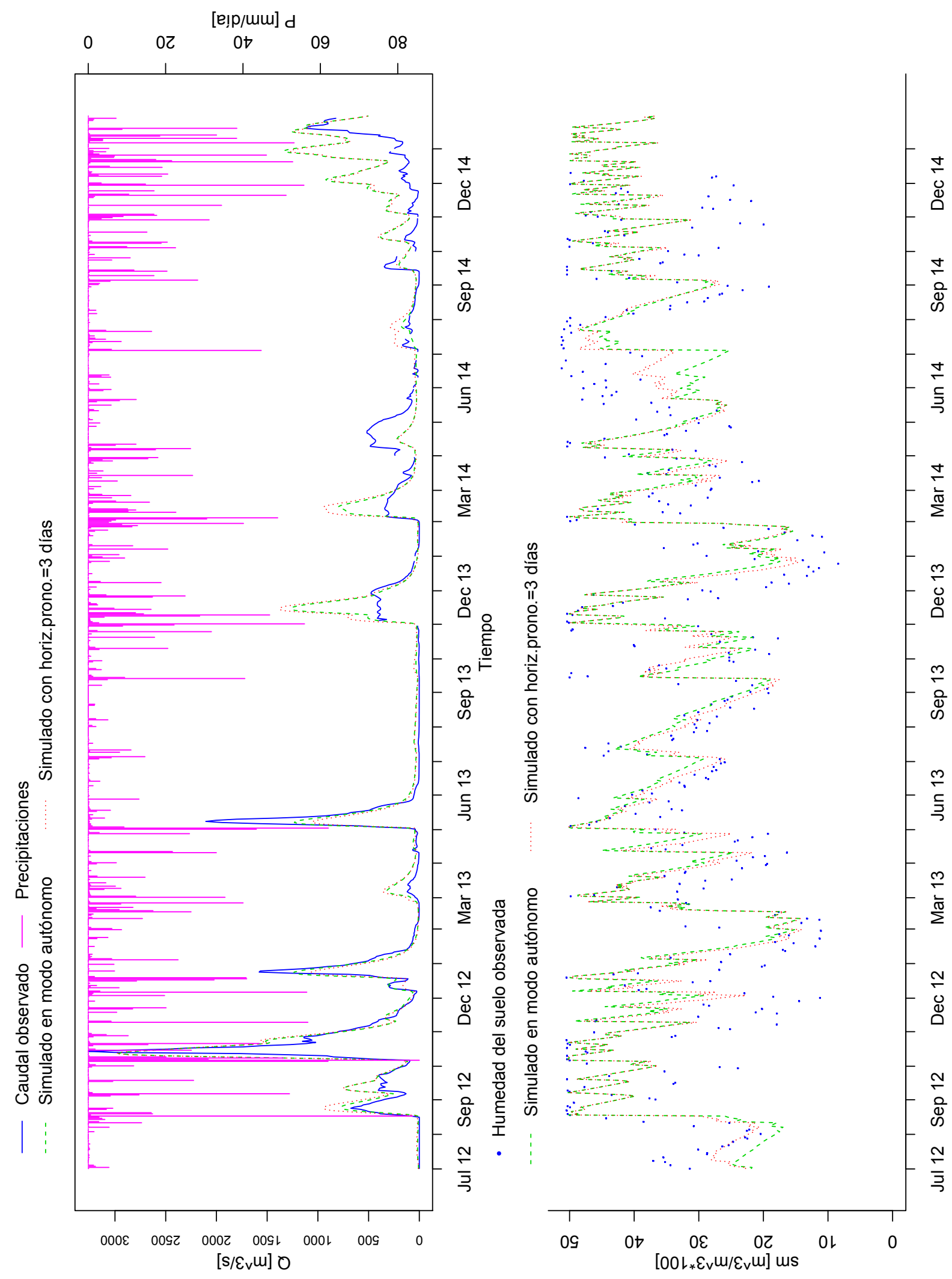

Figura 40: SAC-EnKF con asimilación de Aquarius 


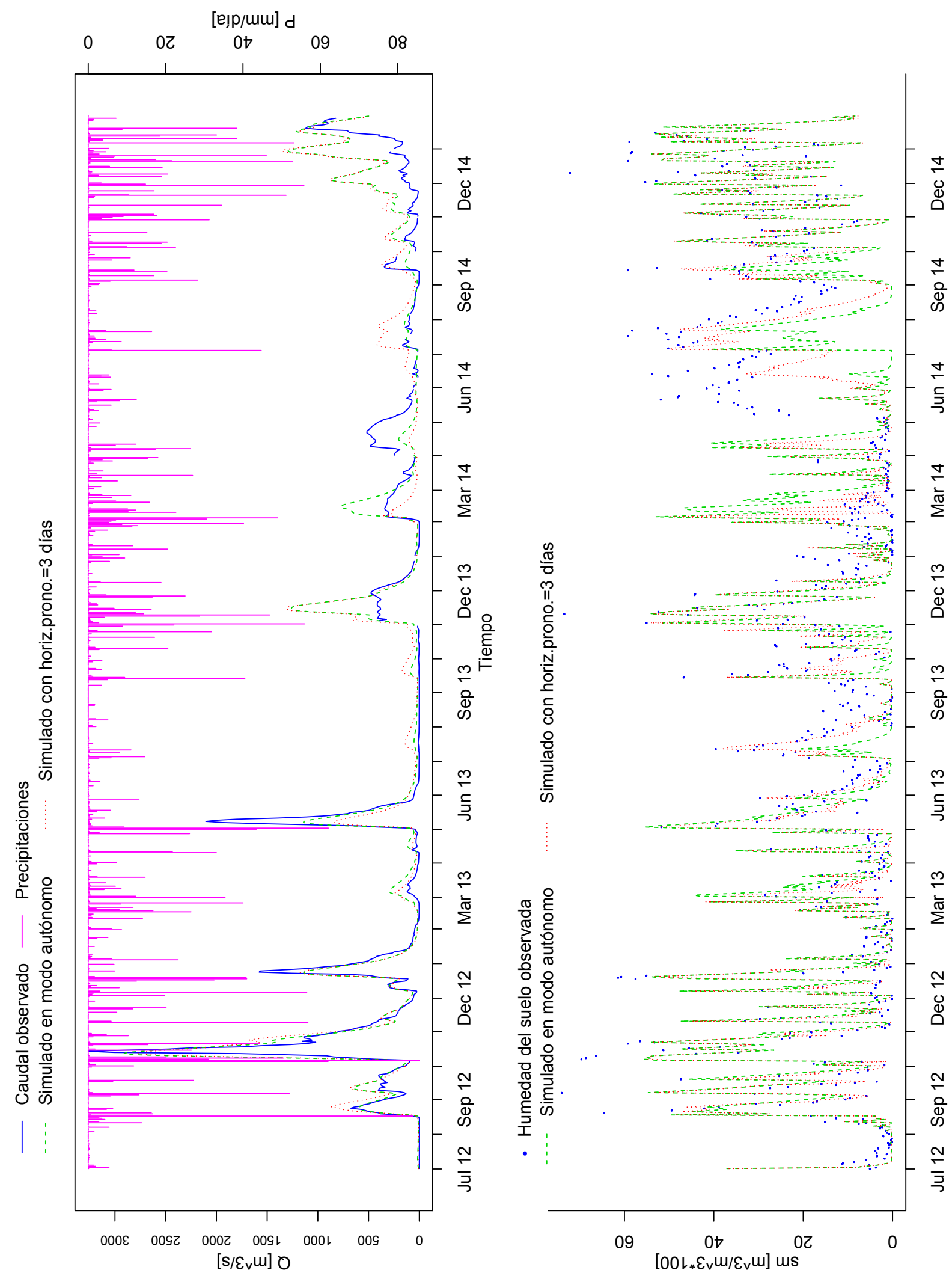

Figura 41: SAC-EnKF con asimilación de SMOS 


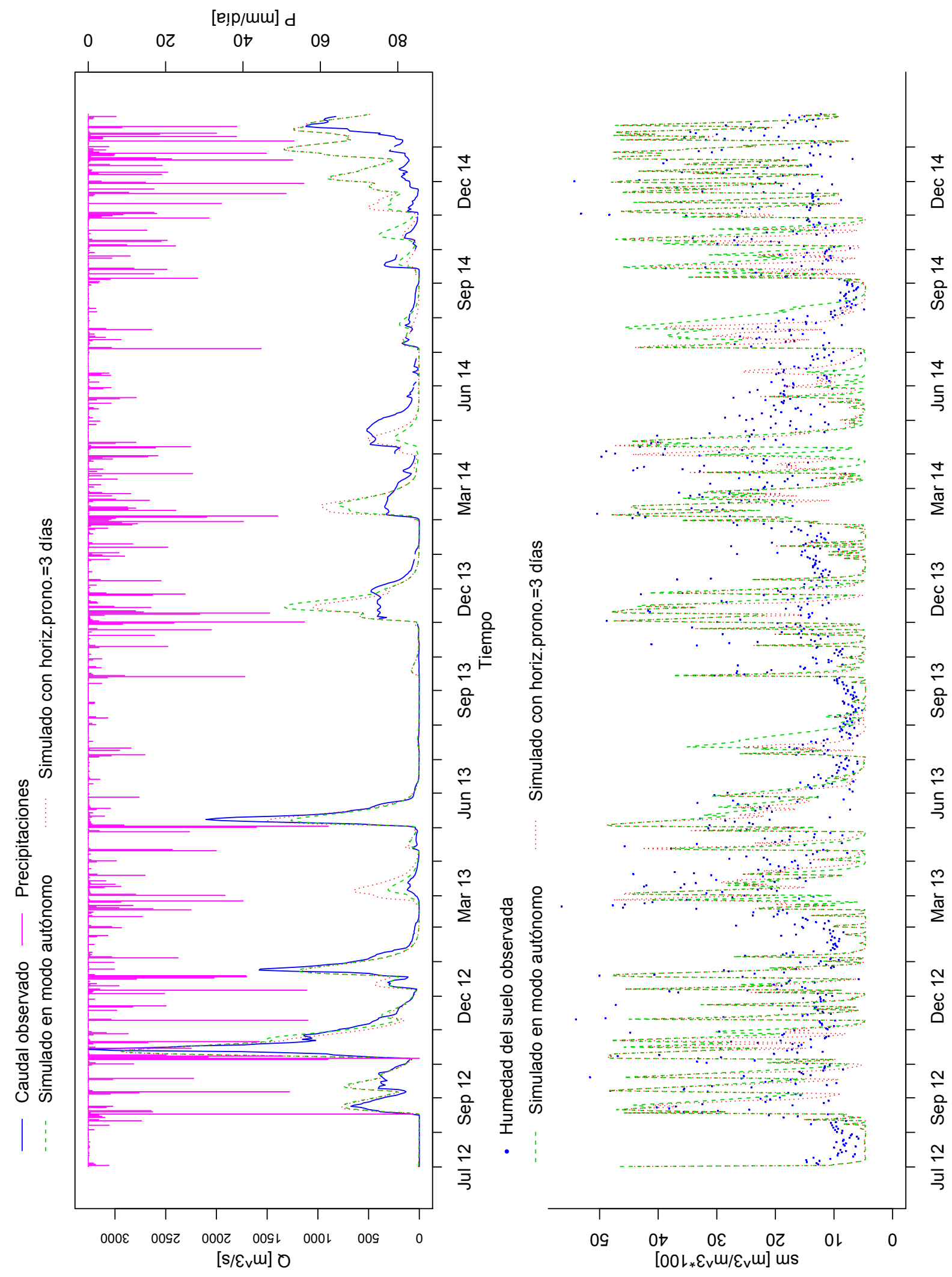

Figura 42: SAC-EnKF con asimilación de AMSR2 


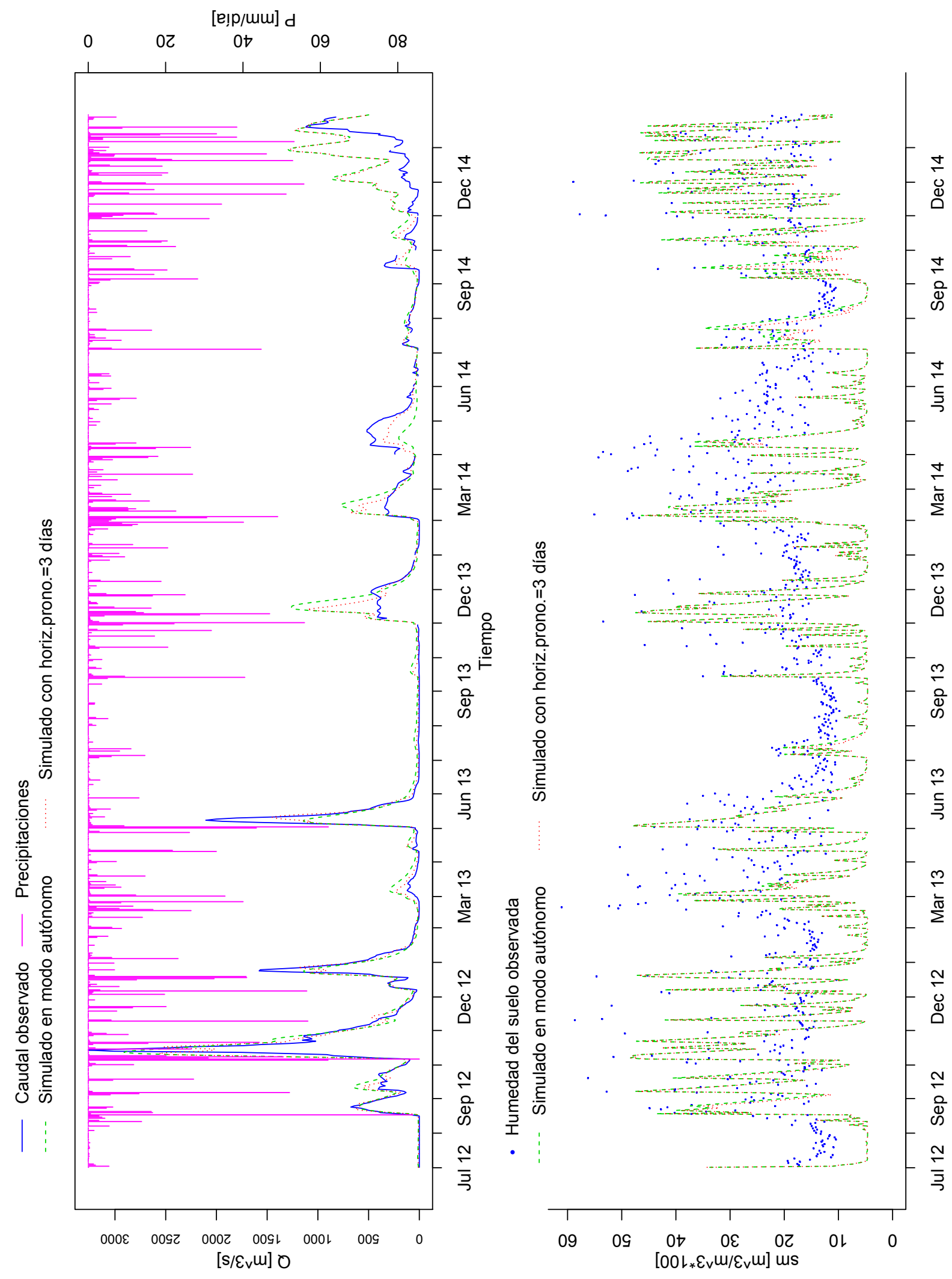

Figura 43: SAC-EnKF con asimilación de caudales 


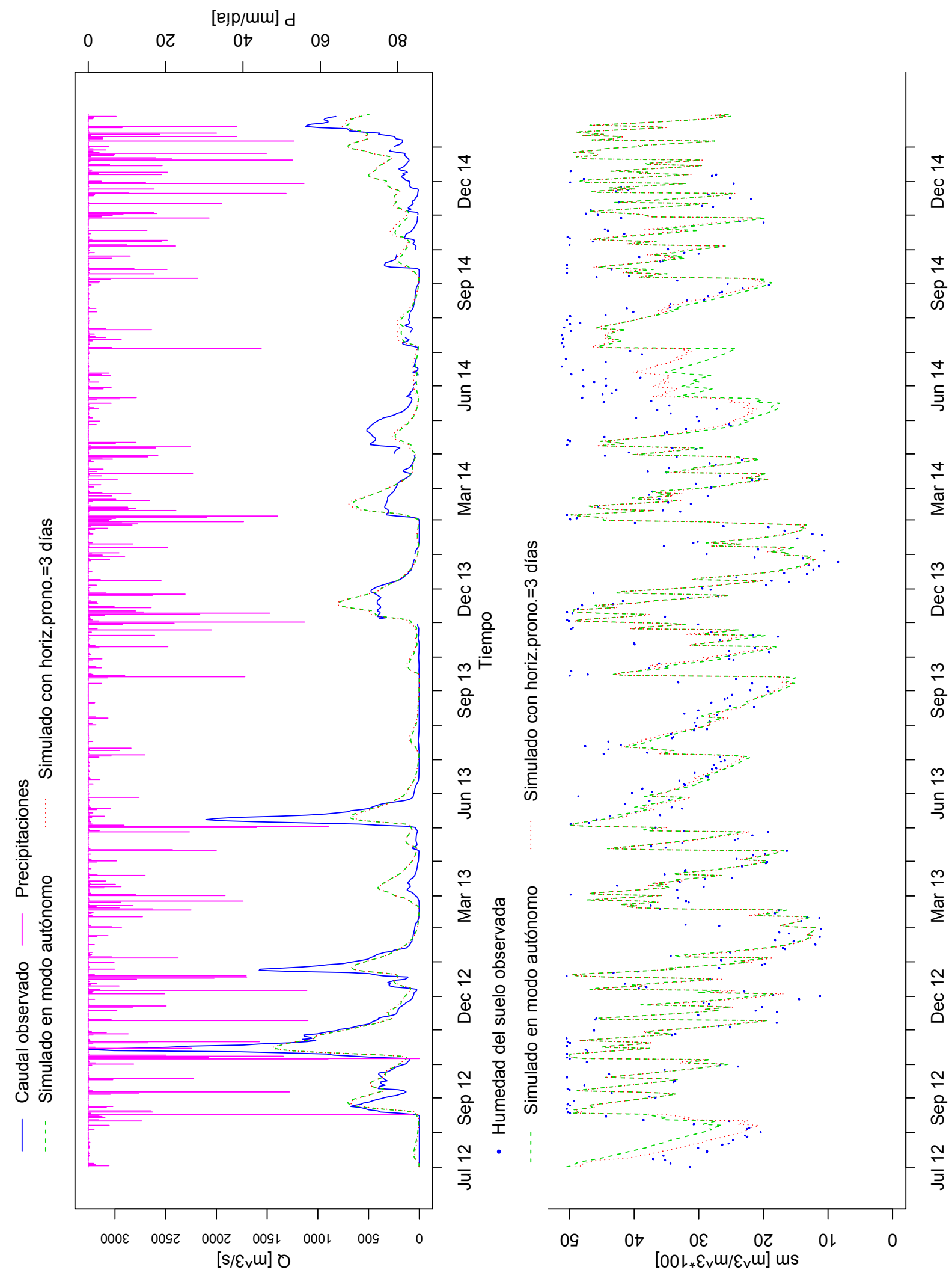

Figura 44: GRP-EnKF con asimilación de Aquarius 


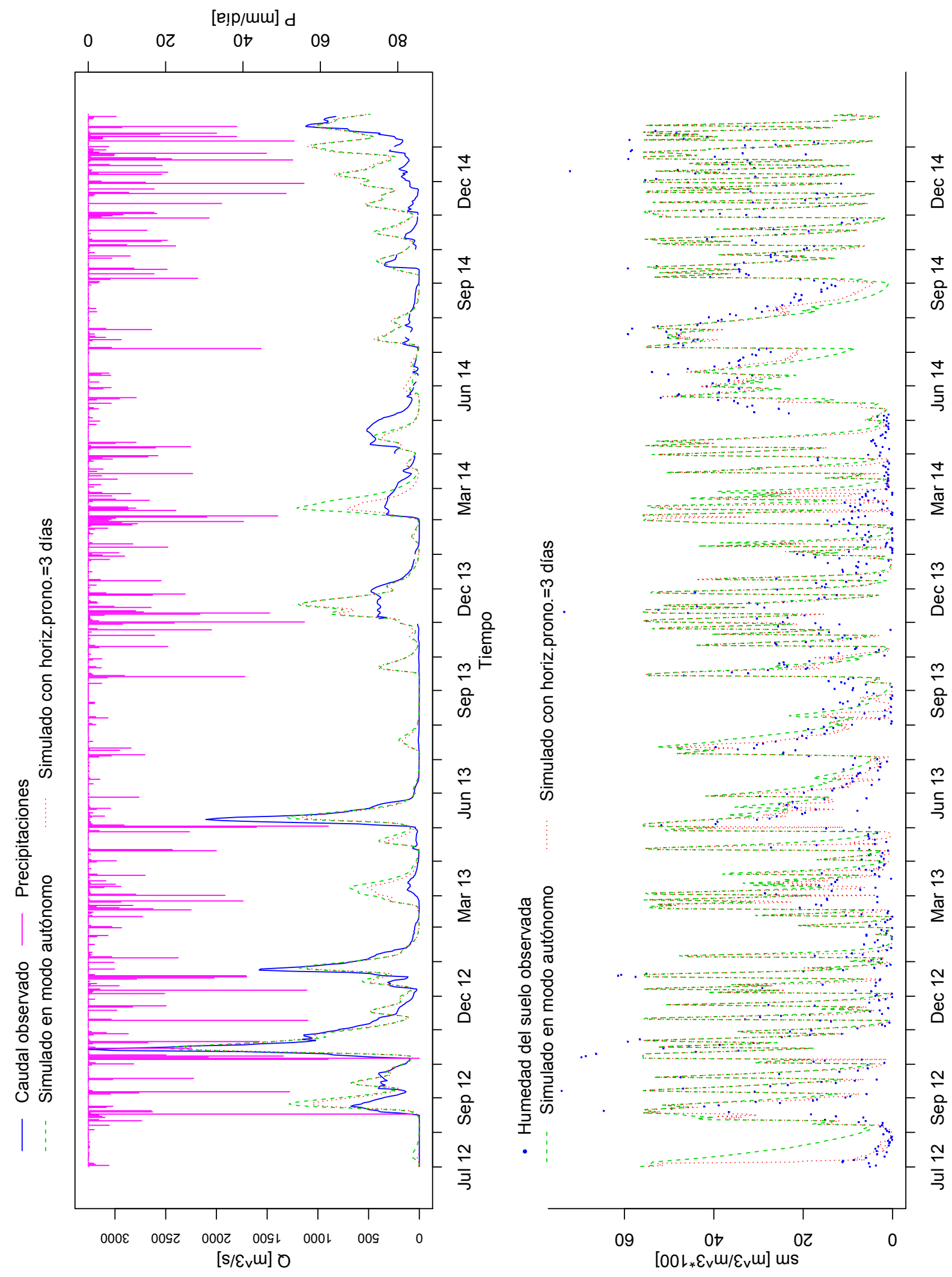

Figura 45: GRP-EnKF con asimilación de SMOS 


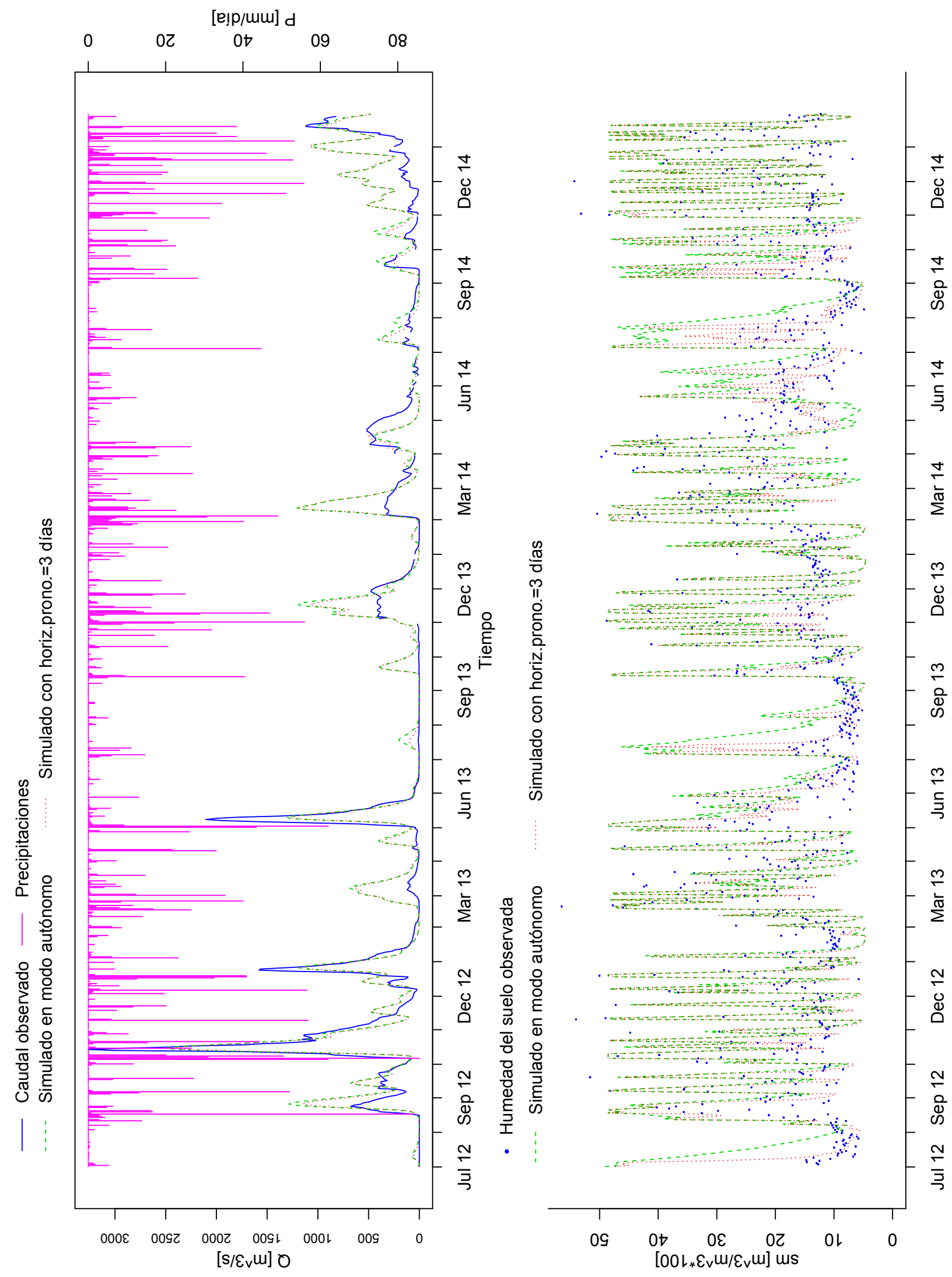

Figura 46: GRP-EnKF con asimilación de AMSR2 


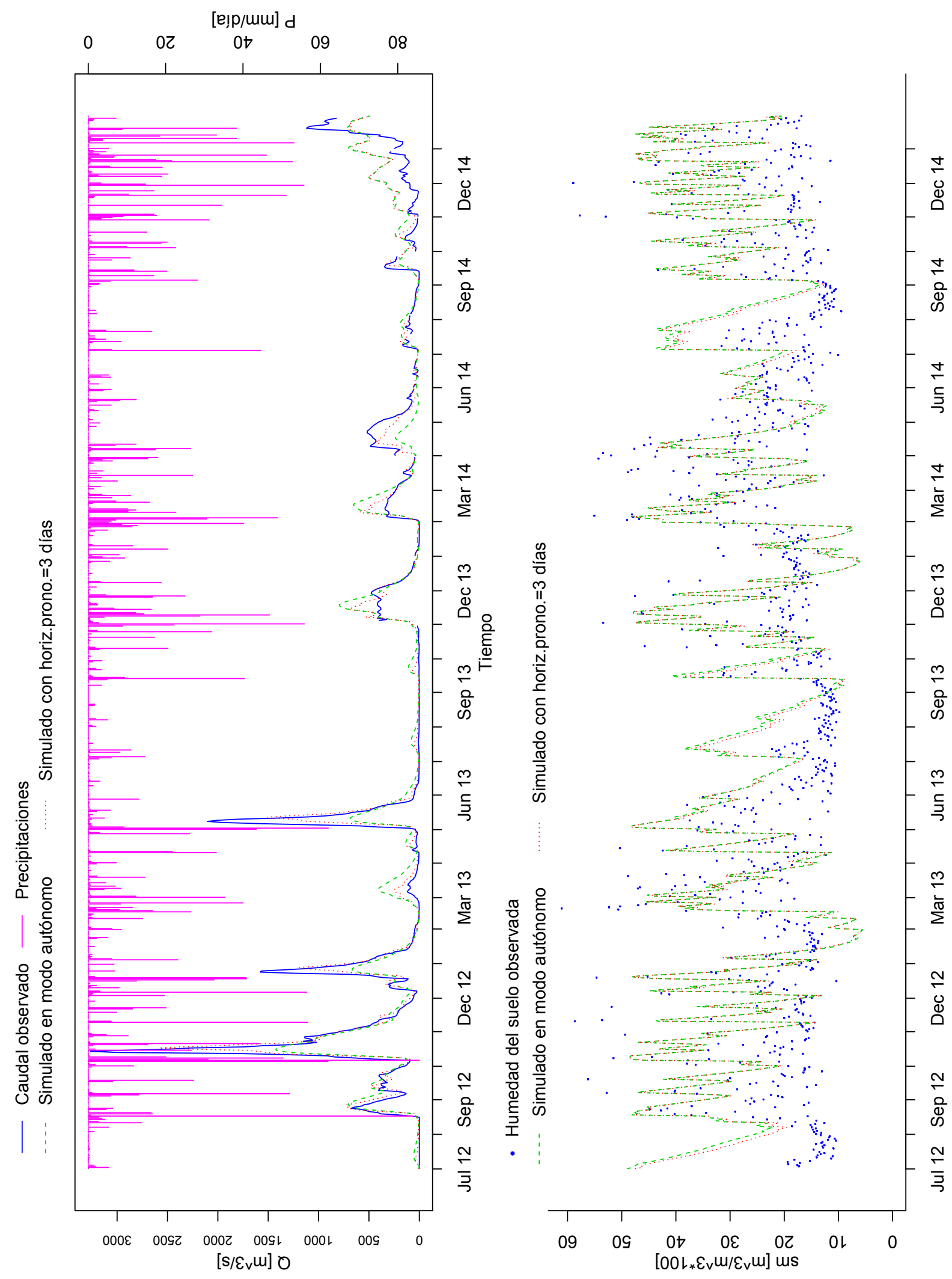

Figura 47: GRP-EnKF con asimilación de caudales 